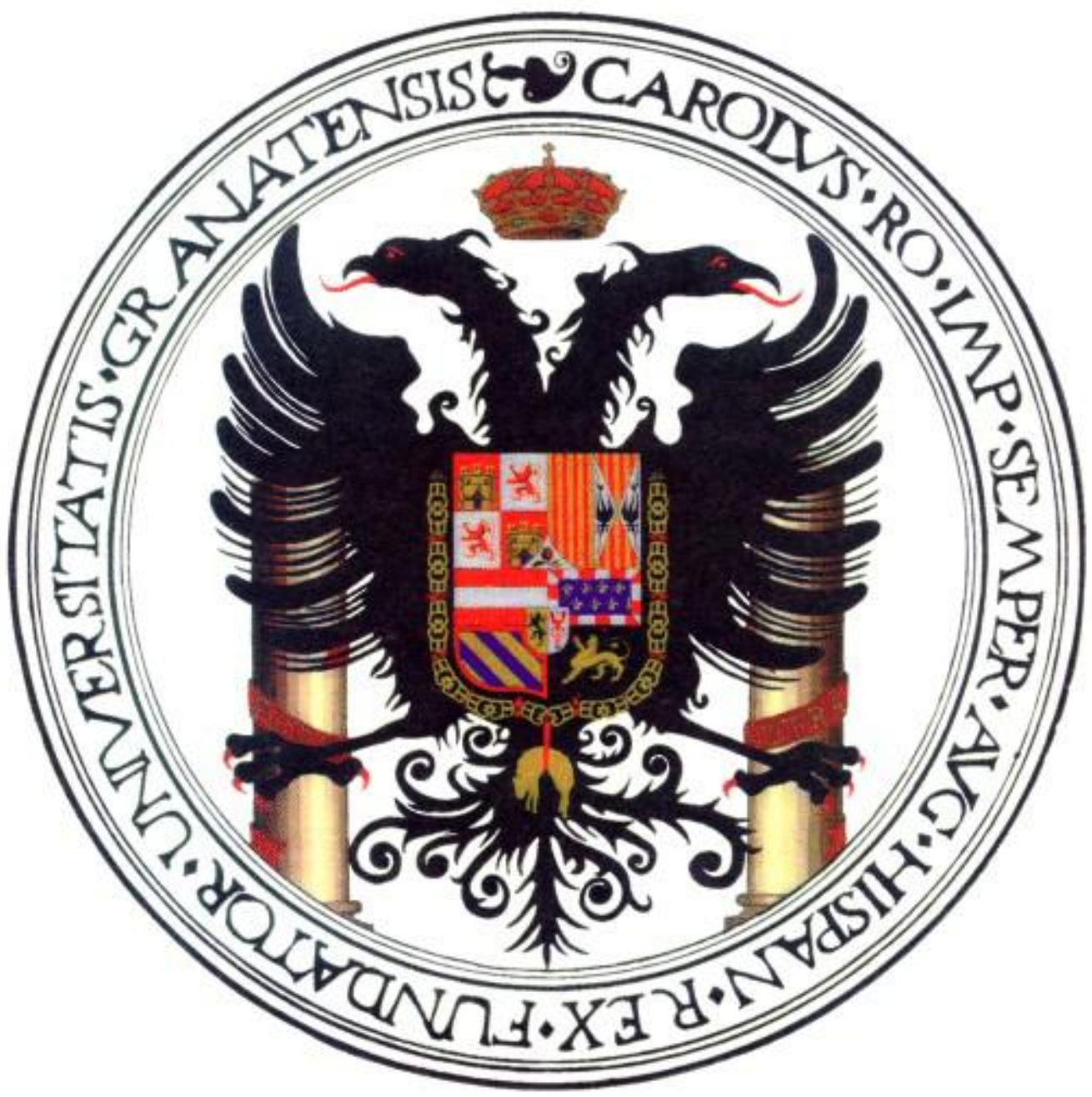

Alumno: Koldo Lekuona Ruiz de Luzuriaga

K2lekuko@gmail.com

TRABAJO DE FIN DE MÁSTER

Máster Universitario Oficial en Profesorado de Educación Secundaria Obligatoria, Bachillerato, Formación Profesional y Enseñanza de Idiomas Lógica formal e informal: falacias y falsos argumentos -Unidad didácticaKoldo Lekuona Ruiz de Luzuriaga K2lekuko@gmail.com Universidad de Granada Curso 2011/2012 
COMISIÓN EVALUADORA.

Fecha: 27 de Junio (10 de la mañana).

AULA: Sala de Juntas.

Presidenta: María del Carmen Lara Nieto

Vocal 1: Hermenegildo Ortigosa Luque

Vocal 2: Paloma García Díaz. 


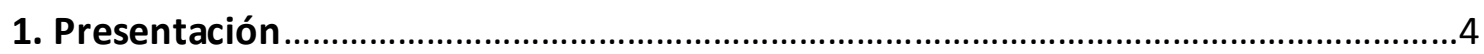

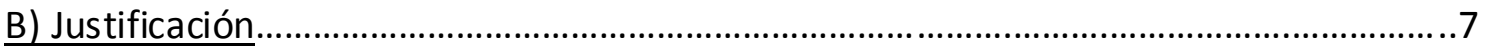

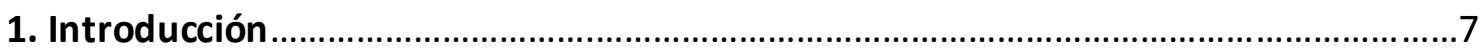

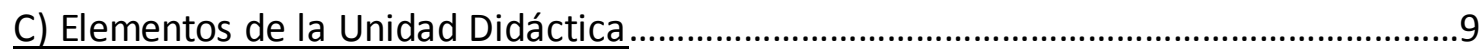

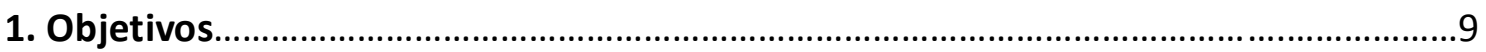

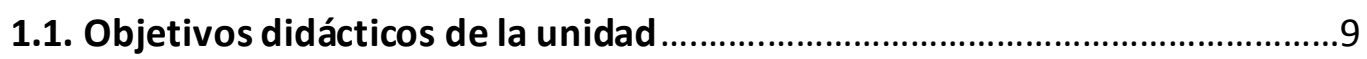

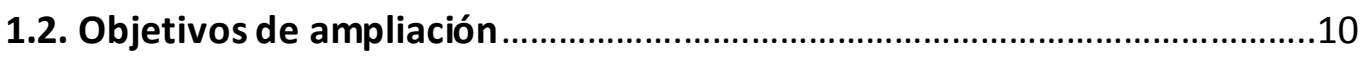

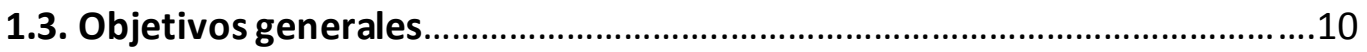

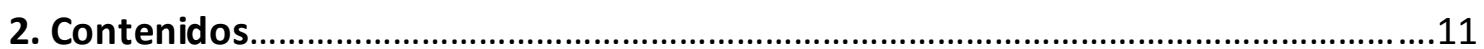

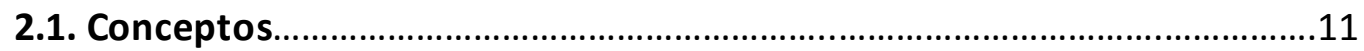

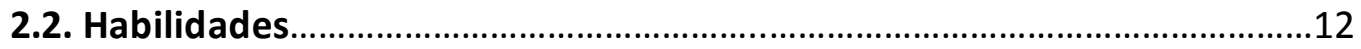

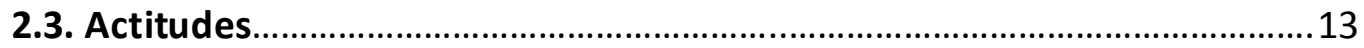

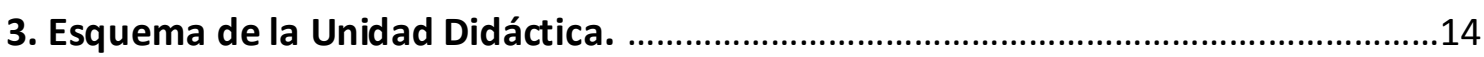

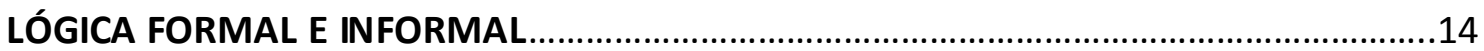

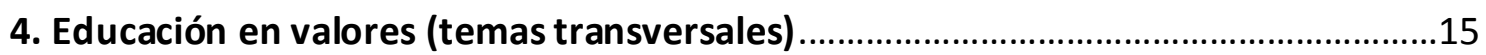

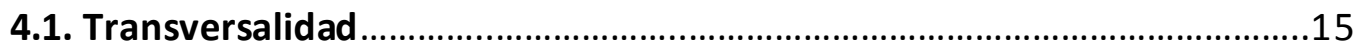

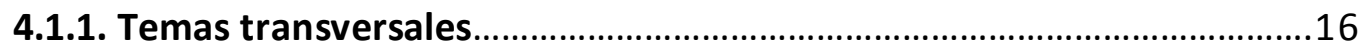

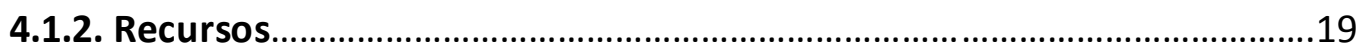

4.1.3. Recursos: Films, documentales y páginas de interés.............................22

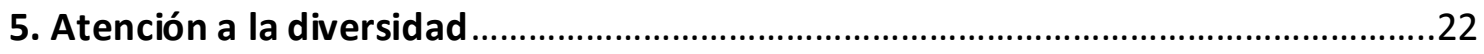

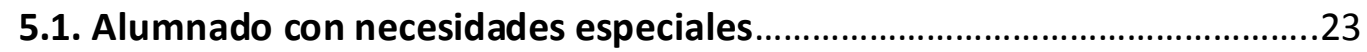

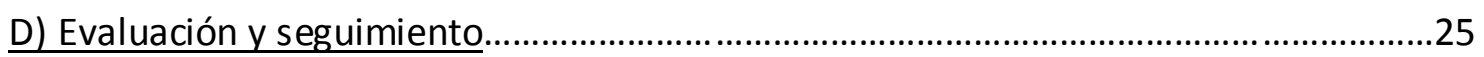

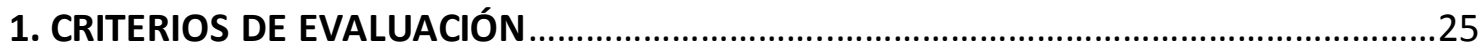

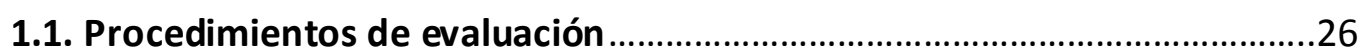

1.2. Calificación y mecanismos de recuperación ..................................................27

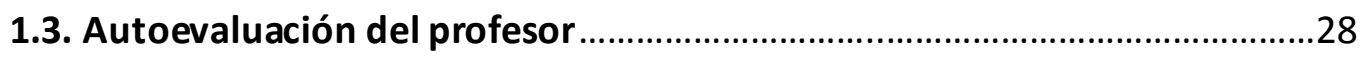

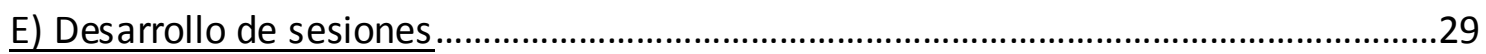

1. METODOLOGÍA Y ACTIVIDADESDE ENSEÑANZA Y APRENDIZAJE .............................29

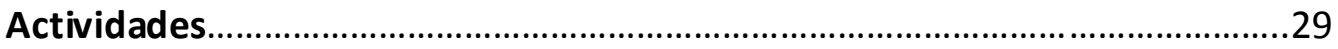

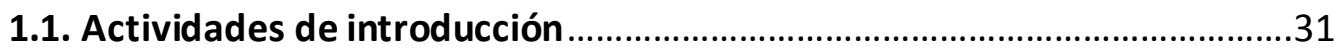

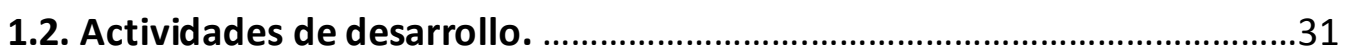

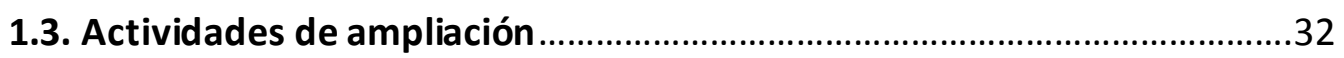




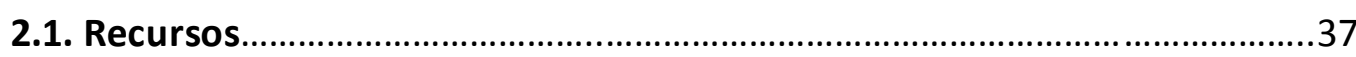

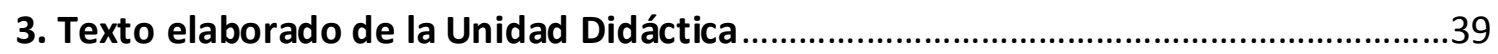

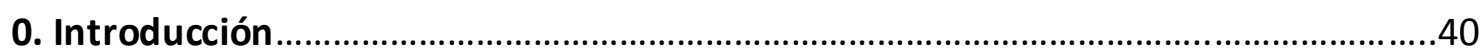

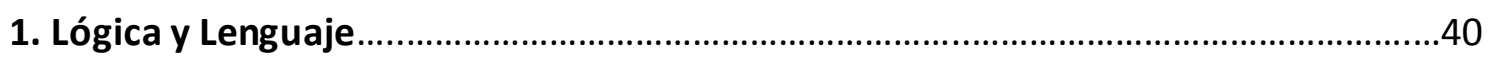

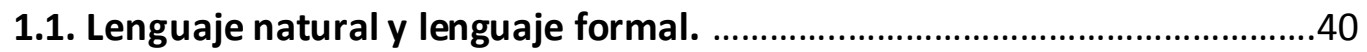

1.2. Lenguaje objeto y metalenguaje: uso y mención. .........................................41

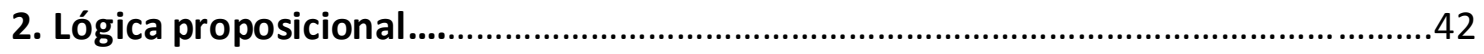

2.1. El lenguaje de la Lógica proposicional .......................................................43

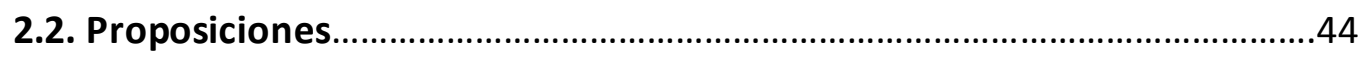

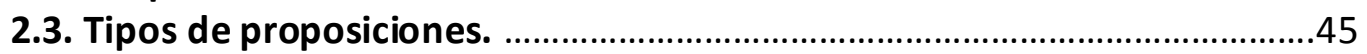

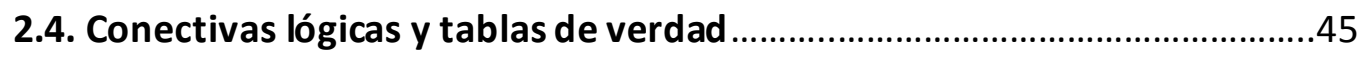

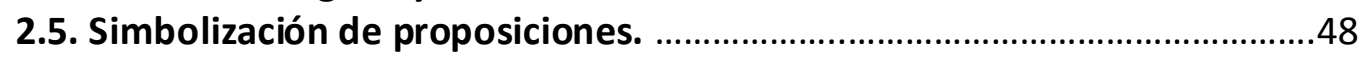

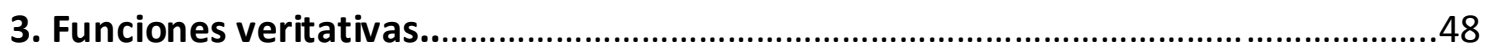

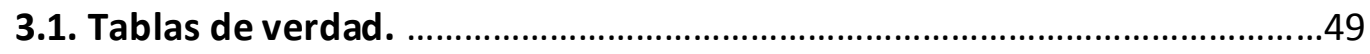

3.2. Evaluación de fórmulas mediante tablas de verdad. ................................49

3.3. Tautología, antilogía (o contradicción) y indeterminada (contingente) ...49

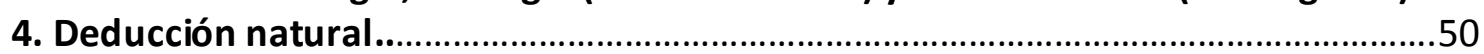

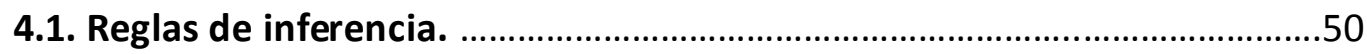

4.2. Metodología para el cálculo deductivo. ......................................................52

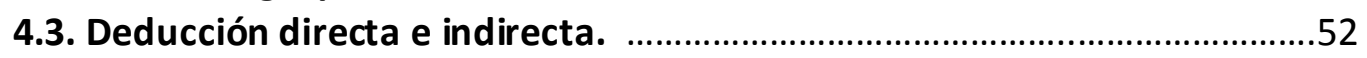

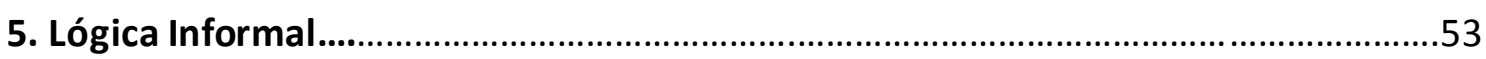

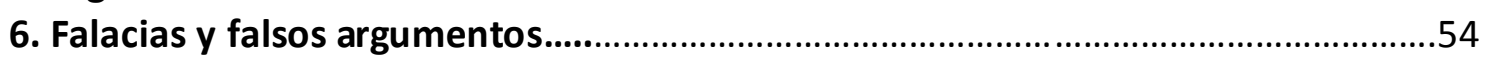

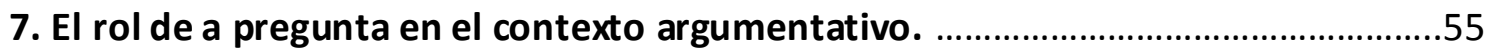

7.1. El fenómeno de la presuposición. ..............................................................56

7.2. Tipología de preguntas: Pregunta con presuposición, pregunta múltiple y

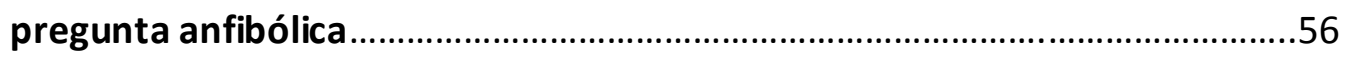

7.2.1. Pregunta con presuposición ..........................................................57

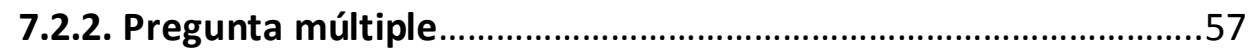

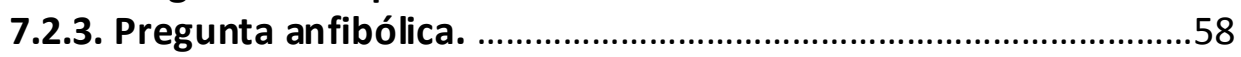

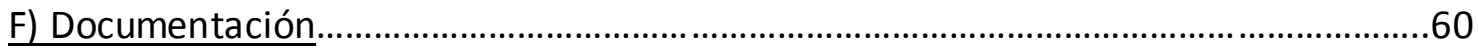

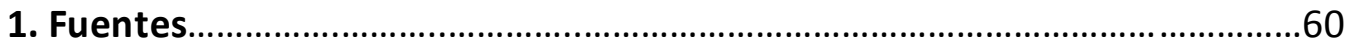

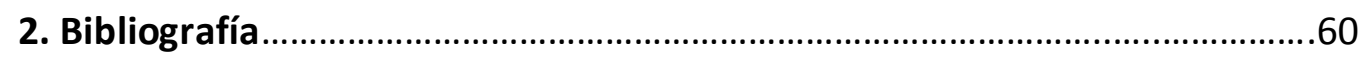

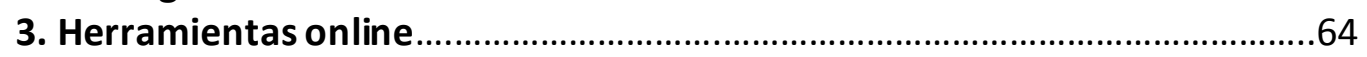

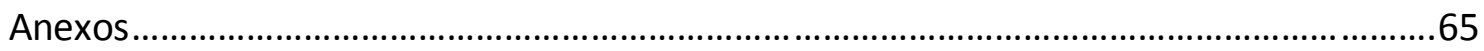




\section{UNIDAD DIDÁCTICA}

\section{A) Fundamentación y Relevancia}

\section{Presentación.}

En este trabajo el lector se encontrará con una Unidad Didáctica de Lógica Proposicional y Lógica Informal. Sin duda, no se trata de una temática novedosa ya que durante tiempo se ha impartido esta asignatura en educación secundaria. No obstante, los estudios de contemporáneos en lógica informal nos indican que los libros de texto que empleamos en secundaria necesitan ser revisados y renovados.

La lógica Proposicional, la Lógica Informal, la teoría de la argumentación, la retórica, la dialéctica y la filosofía del lenguaje son materias que independientemente del recorrido, las diferencias y la antigüedad que puedan tener, están en auge y tienen gran actualidad. En efecto, el interés filosófico que suscita el estudio del lenguaje es tan antiguo como la filosofía. De hecho, si aceptamos el llamado "giro lingüístico" que se da a comienzos del siglo XX [la tes is de Dummett (1993)], nos podemos percatar que el estudio del lenguaje tiene preeminencia sobre el estudio del pensamiento, o mejor dicho: sólo se puede dar cuenta del pensamiento a través del estudio filosófico del lenguaje. Asimismo, en el estudio del lenguaje se abarcan las dos tradiciones existentes en filosofía (analítica y continental). La lógica Proposicional es analítica mientras que la Lógica Informal es continental porque tiene influencias retóricas. Mediante esta Unidad daremos cuenta de estas dos corrientes, que lejos de tratarse de estilos contrapuestos son a nuestro entender complementarios.

Nuestro propósito principal es reunir las herramientas conceptuales para que se adquiera destreza en la argumentación, para que se aprenda a argumentar; pue sto que, argumentar es el proceder del filosofar. A nuestro entender, la capacidad de argumentar es una competencia de gran importancia en la formación integral de las personas que no solamente revierten en el aspecto académico, sino también, en su vertiente ciudadana. Posiblemente, unas de las principales dificultades que se presentan con las Unidades de Lógica son los pobres resultados en capacidades que adquiere el alumnado. Mediante la Lógica Informal queremos hacer de esta Unidad una enseñanza que se materialice de forma efectiva en una competencia argumentativa. Para ello nos dotamos de los útiles que proporcionan la Lógica Proposicional y la Lógica Informal, con el propósito de aplicarlos a contextos y discursos que son cotidianos.

El estudio de las falacias, los argumentos y el razonamiento correcto tanto por su importancia teórica, así como por su utilidad práctica y el interés que despierta en el alumnado es algo que merece ser destacado; 
no debe ser una actividad meramente académica. ${ }^{1}$ Su aplicabilidad se debe enfocar tanto a contextos escolares como a extraescolares, puesto que nos capacita de recursos críticos en nuestra vida de alumnos y de ciudadanos. ¿Por qué ponemos en valor el estudio de las falacias, la argumentación y el pensamiento crítico?

1-El dialogo libre de errores argumentativos nos conduce a la resolución de conflictos de manera racional sin necesidad de recurrir a la fuerza. Es decir, la fuerza de la razón es más poderosa que la razón de la fuerza (aprender a dialogar).

2-En las discusiones nos enfrentamos con gente que tienen habilidades retóricas para usar fraudulentamente las palabras y las razones, y nos encontramos sin recursos teóricos para poder refutar de manera adecuada y razona da (aprender a criticar).

3-Por que usualmente damos por bueno argumentos que no lo son; tener ciertos conocimientos teóricos es un buen comienzo para poder desarrollar un pensamiento crítico y consecuente con uno mismo (aprender a pensar).

En la temática propuesta para la Unidad creemos que la parte de la Lógica Informal hace una aportación relevante y actualizada en la enseñanza que proponemos. Por un lado, la Lógica Informal es una disciplina con una trayectoria joven que no tiene más de cuarenta años, se trata de una rama de la lógica y la argumentación que tiene por objeto el estudio de los discursos y argumentos que se realizan en el día a día. Es decir, es un saber con utilidad práctica. Por otra parte, introduciremos dos elementos que tienen importancia teórica en la filosofía del lenguaje y también, en la Lógica Informal, a saber, el fenómeno de la presuposición y la pregunta.

El tratamiento de la pregunta en el marco de la teoría de la argumentación es un terreno fértil para la investigación. Y ello, independientemente de que la pregunta haya sido estudiada tiempo atrás por autores clásicos como Aristóteles, modernos como Lausberg o contemporá neos como Walton.

La pregunta socava las concepciones canónicas acerca del argumento y la argumentación. Por un lado, al tratar la pregunta como un topos/tópico (a saber, el material que forma parte de la invención retórica) permite ir más lejos en la concepción del término argumento. Al menos, si entendemos por argumento el conjunto de proposiciones donde unas de ellas cuenta como premisas y la otra como conclusión. Por otro lado, la pregunta no es sólo un mecanismo dialéctico en toda regla que permite desencadenar y desarrollar el proceso argumentativo, sino que, también, es un mecanismo ilativo que propicia la ilación en la argumentación.

\footnotetext{
${ }^{1}$ ¿Quién no desea argumentar correctamente? ¿Quién no persigue el engaño? ¿A quién le gusta ser engañado con argumentos falaces? ¿Quién no refuta discursos basados en la mentira y la distorsión para ser persuadido?
} 
La razón principal es que las preguntas tienen presuposición/es; lo que comúnmente se conoce por el material semántico que se da por hecho "captado, aceptado" (semantic material that is taken for granted). El fenómeno de la presuposición ha sido abordado con relativa frecuencia en los últimos cien años, y se puede afirmar a su vez, que el fenómeno de la presuposición en relación con la pregunta ha sido estudiado en el último medio siglo. En cualquier caso, a nuestro entender, el tratamiento que se da a la pregunta y al fenómeno de la presuposición en el marco de la argumentación es insuficiente, ya que no se integran estos dos elementos (pregunta y presuposición) de manera adecuada. Prueba de ello, es la confusión conceptual que hay bajo la etiqueta de "pregunta compleja", puesto que esta etiqueta sirve para referirse a distintos tipos de pregunta que difieren entre sí, tanto en su definición formal como en su explicación funcional.

Nos estamos refiriendo, en concreto, al tratamiento análogo que se da entre la "pregunta múltiple", "la pregunta con presuposición" y la pregunta anfibólica. En nuestra Unidad profundiza remos y avanzaremos en el conocimiento y la comprensión del rol de la pregunta y el fenómeno de la presuposición en el marco de la teoría de la argumentación.

Nuestra aportación novedosa no se limita en el campo de los contenidos, también, vamos a innovar en recursos, metodología y didáctica. A lo largo de esta Unidad reiteramos que la filosofía no puede ser un saber caduco y fosilizado, y que debe de tratar con problemas de actualidad. Por ello, el empleo de las Tics (que hacen referencia a los materiales y herramientas que pertenecen a las Tecnologías de la Información y la Comunicación) deben ser usadas en la enseñanza. Potenciaremos una actualización en materiales y medios a emplear. Mediante el empleo de las Tics trabajaremos los temas transversales a lo largo de la unidad.

Los recursos que emplearemos para trabajar la transversalidad serán informáticos (Tics: el blog y el Dropbox) y instrumentales (la disertación). Vamos a emplear toda una serie de recursos gráficos disponibles en Internet.... Por ejemplo, las redes sociales son medios que permiten crear opinión de una manera sencilla y directa, pero, no podemos olvidar que son mensajes con una carga retórica muy importante, pues en estos mensajes se emplean dilemas, analogías, contradicciones, antimetaboles, metáforas, retruécanos, preguntas retóricas, anfibolías, etc. Por lo tanto, no solamente nos permiten enfocar un problema concreto, también, podemos hacer un análisis retórico sobre la forma de presentar el tema que se aborda.

Por ultimo agradecer al alumnado y profesorado que me ha ayudado a realizar este trabajo con sus críticas y sus aportaciones, sobra decir que los fallos e incorrecciones son culpa mía. 


\section{B) Justificación}

\section{Introducción}

La unidad didáctica que vamos a desarrollar lleva por título lógica formal e informal: falacias y falsos argumentos, y pertenece al primer núcleo temático del currículo de la asignatura de Filosofía y Ciudadanía ${ }^{2}$ que se imparte con carácter de materia común en el primer curso del bachillerato, ${ }^{3}$ e incluye los objetivos, contenidos y criterios de evaluación establecidos para esta materia en el Real Decreto 1467/2007, de 2 de noviembre, junto con las aportaciones específicas (es decir, teniendo en cuenta las premisas establecidas y desarrolladas por la Comunidad Autónoma de Andalucía a través del Decreto 416/2008, de 22 de julio en el que se establecen la ordenación y las enseñanzas correspondientes al bachillerato) para la Comunidad Autónoma de Andalucía que se desarrollan a continuación.

En esta unidad se abordan las nociones principales de la lógica formal e informal, en tanto y cuanto, la lógica es el arte (habilidad) y la ciencia (estudio de los principios y reglas) que nos enseña a discriminar entre argumentos correctos e incorrectos. Estudiar lógica sirve para razonar y argumentar correctamente, además, ayuda a detectar las formas erróneas de razonar y evita caer en trampas y falacias. Aprender y ejercitarse en la lógica es, en definitiva, atender a la misma estructura del pensamiento. La dimensión teórica y práctica de este saber incide en el sentido y la razón de que se trate de un saber necesario.

La educación, en general, tiene por objetivo formar y desarrollar a las personas tanto en el plano académico como en el plano moral y social dotándoles de conocimientos y habilidades para que se desenvuelvan de la mejor manera en su vida social y activa. Es decir, no solo se forman estudiantes, también, se forman ciudadanos. La asignatura de filosofía se presta de manera natural y efectiva a tratar estas actitudes y comportamientos ya que, ante los problemas se propicia la reflexión y el pensamiento crítico, y a su vez, se fomenta una educación ético-cívica; la lógica formal en general y la lógica informal en particular, contribuyen de manera eficaz en ese propósito. ${ }^{4}$

\footnotetext{
${ }^{2}$ Núcleos temáticos:

1. Características generales del saber filosófico y dela argumentación válida.

2. Antropología fil osófica.

3. Filosofía moral y política.

4. Democracia y ciudadanía.

URL=<http://www.juntadeandalucia.es/educacion/portal/com/bin/Contenidos/OEE/ordenacion/Orden Curriculo Bachillerato/1220265787283 orden_bachillerato.pdf>

Ver anexo (I).

3 Las materias comunes del bachillerato son las establecidas en el artículo 34.6 de la Ley Orgánica 2/2006, de 3 de mayo.

4 Esta Unidad didáctica tiene como base el currículo prescriptivo aprobado por la Administración (Decreto 461/2008, de 22 de julio por el que se establece la ordenación y las enseñanza correspondientes al bachillerato en Andalucía y Real Decreto 1467/2007, de 2 de noviembre por el que se establecen la estructura del bachillerato y se fijan las enseñanzas mínimas correspondientes al
} 
La unidad didáctica que presentamos está en consonancia con los objetivos que se recogen en el Real Decreto [artículo 3. (Objetivos del bachillerato)] y ta mbién, en la LOE [artículo 33. (Objetivos)], puesto que son los mismos, en especial, los objetivos a, b, c, e, g, h y k. ${ }^{5}$ El propósito de esta unidad didáctica es: enseñarles a argumentar; a defender sus propuestas; desarrollar un uso adecuado de la oralidad y saber dirimir las diferencias de opinión mediante la palabra. Efectivamente, esta unidad trabaja sobre tres competencias básicas que se mencionan en la Ley Orgánica de Educación (LOE), como la competencia lingüística, la matemática y la social y ciudadana.

Para finalizar, sólo decir que la Unidad Didáctica es una herramienta que todo profesor/a debe tener en su trabajo, puesto que la docencia no puede ser una práctica improvisada. De esta manera, podemos asegurar una base sobre la que trabajar, que indica cuáles son los objetivos y metas que se pretenden alcanzar. $Y$ aunque sea cierto que las unidades didácticas son documentos vivos, flexibles y que en última instancia, es el alumnado y sus características los que marcarán el verdadero desarrollo; nos tenemos que apoyar en estos documentos ya que son la brújula que guía la práctica docente.

bachillerato). Asimismo, es el profesor el que ha de adecuar estos elementos en función del entorno inmediato, las características concretas del aula y las peculiaridades que presentan los alumnos/as.

${ }^{5}$ Estos son unos de los objetivos generales del bachillerato que hemos seleccionado para nuestra unidad didáctica, de tal manera que trabajaremos y desarrollaremos dichos objetivos:

a) Ejercer la ciudadanía democrática, desde una perspectiva global, y adquirir una conciencia cívica responsable, inspirada por los valores de la Constitución española así como por los derechos humanos, que fomen te la corresponsabilidad en la construcción de una sociedad justa y equitativa.

b) Consolidar una madurez personal y social que les permita actuar de forma responsable y autónoma y desarrollar su espíritu crítico. Prever y resolver pacíficamente los conflictos personales, familiares y sociales.

c) Fomentar la igualdad efectiva de derechos y oportunidades entre hombres y mujeres, analizar y valorar críticamente las desigual dades existentes e impulsar la igualdad real y la no discriminación de las personas con discapacidad.

e) Dominar, tanto en su expresión oral como escrita, la lengua castellana y, en su caso, la lengua cooficial de su Comunidad Autónoma.

g) Utilizar con solvencia y responsabilidad las tecnologías de la información y la comunicación.

h) Conocer y valorar críticamente las realidades del mundo contemporáneo, sus anteceden tes históricos y los principales factores de su evolución. Participar de forma solidaria en el desarrollo y mejora de su entorno social.

k) Afianzar el espíritu emprendedor con actitudes de creatividad, flexibilidad, iniciativa, trabajo en equipo, confianza en uno mismo y sentido crítico.

${ }^{6}$ En la educación secundaria las unidades, programaciones, etc., se justifican mediante la inclusión de las ocho competencias básicas. En nuestro caso, al estar programando para bachillerato su inclusión no es obligatoria (en la Educación Secundaria Obligatoria la referencia explícita a cerca de la contribución de la materia para la adquisición de las competencias básicas es obligatoria. Ver decreto 327/2010, de 13 de julio, art 29).

URL=<http://www.boe.es/buscar/doc.php?id=BOE-A-2006-7899>

Decreto 327/2010, de 13 de julio, por el que se aprueba el Reglamento Orgánico de los Institutos de Educación Secundaria.

URL=<http://noticias.juridicas.com/base_datos/CCAA/an-d327-2010.t5.html> 


\section{C) Elementos de la Unidad Didáctica}

\section{Objetivos}

Los objetivos son las metas que han de guiar todo el proceso de desarrollo de la Unidad Didáctica, y hacia su consecución deben estar orientadas todas las actividades que se realicen. Se entiende que una vez finalizada la Unidad Didáctica el alumnado ha alcanzado las metas propuestas como resultado del desarrollo del proceso de enseñanza y aprendizaje, y por lo tanto, habrán desarrollado las siguientes capacidades. De acuerdo con los apartados a) [Fundamentación y relevancia] y b) [Justificación] anteriormente expuestos, los objetivos seleccionados se diferencian entre objetivos didácticos de la Unidad Didáctica y los Objetivos Generales pertenecientes al bachillerato que se recogen en el RD 1467/2007. Asimismo, parte de los objetivos son de temática transversal, y se hayan dentro de los objetivos didácticos; estos tienen por finalidad contribuir en la educación mediante el refuerzo de valores morales y ciudadanos (tolerancia, respeto, solidaridad, etc.), y también, el desarrollo personal y el talante crítico.

\subsection{Objetivos didácticos de la unidad}

1. Comprender las razones que han llevado a la aparición de los lenguajes formales.

2. Descubrir la dimensión argumentativa del discurso humano y obtener una competencia básica en la explicitación y análisis de las estructuras argumentales subyacentes.

\section{Aprender a formalizar.}

4. Distinguir entre estructuras argumentales válidas, inválidas y, muy especialmente, dentro de estas últimas, las falaces.

5. Ejercitarse en el trabajo de la lógica y sus reglas (deducción natural).

6. Comprender la función de la lógica en el contexto de la filosofía.

7. Valorar la necesidad del rigor metodológico, estructural y argumenta tivo en la tarea del conocimiento y el pensamiento.

8. Distinguir los diferentes tipos de argumentación no formal.

9. Aprender y reconocer las falacias que aparecen en la argumentación.

10. Utilizar con sentido crítico los distintos contenidos, mensajes y fuentes de información, y adquirir nuevos conocimientos con su propio esfuerzo.

11. Valorar críticamente los hábitos sociales relacionados con el consumo, así como la publicidad "engañosa". 
12. Tomar conciencia de la importancia del espíritu de cooperación, responsabilidad moral, solidaridad y tolerancia, y del respeto sobre principio de la no discriminación entre las personas.

13. Valorar el dialogo y el poder de la palabra como proceso de encuentro racional, y también, como elemento persuasivo que nos aleja de la confrontación violenta y permite el ejercicio de la ciudadanía democrática.

\subsection{Objetivos de ampliación}

14. Analizar el rol de la pregunta y el fenómeno de la presuposición en el contexto argumentativo.

15. Distinguir entre diferentes tipos de preguntas falaces: preguntas con presuposición, preguntas múltiples y preguntas anfibólicas.

16. Estudiar y comprender la función de la interrogación retórica en la argumentación.

\subsection{Objetivos Generales}

Identificar y apreciar el sentido de los problemas filosóficos y emplear con propiedad y rigor los nuevos conceptos y términos asimilados para el análisis y la discusión. (Objetivo General 1)

Adoptar una actitud crítica y reflexiva ante las cuestiones teóricas y prácticas, funda mentando adecuada mente las ideas. (Objetivo General 3)

Argumentar de modo coherente el propio pensamiento de forma oral y escrita, contrastándolo con otras posiciones y argumentaciones. (Objetivo General 3)

Practicar y valorar el diálogo filosófico como proceso de encuentro racional y búsqueda colectiva de la verdad. (Objetivo General 4)

Analizar y comentar textos filosóficos, tanto en su coherencia interna como en su contexto histórico, identificando los problemas que plantean, así como los argumentos y soluciones propuestas. (Objetivo General 5)

Adoptar una actitud de respeto de las diferencias y crítica ante todo intento de justificación de las desigualdades sociales y ante toda discriminación, ya sea por sexo, etnia, cultura, creencias u otras características individuales y sociales. (Objetivo General 7)

Valorar la capacidad normativa y transformadora de la razón para construir una sociedad más justa, en la que exista una verdadera igualdad de oportunidades. (Objetivo General 8)

Ver anexo (II). 


\section{Contenidos}

Los objetivos didácticos orientan a la selección de contenidos (conceptos, habilidades y actitudes); además, tienen en cuenta los temas transversales (que en este caso tienen que ver con la educación para la convivencia, una educación no sexista y una educación del consumidor) y dirigen la secuencia y los diferentes tipos de actividades. En coherencia con los objetivos didácticos, para atender a la diversidad del alumnado, la propuesta de contenidos también diferencia aquellos que se estipulan como básicos, de aquellos otros, que se consideran de ampliación. ${ }^{7}$

Los contenidos, de la materia de Filosofía y Ciudadanía de primero de Bachillerato son los establecidos por el Real Decreto 1467/2008, de 2 de noviembre. ${ }^{8}$ La formulación de los contenidos tiene una particularidad: Ios organiza en bloques de forma global. En la Orden del 5 de agosto de 2008 la asignatura de Filosofía y Ciudadanía aparece en cuatro bloques distintos. Los contenidos que se imparten corresponden a la segunda parte del primer bloque "Características generales del saber filosófico y de la argumentación válida." es decir, a "la argumentación válida". A continuación, en nuestra unidad didáctica serán expuestos y desglosados los contenidos en conceptos, habilidades y actitudes, con la intención de proporcionar una mayor claridad pedagógica

\subsection{Conceptos.}

1. Lógica y Lenguaje. Lenguaje natural y lenguaje formal. Lenguaje objeto y metalenguaje: uso y mención. Lenguaje natural, metalenguaje y lenguaje formal.

2. Lógica proposicional. Proposiciones. Conectivas lógicas. Simbolización de proposiciones. Formulas proposicionales.

3. Funciones veritativas. Tablas de verdad. Evaluación de fórmulas mediante tablas de verdad. Tautología, antilogía (o contradicción) y indeterminada (contingente).

4. Deducción natural. Deducción directa e indirecta. Esquemas de argumentos. Reglas de inferencia

5. Lógica Informal.

6. Falacias y falsos argumentos.

\footnotetext{
${ }^{7}$ Asimismo, teniendo en cuenta el apartado b) [Justificación] del TFM aquí expuesto, la Unidad Didáctica de Filosofía y Ciudadanía de primero de Bachillerato está realizada teniendo en cuenta las premisas establecidas y desarrolladas por la Comunidad Autónoma de Andalucía a través del Decreto 416/2008, de 22 de julio en el que se establecen la ordenación y las enseñanzas correspondientes al bachillerato en Andalucía de conformidad con lo dispuesto en el Real Decreto 1467/2007, de 2 de noviembre por el que se establecen la estructura del bachillerato y se fijan sus enseñanzas mínimas.

${ }^{8}$ Ver anexo (I).
} 


\section{Contenidos de ampliación}

La propuesta de contenidos tiene por objetivo dar una respuesta efectiva a la diversidad en el aula, aunque también, puede ser una respuesta para la diversidad entre centros. Merece tenerse en cuenta que la determinación de si un contenido es básico o de a mpliación depende de quienes son los estudiantes y de los objetivos que se pretendan lograr; es decir, se trata de una distinción muy relativa y circunstancial. Por ejemplo, puede darse el caso que un mismo contenido puede ser de ampliación para un alumno y al mismo tiempo puede ser básico para otro. En lo que se sigue, está es la diferencia principal:

Contenido Básico: El contenido que debe ser aprendido por todo el alumnado.

Contenido de Ampliación: Son aquellos que expanden los contenidos relacionados con el eje organizador. Estos permiten extender las habilidades, aumentar la cantidad de textos, complejizar la ejercitación, diversificar los ejemplos. Este tipo de contenidos se propondrán para el alumnado más talentoso y también, para la/os interesada/os en el tema.

7. El rol de a pregunta en el contexto argumentativo. El fenómeno de la presuposición.

8. Tipología de preguntas. Pregunta con presuposición. Pregunta múltiple. Pregunta anfibólica.

9. La interrogación retórica.

\subsection{Habilidades}

1. Definición precisa de los siguientes términos:

Argumento, antilogía, axioma, conclusión, contingencia, contradicción, enunciado, falacia ad baculum, falacia ad hominem, falacia ad ignorantiam, falacia ad misericordiam, falacia ad populum, falacia ad verecundiam, falsa causa, falso dilema, falacia formal, falacia informal, petición de principio, fórmula, inferencia, lenguaje objeto, lógica, metalenguaje, persuasión, proposición, pregunta anfibólica, pregunta compleja, pregunta múltiple, pregunta con presuposición, premisa, predicado, presuposición, tautología, validez, variable.

2. Diferenciación entre la materia de un discurso y su estructura argumental.

3. Diseño de razonamientos con estructura lógica formalmente válida.

4. Formalización de enunciados y argumentos del lenguaje ordinario.

5. Elaboración de tablas de verdad. 
6. Aprender y ejercitar las reglas de la lógica. Hacer ejercicios de deducción y de decisión de la verdad o falsedad de las fórmulas.

7. Aprender a descubrir falacias tanto en los razonamientos deductivos como en las argumentaciones informales. Recopilación de falacias (políticas, domésticas, académicas, etc. y clasificación de las mismas.)

\section{Contenidos de ampliación}

8. Elaboración de una disertación sobre la ocurrencia de preguntas falaces en el ámbito público (encuestas, debates parlamentarios, platos televisivos, etc,).

9. Elaborar una disertación sobre publicidad engañosa.

10. Análisis de imágenes reflejando la tesis principal y recursos retóricos empleados

\subsection{Actitudes}

1. Asimilar la importancia de los lenguajes formales.

2. Valorar el cálculo de enunciados como una herramienta útil para valorar la validez de un razonamiento.

3. Apreciar la diferencia entre validez y verdad, razonamiento lógico y falso argumento, y promover el uso correcto de la razón.

4. Reflexionar sobre los motivos que llevan a usar frecuentemente razonamientos falaces.

5. Adoptar una actitud de prevención ante determinados tipos de discurso: falacias y otros falsos argumentos.

6. Tomar conciencia de la importancia de las preguntas en su uso cotidiano; contextos discursivos, encuestas de opinión...

\section{Contenidos de ampliación}

7. Asumir el valor de la lógica en la construcción de un pensamiento racional y fundamentado.

8. Promover una actitud de respeto y pertinencia en el diálog o y la controversia, que sea compatible con el análisis y la reflexión sobre la estructura de la misma.

9. Adoptar una actitud crítica ante determinados contenidos, mensajes y fuentes de información que incurran en la discriminación, el odio, el sexismo o el consumismo.

10. Valorar críticamente la publicidad "engañosa". 
11. Apreciar la importancia del espíritu de cooperación, responsabilidad moral, solidaridad y tolerancia, y del respeto sobre principio de la no discriminación entre las personas.

12. Asimilar el valor del dialogo y el poder de la palabra como proceso de encuentro racional, y también, como elemento persuasivo que nos aleja de la confrontación violenta y permite el ejercicio de la ciudadanía democrática.

\section{Esquema de la Unidad Didáctica.}

LÓGICA FORMAL E INFORMAL

0. Introducción

1. Lógica y Lenguaje.

1.1. Lenguaje natural y lenguaje formal.

1.2. Lenguaje objeto y metalenguaje: uso y mención.

2. Lógica proposicional.

2.1. El lenguaje de la Lógica proposicional

2.2. Proposiciones.

2.3. Conectivas lógicas.

2.4. Simbolización de proposiciones.

3. Funciones veritativas.

3.1. Tablas de verdad.

3.2. Evaluación de fórmulas mediante tablas de verdad.

3.3. Tautología, antilogía (o contradicción) y indeterminada (contingente).

4. Deducción natural.

4.1. Deducción directa e indirecta.

4.2. Esquemas de argumentos.

4.3. Reglas de inferencia.

5. Lógica Informal.

6. Falacias y falsos argumentos.

7. El rol de a pregunta en el contexto argumentativo.

7.1. El fenómeno de la presuposición.

7.2. Tipología de preguntas:

7.2.1. Pregunta compleja

7.2.2. Pregunta múltiple

7.2.3. Pregunta anfibólica. 


\section{Educación en valores.}

Los objetivos didácticos orientan a la selección de contenidos (conceptos, habilidades y aptitudes) que tienen en cuenta los temas transversales (en este caso nos centraremos principalmente en la educación para la convivencia y la paz, una educación no sexista y una educación del consumidor). En este apartado se concretarán ciertos aspectos de la unidad didáctica que consideramos novedosos ya sea por el enfoque que se da (en temática transversal) o por los medios (recursos) que se emplean.

\section{1. Transversalidad.}

La inclusión de temas transversales en el currículo escolar pretende mitigar ciertas necesidades sociales que ni la escuela ni la familia han suplido de manera satisfactoria. Además, en la sociedad de la información los principales medios de comunicación, Internet, redes sociales etc., no hacen una defensa de valores que se caractericen por la tolerancia, la solidaridad y el respeto. Y por lo tanto, se puede afirmar que a nte está crisis de valores la escuela ha de adoptar una actitud activa; mediante la introducción de temas transversales se intenta hacer frente a esta situación de falta de valores éticos y ciudadanos.

La educación tiene por objetivo desarrollar personas tanto en el plano académico como en el plano moral y social para que se desenvuelvan de la mejor manera. Es decir, no solo se forman estudiantes, también, se forman ciudadanos.

A nuestro entender, la asignatura de filosofía se presta de manera natural y efectiva a tratar estos temas desde un enfoque que propicie la reflexión y el pensamiento crítico fomentando una educación ético-cívica. Independientemente de la asignatura (matemática, biología, literatura, gimnasia, etc.) que se imparta en la Educación Secundaria, los temas transversales no se estudian de manera particular, sino que, se insertan dentro de la Unidad Didáctica o la Programación de Aula. Son ocho los temas transversales identificados en educación: Educación ambiental (1), Educación para la paz (2), Educación del consumidor (3), Educación vial (4), Educación para la igualdad de oportunidades entre sexos (5), Educación para la salud (6), Educación en la sexualidad (7), Educación cívica y moral (8). ${ }^{9}$

En nuestra Unidad Didáctica de lógica orientaremos nuestros objetivos didácticos al análisis de discursos y argumentaciones que provengan de campos como

9 En la Educación Secundaria Obligatoria, el "Art. 19 de la LOGSE" trata sobre las capacidades generales a desarrollar en el alumnado. De las capacidades propuestas no todas pero sí la mayoría- están en clara relación con la educación en valores y los temas transversales. Igualmente, en la Ley Orgánica del 2006 los objetivos del bachillerato como las capacidades a desarrollar también están en relación con la educación en valores (Ley Orgánica 2/2006, de 3 de mayo). 
los medios de comunicación, blogs, redes sociales, declaraciones de política/os, etc. Para ello trabajaremos tres temas transversales: Educación para la paz (2), Educación del consumidor (3) y Educación para la igualdad de oportunidades entre sexos (5).

Consideramos que la disciplina filosófica es un saber de actualidad tan importante como lo fue en la antigüedad; o al menos, así debería de ser. Entendemos que la filosofía es una asignatura que tiene que estar actualizada e incardinada en los problemas actuales, su enseñanza teórica debe ser acompañada mediante una proyección práctica y real. A su vez, es necesario aplicar tanto los formatos actuales como las herramientas de última generación. En nuestra opinión, está fuera de toda discusión que las redes sociales, los blogs e Internet ofrecen su particular punto de vista de los problemas que nos acucian hoy en día. Saber manejar estas herramientas y tratar con los problemas que plantean es un reto para el profesorado; pero a su vez, es la vía (entre otras) para acercar la filosofía al alumnado. No se puede obviar el hecho de que tratamos con personas que están viviendo la revolución de la información y las nuevas tecnologías.

Diferenciaremos tres estadios a la hora de trabajar los temas transversales:

a) Estadio Objetivo: panorámica general y problemática del tema que se estudia.

b) Estadio Subjetivo: extrapolación al plano individual el tema estudiado en el estadio objetivo. Análisis sincero y crítico para solucionar (y desterrar) de manera efectiva las actitudes que promuevan valores que van en contra de los principios señalados

c) Estadio Intersubjetivo: el paso del estadio objetivo al estadio personal todavía requiere de otro paso, pues, los valores que se interiorizan deben ser materializados en nuestras relaciones interpersonales, es decir, en la sociedad. Es ahí donde nuestros compromisos cívicos garantizan una convivencia en armonía entre toda/os sin discriminación.

\subsubsection{Temas transversales.}

\subsubsection{Educación para la paz (2).}

Entendemos que la aportación de la filosofía y de la lógica en estos temas es fundamental; la filosofía promueve el diálogo racional como condición necesaria para la paz. La paz en este sentido no implica una ausencia de confrontación y polémica, sino más bien, es el intento de hacer frente a los problemas (sociales, económicos, políticos, culturales, etc.) desde el convencimiento de que la palabra y la argumentación son medios efectivos para la resolución de conflictos. Es decir, promover una relación entre diferentes donde el respeto, la solidaridad y la participación sean los valores que rijan la convivencia. 
Actualmente, los países europeos viven una época muy convulsa en los aspectos antes señalados: vivimos un severa recesión económica; los sectores sociales desfavorecidos sufren recortes en derechos básicos; la justicia social brilla por su ausencia; el fenómeno de los nacionalismos está presente; los movimientos ultraderechistas van en auge; el intervencionismo militarista (OTAN) en países árabes; el choque de civilizaciones, etc. La filosofía debe de hacer un esfuerzo de aproximación, comprensión y detección de estos problemas, además de plantear soluciones.

En la práctica, tanto en el apartado de Actividades como en el de Temporalización, indicaremos la manera en la que la temática transversal va a ser trabajada a lo largo de la unidad. De todos modos, se dará libertad de elección para trabajar el tema que prefiera el alumnado y también, se dará libertad de elección sobre los materiales a emplear para desarrollar la disertación. Entendemos que, por nuestra parte, tanto la temática como los recursos a emplear serán suficientes; en cualquier caso, el alumnado -de acuerdo con el profesor- será quien decida en última instancia.

Temas que se plantean para la libre elección del alumnado:

\subsubsection{Tema (2)}

\section{Guerra}

Presentar la guerra como una lacra propia de la condición humana. No hay misiones civilizadoras, ni tampoco guerras justas; es más, toda guerra es un fracaso en nuestro compromiso con los valores ético-cívicos.

\section{Derechos humanos}

Los recortes en derechos básicos vienen precedidos de luchas que a menudo se desconocen, sin una memoria que nos advierta de esos logros se pierde la perspectiva. Asimismo, conocer e identificar los derechos básicos recogidos en la Declaración Universal de Derechos Humanos es una obligación que necesita corrobora rse a diario.

\section{Inmigración}

La inmigración es un chivo expiatorio clásico para la adjudicación de todos los males presentes en la sociedad. Todas las sociedades han sido inmigrantes alguna vez en su historia, y se a de ser consciente de ello. Además, hay que huir de clichés y estereotipos, y hay que valorar la aportación de estos colectivos en materia económica, social y cultural. Tampoco, nos podemos relajar con las expresiones xenófobas que van en aumento en la sociedad europea. Además muchos razona mientos entorno a la inmigración recaen en falsas generalizaciones, apelaciones al miedo, a la masa, a los sentimientos y la caricatura...Sin duda, la lógica informal es de gran utilidad para desenmascarar discursos y mensajes que son xenófobos y contrarios a los principios de la solidaridad e igualdad. 


\section{Crisis}

La crisis económica y financiera está azotando en el mundo globalizado, en Europa sus consecuencias se pueden comprobar, y en España ya se están sufriendo estas consecuencias de manera dramática. Hace falta hacer una "visión crítica" de la situación (capitalismo, mercado, crecimiento sostenido y competitividad), de todo lo que se ha hecho (especulación, inflación, deuda, etc.). Asimismo, se a de poner en valor otro tipos de riquezas más allá del lucro personal, entender la calidad de vida más allá de los bienes materiales.

\section{Huelga general del 29 de marzo}

Poner a prueba la lógica informal en el discurso de los políticos, agentes sociales y sindicales, así como el de los medios de comunicación es un desafío que se debe afrontar sin demora y de forma directa. Por lo general, los discursos políticos de los diferentes partidos están plagados de incorrecciones argumentativas. Hacer una labor de detección y análisis para su posterior evaluación no solo prueba la utilidad de la lógica informal, sino que también, es provechoso para la convivencia en la sociedad.

\section{Monarquía vs. República}

Últimamente, este es uno de los temas que están en discusión; tanto detractores como partidarios de uno $u$ otro modelo político, pueden afrontar la discusión de forma argumentada mostrando los pros y contras.

\section{Pensamiento crítico}

En esta sociedad actual el pensamiento crítico no está lo suficientemente valorado, vivimos en una sociedad presa de lemas como la seguridad, el control, riesgo, etc. El pensamiento único nos impide ver de forma crítica cuestiones de actualidad como son las nuevas tecnologías, la prensa rosa, el consumismo, el trabajo, el hambre, la pobreza, etc.

\subsubsection{Tema (3)}

Educación del consumidor

Vivimos en una sociedad de consumo, toda la propaganda mediática ha creado una sociedad que consume de manera irresponsable y acrítica. Como consecuencia de esta conducta consumista hemos organizado una sociedad que acumula bienes a toda costa independientemente de su utilidad y su necesidad, sin olvidar, la cantidad de deshechos que se generan. Ciertos problemas de la sociedad (la bulimia, la anorexia, el "Fashion victim", la baja autoestima, violencia, agresividad, asignación de roles por género, etc.) están motivadas -no en exclusiva, pero sí en parte- por este bombardeo publicitario, ya que, no solo sirve para favorecer el consumismo, también es un vehículo para introducir valores e ideales de vida (ideología). 
Ante esta tesitura, la filosofía y en concreto la asignatura de lógica tiene que plantear objeciones, criticas, dudas y alertar acerca de este ideal consumista. Pues, parece que tanto las personas como la calidad de vida se miden en función de las marcas y de los bienes materiales que se acumulan; lo que se conoce por el "tanto tienes, tanto vales". Por ello, la actividad docente y la dinámica de clase tienen que poner en valor a la persona como su calidad humana frente al materialismo consumista. De igual manera, hay que dotar al estudiante de "gafas" críticas para poder ver qué ideología, valores y costumbres se trasmiten mediante los anuncios publicitarios.

Asuntos a tratar: publicidad engañosa, consumismo, marcas, moda, publicidad sexista, culto al cuerpo, ideal de vida, publicidad clasista, juguetes bélicos y sexistas.

\subsubsection{Tema (5)}

Educación no sexista

En la constitución española se recoge el derecho a no ser discriminado por sexo, raza o creencia. En cualquier caso, la brecha entre el articulado constitucional y la dinámica social es evidente. Por tanto, el sistema educativo debe velar por una educación que sea sensible y comprometida con estos valores de igualdad entre diferentes.

De manera especial, hay que hacer hincapié en la discriminación doble o triple que supone la condición de ser mujer, más aún, si no es de raza, ni de creencia "nativa". Además, los campos donde se sufre la discriminación son de diferente índole: en el hogar, en la sociedad, en el contexto laboral, la publicidad, etc. El alumnado ha de ser consciente y consecuente, para ello, no solo es necesario advertirlo, sino que también, hay que introducirlo en dinámicas y actividades que rompan con las barreras discriminatorias.

\subsubsection{Recursos}

Anteriormente hemos dicho que la filosofía no puede ser un saber caduco y fosilizado, y que debe de tratar con problemas de actualidad. A su vez, entendemos que no sólo los contenidos deben ser actualizados, tanto los métodos como las herramientas que empleemos deben ser actuales. Por ello, las Tics (que hacen referencia a los materiales y herramientas que pertenecen a las Tecnologías de la Información y la Comunicación) deben ser empleadas en la enseñanza; este es un recurso relativamente novedoso y de gran utilidad. Potenciaremos, en la medida de las posibilidades, una actualización en temática a estudiar y también, una actualización en materiales y medios a emplear.

Los recursos que emplearemos para trabajar la transversalidad serán informáticos (Tics: el blog y el Dropbox) e instrumentales (la disertación). Por un lado, vamos a emplear toda una serie de recursos gráficos disponibles en Internet. Las redes sociales (Twitter, Facebook, etc.) son medios que permiten crear opinión de una manera sencilla y directa, pero, no podemos olvidar que son mensajes con una carga 
retórica muy importante. En estos mensajes se emplean dilemas, analogías, contradicciones, antimetáboles, metáforas, retruécanos, preguntas retóricas, anfibolías, etc. Por lo tanto, no solamente nos permiten enfocar y profundizar sobre un problema en concreto, también, podemos hacer un análisis retórico sobre la forma de presentar -es decir, dar cuenta de los recursos retóricos que se emplean- el tema que se aborda. Por otro lado, aprovecharemos todo este trabajo para publicitarlo en un blog (si el centro tiene página Web ahí mismo, sino se creará un blog), donde el alumnado será protagonista y autor. La idea es emplear los recursos informáticos de tal manera que se conviertan tanto en objeto de estudio, así como medio o vehículo para comunicar y publicar nuestros estudios.

Somos conscientes de que en la sociedad actual se está perdiendo el gusto por los análisis profundos y teóricos; entendemos que el recurso instrumental de la disertación puede contrarrestar esa tendencia. De todos modos, vamos a intentar explicar el por qué creemos que se está perdiendo el gusto por análisis racionales, razonados, documentados y lo suficientemente extensos sobre problemáticas que conciernen a todo el mundo y que son de interés general.

La cultura dominante, la que conocemos como posmodernidad-que no sólo es una época, también, es ideología-, se caracteriza por la fragmentación y la irrupción de nuevas y variadas tecnologías en la sociedad de la era de la información (y por paradójico que sea, también, de la desinformación). Existen tendencias que son preocupantes, por ejemplo, se prescinde de manera manifiesta de todo lo que implique teoría, investigación, documentación, memoria, etc. $\mathrm{Si}$ somos lo suficientemente críticos, llegaremos a esa conclusión. La cultura dominante -en esta época posmoderna- a nivel conceptual es pobre, y ello independientemente que pueda ser ingeniosa y colorida. Pensemos sino cuales son los formatos preferidos -por la sociedad en general, y la juventud en particular- a la hora de estudiar o dar cuenta de cualquier fenómeno: Youtube, Facebook, Twitter, revistas con poco texto y libros best seller.

Se puede afirmar por ello, que vivimos en una cultura de la inmediatez, de fácil digestión y reflexión, que no supone apenas ningún esfuerzo. Esta cultura a nivel intelectual es simple y populista; y a nivel práctico precisa de resultados instantáneos. De esa realidad se ha de ser consciente.

Frente a la inmediatez y sencillez posmoderna, entendemos que la disertación es un ejercicio que contrarresta la tendencia que criticamos. En nuestra opinión, las exposiciones sesudas y documentadas son necesarias y se han de potenciar; esa madurez intelectual no se adquiere sin sacrificio y menos aún, de forma espontánea. Para ello, vamos a involucrar al alumnado en procesos de reflexión, que requieren trabajo, esfuerzo y concentración, además de, un posicionamiento argumentado y fundamentado en razones.

La disertación es un escrito que lo elabora el alumnado de forma autónoma, es una actividad critica, creativa, reflexiva y compleja. Además, es buen mecanismo 
para la evaluación escolar de la competencia lingüística. En principio, no hay una fórmula única para elaborar una disertación y se puede hacer de dos maneras: una exposición o una argumentación. Quizás, es deseable hacerlo de la segunda manera ya que el estudiante se familiarizará con la argumentación; pero también es cierto que cualquier tema que se aborde se puede realizar de esas dos maneras. Ambos modelos de disertación requieren de una comprensión del problema que se estudia, obliga al alumnado a realizar una labor investigadora y también, implica un posicionamiento que debe hacerse de manera autónoma y crítica.

El texto argumentativo está dividido en tres partes: introducción, nudo y desenlace. La introducción sirve para presentar el problema, ha de hacer referencia a la tesis que se quiere defender. De las tres partes es la más breve de todas. Para estimular al lector a entrar en el problema se suelen emplear diversas técnicas: planteando preguntas retóricas, citando fuentes periodísticas, comentando vivencias personales, recordando acontecimientos históricos o exponiendo el estado de arte. El nudo es la parte central, ahí es donde la argumentación debe ser lo más pertinente y ordenada posible. En general, las razones tienen que estar ordenadas en función de la importancia; se debe tener claro el objetivo de la argumentación: lo que se quiere probar; las consecuencias que se derivan y las conclusiones que se pretenden alcanzar; así como, proponer soluciones y alternativas (si las hubiera). Las técnicas argumentativas son diversas: argumentar apelando a la autoridad, por ejemplo, la comunidad científica; a través de ejemplos; contraponiendo tesis; o de forma personal, inductivamente... Por último, está la conclusión, donde se resume todo lo expuesto y se extraen las conclusiones pertinentes; para finalizar, es conveniente dar la opinión y valoración personal porque se consigue un posicionamiento por parte del alumnado. A nuestro entender, el sentimiento de indiferencia no puede ser resultado de una disertación desarrollada por el alumnado.

La disertación en forma de exposición varía del texto argumentativo en el desarrollo del nudo. Por un lado, las partes claves del texto argumentativo son el razonamiento, las consecuencias y las alternativas; por otro lado, las partes claves de la exposición, son los datos generales, los pros y los contras. El objetivo principal de la exposición no es hacer un defensa o una acusación de una tesis en concreto, sino más bien, se trata de presentar una problemática de la manera más objetiva posible. Para ello, se han de presentar ciertos datos generales (documentados), dar cuenta del origen, su contexto y el desarrollo. A su vez, se deben contemplar los lados buenos y malos que tiene la problemática que se estudia. Y para finalizar, hay que desarrollar una opinión y una valoración personal en forma de conclusión.

Ambos modelos tienen sus potencialidades y hay que saber emplearlas. Si queremos abordar un problema que es de dominio público, entonces lo más conveniente es defender o rebatir una tesis que gire en torno al problema que es conocido por todo el alumnado. Si por el contrario, el problema que se analiza es novedoso y presenta dificultades para su comprensión, entonces lo más conveniente es presentarlo en forma de exposición. Pero hay que ser flexibles en este aspecto, porque cualquier problema se presta a ser tratado de una u otra forma. 
Esta sería la estructura que conviene mantener cuando se hace una disertación:

\begin{tabular}{l|l|}
\multicolumn{1}{l}{ Argumentación } & \multicolumn{1}{l}{ Exposición } \\
\hline 1. Introducción & 1. Introducción \\
\hline 2.1. Razonamiento & \multicolumn{1}{l}{ 2.1. Datos generales } \\
\hline 2.2. Consecuencias & 2.2. Pros \\
\hline 2.3. Solución/alternativas & \multicolumn{1}{l}{ 2.3. Contras } \\
\hline 3. Conclusión & 3. Conclusión \\
\hline
\end{tabular}

Para finalizar, en función de los materiales que se empleen para trabajar una disertación, se hará un breve análisis retórico. Si se pretende abordar un problema recurriendo a un discurso, un eslogan, una campaña publicitaria, el titular de un periódico, etc., entonces se dará cuenta de los mecanismos retóricos que se emplean y el propósito que persiguen. Además, se evaluará si estos modos de presentación son legítimas o no, y también, el grado de efectividad que tienen para el remitente de tales mensajes.

\subsubsection{Recursos: Films, documentales y páginas de interés}

Todos estos recursos instrumentales que proponemos como films, documentales, videos de corta duración, páginas web, etc., tienen como finalidad suplir al alumnado de recursos que satisfagan sus intereses tanto a nivel de formato como de contenido. Efectivamente, si hubiese en el centro las dotaciones suficientes para el empleo de videos que se proyectan en youtube (por poner un ejemplo), se aprovecharán las circunstancias para desarrollar una sesión acorde con las limitaciones horarias. Una película de dos horas de duración, por ejemplo, no permite que en una sesión se debata el tema que se trata, se adopten diferentes puntos de vista, se gestionen las intervenciones del alumnado, se identifiquen los puntos débiles y fuertes de cada posicionamiento, etc. Pero los videos de youtube que suelen ser de corta duración, sí nos permiten emplear una sesión con diferentes actividades. En la sección de temporalización aparece detallado las sesiones en las que se propondrá debates.

Ver anexo (XI).

\section{Atención a la diversidad:}

Por diversidad se entiende la atención prestada a alumnos que tienen cierta peculiaridad, por ejemplo, estas especifidades se pueden dar a nivel de integración, (alumnado extranjero), a nivel social (contextos descompensados, desventaja social, etc.), incorporación tardía, de altas capacidades, de bajas capacidades, motivaciones e intereses, etc. (Ver Boja 167/22-08-2008). Por ello, es conveniente que el profesor este asesorado por los equipos de orientación (mediante los llamados informes psicopedagógicos del departamento de orientación) del centro porque disponen de información relativa al alumnado. 
Para garantizar la diversidad en lo referido a las diferencias individuales en capacidades, motivación e intereses, y sin que se lleguen a efectuar adaptaciones curriculares significativas, se contemplan diferentes elementos: diversidad en la programación y adopción de medidas complementarias

-La diversidad en la programación se refiere a la determinación de objetivos, al tratamiento de los contenidos y al diseño de las actividades. Para ello se han establecido unos objetivos básicos y otros de ampliación. En efecto, los objetivos de ampliación serán para aquella/os alumna/os que por sus características, capacidades y motivaciones se les da la posibilidad de avanzar en la unidad.

-La adopción de medidas complementarias para mejorar la atención a la diversidad pueden ser: a) proponer diferentes mecanismos de recuperación; b) tener en cuenta el ritmo de aprendizaje de los alumnos; c) insistir en los refuerzos positivos para mejorar la autoestima y d) favorecer un buen clima de aprendizaje en el aula.

No podemos obviar el hecho que la diversidad es un factor muy contextual y personal; el profesor debe estar atento a estas personas, al trabajo que realizan y su disposición; saber adaptar pertinentemente las actividades a la peculiaridad del alumnado es un ejercicio circunstancial y complicado. Por ello, el profesorado debe ejercer una práctica "flexible" tanto en el plano de los contenidos como en el plano de los propósitos didácticos.

En cualquier caso, trasmitir normalidad en la clase -independientemente de las peculiaridades del alumnado- es una buena táctica. Pues favoreceremos la integración y colaboración entre los diversos y los demás.

\subsection{Alumnado con necesidades especiales}

Ciertamente es un dilema las adaptaciones al currículo del alumnado con necesidades especiales. Nos referimos principalmente al alumnado que por sus características físicas, motores, sensoriales, etc. (el alumnado con discapacidades en general) tienen dificultades y por lo tanto, también tienen necesidades educativas especiales. Estos serán los posibles tipos de adaptaciones:

- Personal especializado: En ocasiones será necesario el apoyo de personal cualificado para dar respuesta satisfactoria a las necesidades educativas.

- Adecuación del espacio: Tanto el espacio como el mobiliario del centro tiene que estar convenientemente adaptado para todo tipo de personas que por una causa u otra tengan dificultades de acceso, etc. El centro no puede ser un lugar que posibilite la marginación o discriminación, ni que impida el acceso de cualquier persona, es decir, se han de eliminar cualquiera de las barreras arquitectónicas que puedan existir. 
- Adecuación en materiales y recursos didácticos: Serán necesarios materiales especializados para las personas que por sus características no puedan emplear los materiales y la metodología educativa "convencional".

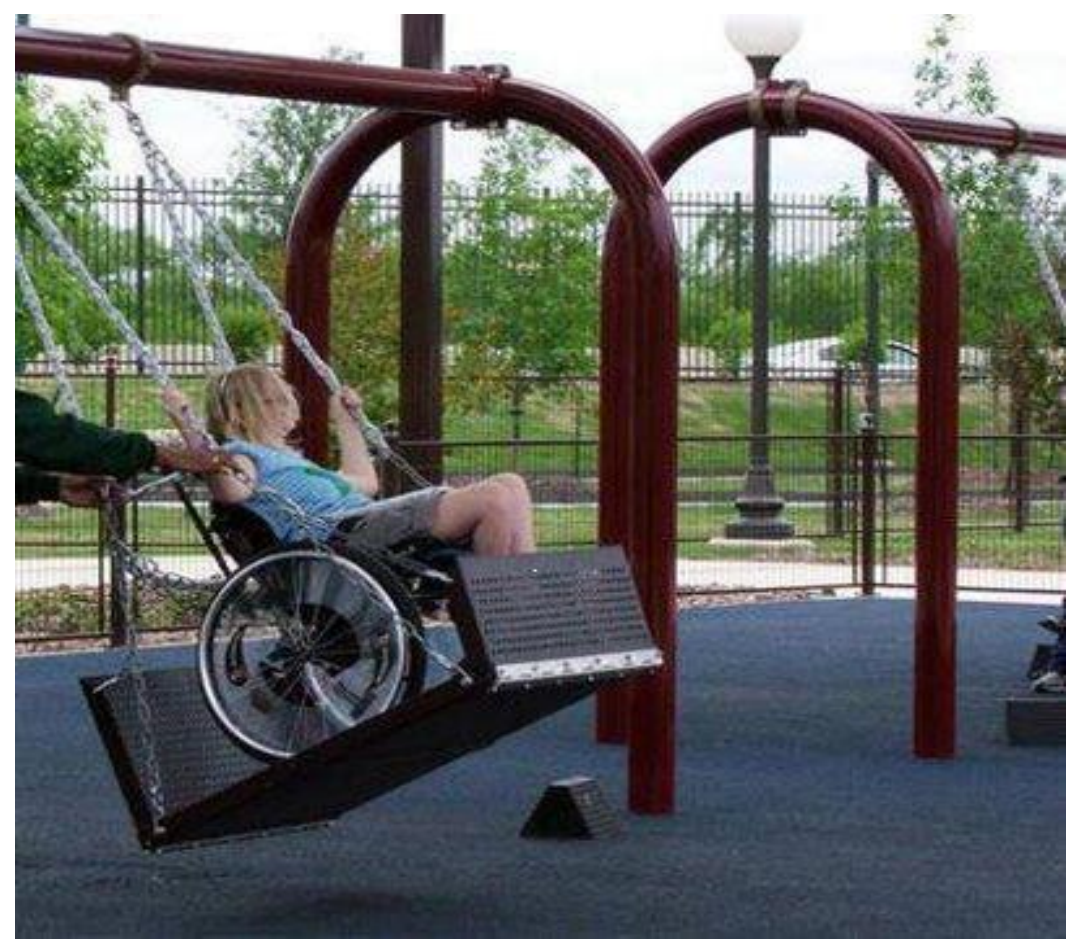




\section{D) Evaluación y seguimiento}

La evaluación nos permite obtener información sobre el proceso de enseñanzaaprendizaje; esta información se ha de emplear para adecuar las necesidades del alumnado en su propósito educativo. Como se trata de un procedimiento complicado, es deseable que la metodología sea exhaustiva cuando se evalúa los factores que inciden en este proceso, al menos, si se pretende que la evaluación cumpla con el propósito para el que se idea. Efectivamente, la evaluación puede ser una mera calificación, o por el contrario, un instrumento para la mejora educativa. De acuerdo con la segunda opción, entendemos que la evaluación nos sirve para controlar el proceso educativo; introducir cambios para su mejora y ver los resultados mediante la recogida y tratamiento continuo de datos. Por ello, este proceso debe ser un conjunto de actividades previstas lo suficientemente objetivo y riguroso que nos permita mejorar en la calidad de la enseñanza.

No podemos obviar el hecho de que no solamente se evalúa al alumnado. El profesor también ha de evaluar su práctica docente, el proyecto curricular y las programaciones didácticas de los departamentos. La complacencia e incluso el autoengaño son prácticas a desterrar que no se deben contemplar ni como excusas en la profesionalidad del docente.

\section{CRITERIOS DE EVALUACIÓN.}

Estos criterios nos permiten determinar si los objetivos propuestos han sido alcanzados, a saber, si una vez impartida la unidad didáctica se han alcanzado las capacidades que se persiguen.

1. Explica las diferencias entre el lenguaje natural y el lenguaje formalizado.

2. Formaliza enunciados y argumentos del lenguaje natural, elucidando su estructura lógica.

3. Determina el valor de verdad de una fórmula (tautológica, contingente o antilógica) mediante el empleo de tablas de verdad.

4. Aprende las reglas de la lógica y aplícalas en la resolución de ejercicios propuestos.

5. Averigua la validez de un razona miento mediante deducción natural.

6. Distingue entre razonamientos no formales, válidos y falaces.

7. Explica el fenómeno de la presuposición.

8. Distingue y explica el funcionamiento de los diferentes tipos de preguntas falaces. 
9. Expone argumentaciones y compone textos propios en los que se logra una integración de las diversas perspectivas y se avanza en la formación de un pensamiento lógico, racional y autónomo.

10. Reconoce los problemas que plantean los diferentes mensajes y discursos, y adopta una actitud razonada y crítica.

11. Conoce y justifica la necesidad de que el dialogo y la razón se utilice para construir una sociedad más justa, solidaria y democrática.

12. Argumenta de forma oral razonando los propios puntos de vista, sobre cuestiones de interés general en los que se abordan problemáticas transversales.

13. Utiliza y valora el dialogo como forma de comunicación para el entendimiento entre diferentes y la comprensión de diferentes problemas. Asimismo, reconocer y practicar los principios del dialogo racional como el respeto mutuo, la sinceridad, la tolerancia, etc., para la resolución de diferencias.

\subsection{Procedimientos de evaluación.}

En lo que respecta a la evaluación se ha de tener en cuenta que no sólo se valoran conocimientos, sino que también se valoran actitudes, capacidades y rendimientos. Además, se han de tener en cuenta diferentes variables que afectan al alumnado: unas son internas, como la atención, su interés y sus expectativas; y otras son externas, como su situación física, psicológica, etc. En cualquier caso, el proceso de evaluación es una tarea complicada que necesita de técnicas diversificadas para ser lo más objetivo y ecuánime posible.

Emplearemos para la valoración de aprendizaje una modalidad plural que contemple técnicas evaluativas cuantitativas y cualitativas. Las técnicas cuantitativas serán: pruebas objetivas (tests), pruebas escritas (con preguntas obligatorias y preguntas optativas), preguntas en clase y examen. Las técnicas cualitativas son: los registros de los diarios, análisis de texto, cuadernos de clase y la disertación. Estas últimas se evalúan mediante la observación y el trabajo directo en el aula; con las técnicas cuantitativas evaluaremos mediante prueba.

Para evaluar el aprendizaje de esta unidad usaremos los siguientes procedimientos:

\section{A) Evaluación cualitativa.}

Observación y análisis de tareas (\%40). Asistencia a clase y grado de interés atención, disposición y colaboración- (5\%). La participación en las actividades y su implicación con los compañeros -trabajos en equipo, debates, etc.- (5\%). El cuaderno de clase (15\%). La actitud y la relación con el alumnado así como con el profesorado -el respeto y el talante colaborador- (5\%). La realización de tareas y ejercicios programados (10\%). 
Mediante la evaluación cualitativa se pretende recoger los criterios de evaluación que se recogen en el R.D. 1467/2007 [ver Anexo (III)]. En concreto, mediante la asistencia a clase, la participación en actividades y las relaciones con las personas del centro se tendrán en cuenta los criterios 4 y 6 . Asimismo, mediante la realización de tareas, ejercicios y la disertación se tendrá en cuenta los criterios 2,3 y 5.

\section{B) Evaluación cuantitativa.}

Pruebas de control (\%40): test $(5 \%)$; pruebas escritas $(10 \%)$ y orales $(10 \%)$; examen (15\%). Las preguntas que se planteen serán en función de los criterios establecidos para la evaluación y siguiendo los objetivos de la unidad didáctica. Para la calificación se valorará los siguientes aspectos: adecuación pregunta/respuesta; corrección formal y rigor deductivo; variedad de recursos conceptuales; capacidad de definición; capacidad de argumentación; y capacidad de enjuiciamiento crítico.

Siguiendo los criterios del RD 1467/2007 se evaluará si se recogen los puntos: 1, 2 y 4.

\section{C) Trabajos.}

Trabajos especiales (\%20). Se propondrán al principio de la evaluación. El tipo será variado, desde la lectura de un texto, una disertación, hasta una investigación. Para la realización de estos trabajos especiales se ha propuesto que sean tratados desde la transversalidad (ver apartado C tema 4 transversalidad y Anexo (XI)).

En relación a los criterios de evaluación se tendrá muy en cuenta los puntos 2,3 y 5 recogidos en el RD 1469/2007.

\section{Autoevaluación.}

Es importante el juicio del alumna do acerca del aprendizaje y sus resultados. Un juicio franco del alumnado ayuda a detectar las causas de los resultados (sean buenos o malos), y necesariamente, tiene que tenerse en cuenta para la práctica docente.

\subsection{Calificación y mecanismos de recuperación.}

Para toda prueba se intentará que los días de las pruebas sean negociadas y acordadas con el alumnado; intentando evitar, a ser posible, interferencias con pruebas de otras materias. La calificación de la evaluación total (nota final) será la resultante de la media aritmética de la calificación obtenida de todas las calificaciones.

La nota final se calcula mediante la siguiente fórmula:

$[(40 \%) \mathrm{A}+(40 \%) \mathrm{B}+(20 \%) \mathrm{C}]$

Esto es: la media aritmética ponderada de las notas A, B y C. Donde A es la nota de la evaluación cualitativa, $B$ es la nota de la evaluación cuantitativa y $C$ es la nota de los trabajos especiales. 
A lo largo de la unidad que se imparte, en el caso de que no se apruebe la evaluación (cualquiera que fuera), el alumnado tendrá la posibilidad de hacer una recuperación que se negociará con el profesor. De esta manera posibilitaremos al alumnado alcanzar los objetivos propuestos (aprendizaje). Además, entendemos que los mecanismos de recuperación se tienen que ajustar a las circunstancias del alumnado, y de la misma manera, entendemos que los mecanismos de de recuperación son un instrumento más para la atención a la diversidad. ¿Qué es lo que tendrán que hacer?

-Tendrán que estudiar los contenidos conceptuales y procedimentales si han demostrado que no tenían el nivel exigido.

-Los trabajos que no hayan hecho o su calificación haya sido insuficiente tendrán que reelaborarlos hasta alcanzar los objetivos.

- Si el comporta miento es malo tendrán que rectificar.

\subsection{Autoevaluación del profesor.}

Análisis de la propia labor docente que contemple los siguientes aspectos: la relación con el alumnado, si el planteamiento didáctico ha sido acertado y los motivos, los resultados de los grupos, si se han alcanzado las capacidades programadas, si la atención a la diversidad ha sido atendida. 


\section{E) Desarrollo de sesiones}

\section{METODOLOGÍA Y ACTIVIDADES DE ENSEÑANZA Y APRENDIZAJE.}

Siguiendo las sugerencias sobre metodología y utilización de recursos (Orden $5 / 8 / 2008$ ), la metodología que se propone para el estudio de la lógica formal e informal es eminentemente activa y coherente con el aprendizaje significativo, y también, será eminentemente práctica. Es decir, no se trata únicamente de que la unidad didáctica que presentamos y sus actividades traten de desarrollar un aprendizaje meramente académico que se queda dentro del aula; sino mas bien, de fomentar el aprender a pensar y aprender a aprender: lo que llamamos el aprendizaje significativo. Por ello, se fomentará la lectura y la escritura, el ejercicio puro, así como, aprender a tratar y discriminar la información desde una postura crítica y racional. De esta manera, trata remos de desarrollar un pensamiento crítico en el alumnado y que el aprendizaje realizado pueda trasladarse a ámbitos cotidianos de la vida. A saber, capacitar al alumnado a vincular la esfera académica con la esfera pública y social.

La utilización de las nuevas tecnologías de la información es una herra mienta imprescindible para la enseñanza y el aprendizaje; sus potencialidades, así como, la cantidad de información que generan son inmensas. Por ello, se fomentará el uso de Internet proponiendo al alumnado que visite ciertas páginas Web en las que pueda introducirse en la materia, y a su vez, poder ejercitarse en la lógica y en el estudio de la argumentación. De igual manera, el material que se empleará será principalmente de las TICs, y se estudiarán casos, informaciones, eventos, declaraciones, etc., procedentes de Internet como los blogs, redes sociales, página de editoriales (URL = <http://kiosko.net/es/>) o especializadas en lógica y argumentación -los llamados sitios temáticos-didácticos-, (URL= <http://ntic.educacion.es/w3/eos/MaterialesEducativos/mem2003/logica/> y URL = $<$ http://courses.csusm.edu/fallacies/exercises_main.htm>).

La metodología será variada. Ya hemos mencionado que el aprendizaje ha de ser significativo (es decir, a través de los conocimientos previos y la memorización comprensiva) y para ello, se ha de motivar al alumnado con preocupaciones e intereses que los vinculen directa o indirectamente. Como principio metodológico general siempre se comenzará explicando el contenido y el propósito del tema que se aborda. También, se abordará la dimensión pragmática (realidad concreta) y se fomentará el debate para que haya participación; es decir, se empleará una metodología inductiva y activa. Una parte importante del trabajo del profesor debe ser la aclaración y exposición de conceptos promoviendo cierta riqueza conceptual.

Las actividades ya sean en grupo o individual serán prácticas: por un lado, el la primera parte de Lógica Proposicional el alumnado adquirirá destreza en el ejercicio de la lógica (formalizaciones, tablas de verdad y deducciones); y en la segunda parte de Lógica informal y argumentación abordaremos casos reales de discursos provenientes de diferentes campos: política, medios de comunicación, campañas publicitarias, redes 
sociales, etc. De esta manera contribuiremos a la propia construcción del aprendizaje del alumno.

Las actividades y tareas que se envíen serán variadas: unas se harán en clase tanto individual y en grupo; y otras se harán fuera de clase, también, individual y en grupo. Además, después de clase se mandarán actividades en función del tema que se haya dado. En algunos casos se emplearán las nuevas tecnologías y en otros casos, los apuntes que les haya proporcionado. Muchas de las actividades dependerán de las dotaciones que pueda tener el centro educativo. Por ejemplo, no es lo mismo que un centro tenga una dotación de ordenadores que no los tenga. Lo mismo ocurre para la evaluación, ya que hay test que se pueden hacer online o mediante fotocopia. De todos modos, los materiales didácticos estarán todos en soporte digital. No habrá libro de texto porque se podrá descargar todos los documentos desde el Dropbox (URL=<https://www.dropbox.com/home/Photos/Sample\%20Album>). Asimismo, emplearemos esta herramienta para recoger y compartir los ejercicios y actividades que se hagan. Y sacaremos adelante un blog con la ayuda del profesor y las colaboraciones del alumnado. El alumnado tendrá un cuaderno de clase para tomar nota, hacer mapas conceptuales, ejercicios, etc.

\section{Actividades}

Ahora presentaremos la elección del número y el tipo de actividades, así como la selección de materiales para trabajar la unidad didáctica. Por suerte, tenemos infinidad de recursos, materiales y herramientas disponibles en Internet que se ajustan perfectamente a nuestros propósitos y necesidades educativas -tanto a nivel cuantitativo como cualitativo-, para proceder de manera continua y gradual.

En principio emplearemos ciertos criterios generales a la hora de elaborar las actividades. Toda actividad será planificada con anterioridad. Los materiales (textos, documentos, etc.) irán graduados en función del programa y la complejidad, y también (en la medida de las posibilidades), personalizados atendiendo los principios de la diversidad en el aula. Los ejercicios también seguirán esos criterios. En la Unidad Didáctica de lógica, para la primera parte (Lógica Proposicional) se propondrán ejercicios sencillos de formalización (enunciados y argumentos), tablas de verdad y deducciones... En la segunda parte (lógica Informal) se propondrán lecturas, resúmenes, esquemas, mapas conceptuales y disertaciones.

Con el debate en clase procederemos de la siguiente manera, en un principio pediremos una opinión y valoración personal, para luego plantear al alumnado una valoración razonada y fundamentada. Es importante tener en cuenta que en el debate - más allá de la temática que se empleé-, lo fundamental es el procedimiento, es decir, el cómo se procede a argumentar en una discusión racional para resolver las diferencias de opinión. A nuestro entender es elemental que en todo debate se intente construir de una manera más o menos acertada la "verdad", pero tan elemental o más, es saber dialogar. Saber escuchar, rebatir y polemizar acerca de las cosas -en un modelo comunicativo del tipo discursivo donde todo el mundo tiene la opción de escuchar y ser escuchado, además de ser valorado por lo qué dice-, es el propósito que se persigue. Las clases de lógica informal se prestan de manera natural a ser ejercicios 
prácticos dialécticos. Y su potencialidad se deber desarrollar mediante el empleo de la actividad discursiva.

Los formatos que se emplearán serán diversos: material escrito, audiovisual, imágenes, juegos de ingenio, etc. Los ejercicios exigirán del alumnado adquiera destreza en diferentes modalidades: ejercicios lógicos, de ingenio (más importantes de lo que a primera vista puede parecer, ya que nos permiten relajar al alumnado manteniendo su atención para luego proseguir con el trabajo docente), responder cuestiones, hacer resúmenes, identificar tesis, hacer mapas conceptuales, analizar discursos, buscar información, debatir en clase, elaborar disertaciones, etc.

Para finalizar, mencionaremos el tema de la importancia que tiene la corrección. A menudo los errores, las incorrecciones, etc. se limitan en señalar lo que se ha hecho mal, pero la importancia de la corrección radica en enseñar al alumno el por qué se ha hecho mal. Es difícil conjugar las horas lectivas, el trabajo en casa y las tutorías con la corrección, además, teniendo en cuenta el tiempo que se tiene, tampoco se puede dedicar una sesión o sesiones a la corrección ya sea individual o colectiva. Pero esa actividad es obligatoria y necesaria, ya que nos da una idea de cómo se van asimilando los contenidos.

\section{Actividades.}

\subsection{Actividades de introducción.}

Las actividades de introducción tienen por objetivo entrar en contacto con el alumnado, presentar la materia, ver su actitud y valorar sus conocimientos previos.

1.1.1. Exploración inicial de las ideas previas y motivación. Para llevar a cabo esta tarea como procedimiento para obtener información respecto al tipo de alumnado con el que se va a trabajar, podría utilizarse el siguiente ejercicio:

1.1.2. Escribir frases en las que aparezca el término "lógica" con sus diferentes acepciones.

1.1.3. Intentar completar las diferentes frases:

-La lógica es...

-La lógica intenta...

-La lógica es ciencia porque...

-La lógica estudia...

-Todos somos lógicos cuando...

1.1.4. ¿Crees que la lógica es realmente importante en esta vida?

\subsection{Actividades de desarrollo.}

Una vez introducidas ciertas nociones básicas de Lógica Proposicional procederemos con las actividades de desarrollo que se corresponden con los objetivos básicos que 
hemos señalado. Las actividades serán diversas, des de la clásica exposición temática, presentación y solución de problemas, debates, comentarios de texto, pruebas, hasta los trabajos de investigación. Durante la exposición se fomentará la participación de los alumnos pa ra detecta r las dudas e incidir en la comprensión. Las clases discurrirán mediante exposiciones, sesiones de preguntas y respuestas, aclaración de dudas (para que ellos problematicen el tema); la participación en clase no impide que sea el profesor quién vehiculiza el aprendizaje del alumnado. Es importante buscar un equilibrio entre teoría y práctica, así el alumnado podrá establecer relaciones y desarrollar un aprendizaje comprensivo.

1.2.1. Exposición clara y rigurosa de los contenidos conceptuales de la unidad, de modo que permita a todo el alumnado captar la complejidad, la importancia y las implicaciones de los problemas planteados. Es también importante proporcionar datos (con preferencia sobre los ejemplos ordinarios y prácticos) que posibiliten inductivamente la construcción de conceptos, argumentos e inferencias, de tal modo que alcancen un aprendizaje significativo. En lógica la exposición conceptual se debe complementar con la exposición de problemas, es importante enfrentar al alumnado a identificar y encontrar los conceptos subyacentes del problema, de tal manera que encuentre el camino adecuado para resolverlos. En último caso, se resolverán los problemas, no sin antes, de que el alumnado lo haya investigado y formulado estrategias; para que a continuación las apliquen y las comprueben.

1.2.2. Actividad para reflexionar en torno a los prejuicios. Una de las primeras cosas que conviene que los alumnos comprendan es la gran cantidad de prejuicios infundados (de tipo doxástico) que se asumen en la argumentación cotidiana. También es cierto, que los medios de comunicación y las campañas publicitarias son mecanismos muy efectivos para trasmisión y reproducción de ideología, sentimiento identitario, consumismo y los roles de género. Para ello propondremos una exposición, comentario y debate que sea entorno a una temática transversal (Educación para la Paz (2), Educación del consumidor (3), Educación para la igualdad de oportunidades entre sexos (5)). ${ }^{10}$

1.2.3. Actividades de estudio de textos. Hay multitud de textos que pueden utilizarse para iniciar al alumno en las destrezas argumentativas al tiempo que se afianza la teoría. Por ejemplo emplearemos un diálogo de Platón "Eutidemo" para leer sobre el rol de la pregunta en el contexto argumentativo, y propondremos otras lecturas para tratar sobre las falacias o argumentos incorrectos. Se pedirá que se exponga de manera formalizada el argumento, qué se explique el mecanismo (cómo funciona), sus motivos y sus propósitos.

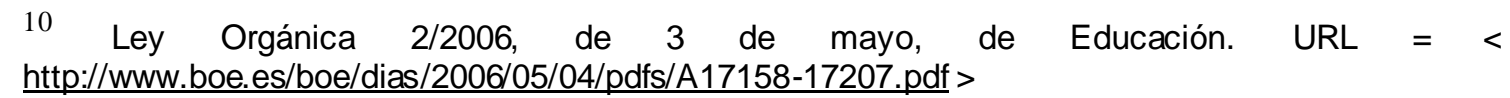


1.2.4. Actividad para reflexionar en torno a las preguntas en el contexto argumentativo. Su uso suele responder a determinados propósitos, que el alumnado comprenda el fenómeno de la presuposición en relación con la pregunta.

Toda exposición estará acompañada de ejercicios complementarios que ayuden a asimilar lo explicado y a resolver las dudas del alumnado. De igual manera las actividades y tareas que se envíen serán generales o personalizadas atendiendo los principios sobre diversidad.

\subsection{Actividades de ampliación}

Estas actividades de ampliación tienen por objetivo desarrollar y materializar la "competencia filosófica" [que aunque no se recoge explícitamente en la LOE (2006), ni tampoco aparece en el bachillerato, sí se puede extraer de los objetivos (2, 3 y 5; ver anexo (II)) que la enseñanza de la "Filosofía y ciudadanía" debe cumplir (RD 1467/2007)]. Entendemos que la argumentación, la fundamentación de opiniones y el análisis crítico del lenguaje pertenecen al dominio de la filosofía en general, y a la Lógica Informal en particular. Este apartado de actividades trata de promover la reflexión y el criticismo, aprender a argumentar, además de practicar el dialogo y el análisis de textos y mensajes.

\subsubsection{Disertación.}

La disertación es un escrito elaborado por el alumnado de forma individual y autónoma, es una actividad crítica, creativa, reflexiva y compleja; de hecho, el propósito de la disertación es promover esas capacidades. Con esta actividad el alumnado se familiarizará y se ejercitará en la argumentación. La disertación requiere de una comprensión del problema que se estudia, obliga al alumnado a realizar una labor investigadora y también, implica un posicionamiento que debe hacerse de manera autónoma y crítica. La temática empleada vendrá determinada por los temas que trataremos en el apartado de transversalidad.

\subsubsection{Webquests o Cazatesoros.}

Una manera de fomentar el uso de Internet consiste en proponer al alumnado, por ejemplo, un caza tesoros o Webquest que les ayude a dar respuesta a diversas cuestiones relativas a la unidad didáctica. Asimismo se puede ejercitar el alumnado en ejercicios de deducción natural. Estas actividades se realizarán en casa principalmente, pero si el centro dispusiera de ordenadores se pueden plantear actividades tanto en grupo como individualmente. Ver Anexo (IV).

\subsubsection{Lectura de textos, artículos, titulares, encuestas etc.}

Establecer un vínculo entre la esfera académica y la esfera social, política y económica es un dilema para la enseñanza de la filosofía. La dificultad no es tal, ya que existen multitud de medios donde se puede dar cuenta de discursos, mensajes, editoriales, encuestas etc. Por ello es necesario desarrollar actividades donde se exponga un tema; se presente mediante un visionado (si es un video); haya un turno de preguntas; 
aclaraciones; se planteen unas preguntas generales; para finalizar con una apuesta en común y un comenta rio. Ver Anexo (XI) para páginas y e-documentos relacionadas con la argumentación.

\section{TEMPORALIZACIÓN Y SESIONES.}

Esta Unidad Didáctica es la primera del currículo de filosofía ("Características generales del saber filosófico y de la argumentación válida" Ver anexo (I)) y se engloba en la parte de la argumentación valida; se trata de un tema introductorio y, por tanto, debe explicarse en el primer cuatrimestre. El tiempo estimado como óptimo para exponer este tema es el de 12 sesiones secuenciadas del modo siguiente:

-En la primera sesión plantearemos las actividades iniciales propuestas en el punto (1.1.); de este modo obtendremos la información sobre los conocimientos y preconcepciones del alumnado, al tiempo que nos hacemos una idea de su competencia lingüística, su nivel cognitivo y sus intereses. Esta sesión, es de suyo, pre-evaluativa. También, en esta sesión se explica en qué consistirá la unidad didáctica de lógica formal e informal, el propósito, la metodología, la evaluación y lo que se espera del alumnado.

-En la segunda sesión, se explicará la relación entre la lógica y el lenguaje. Asimismo, se diferenciará entre el lenguaje natural y lenguaje formal. Y también los usos del lenguaje: lenguaje objeto y metalenguaje. Como ejercicio para casa y después de haber explicado los diferentes tipos de ambigüedades que se pueden detectar en el lenguaje natural, se les pedirá que elaboren una lista de casos de malentendidos tomados del lenguaje natural en los que se de ambigüedad sintáctica, semántica y pragmática. Ver anexo (V).

-En la tercera sesión se abordará la Lógica Proposicional. Se explicará el significado de las proposiciones (se diferencia de otro tipos de enunciados como las exclamaciones, las interrogaciones, ordenes...) y las conectivas lógicas. Se planteará la simbolización de proposiciones. De ejercicio se propone que se distingan entre frases diferentes cuales cuentan como proposiciones y cuáles no. Que hagan traducciones al lenguaje natural de fórmulas atómicas y moleculares (las que tienen conectores). Y que identifiquen las fórmulas. En este estadio aparecen dificultades y es conveniente de dicar un tiempo de la sesión de clase a las correcciones. Ver anexo (VI).

-En la cuarta sesión se comenzará haciendo un repaso de la clase anterior, en especial, se incidirá en las conectivas lógicas pues una buena compresión de cómo se determina el valor de verdad de estos conectores as egura a su vez, un aprendizaje comprensivo de las tablas de verdad. Para ello, se representarán y construirán tablas de verdad, empleando diferentes conectores para su posterior evaluación de fórmulas e interpretación. Es necesario que el alumnado comprenda la función de las tablas de verdad para clasificar las formulas, y asimile los diferentes tipos de formulas que clasificamos mediante el método de las tablas. En la exposición se interactuará con el alumnado para hacer la construcción y la evaluación de las tablas de verdad conjuntamente. Es 
importante identificar el alumnado que pueda tener dificultades para dedicarles un refuerzo, una tutoría, etc. En ese estadio se pueden dar desfases dentro del alumnado y atender la diversidad de manera eficaz hará que la dinámica de clase vaya acompasada. Se pedirá que el alumnado haga un cuadro en el cuaderno de clase de las diferentes conectivas y sus valores de verdad; también, se enviará para casa ejercicios que en la siguiente sesión de aula se corregirán conjuntamente. Ver anexo (VII).

-En la quinta sesión se explicará la deducción natural y sus estrategias. Previamente dedicaremos la primera parte (15 minutos) para corregir los ejercicios enviados para evaluar y clasificar formulas mediante tablas de verdad. Esta parte es complicada para el alumnado y hay que proceder de manera segura. Partiendo de los conceptos previos adquiridos se expondrán argumentos y se analizará la relación de implicación. Se expondrán y explicaran las reglas de inferencia, para ello emplearemos esquemas de argumentos para mostrar lo que es el cálculo deductivo. Ta mbién, se mostra rá el cálculo directo y por reducción al absurdo. En este estadio y en función de las dotaciones que el centro disponga emplearemos la página Web de "Aprende Lógica" para ejercitarnos en cálculo natural. Esta página tiene sus virtudes, cuando hacemos mal los pasos (deducciones) nos avisan y nos corrige, además da lugar a que el alumnado haga tentativas (mediante prueba, error y acierto) y adquiera destreza en el cálculo: ( http://ntic.educacion.es/w3/eos/MaterialesEducativos/mem2003/logica/). Por otra parte, se pueden hacer evaluaciones y pruebas online (Surveymonkey y Weednode) en grupo si se dispone de ordenadores. Ver Anexos (IV; VII y X)

-En la sexta sesión se dedicará a la corrección de ejercicios, planteamiento de dudas y rondas de preguntas (y respuestas) para el alumnado con la intención de comprobar si se ha asimilado lo aprendido. Al final de la sesión se introducirá de una manera general en la lógica Informal y la argumentación para que se vayan haciendo una idea de lo que tendrán que estudiar. Es cierto que la Lógica Informal suscita mayor interés que la Lógica Proposicional. Posiblemente, la razón es que la argumentación tiene un componente dialéctico y pragmático que está en estrecha relación con las vivencias y los intereses de la gente, es decir, a todo el mundo le gusta convencer de manera razonada y también, saber identificar los errores argumentativos (falacias). En esta parte explicaremos como la metodología va a variar, puesto que incidiremos en la importancia del dialogo argumentativo (y argumentado), la composición de disertaciones, análisis y evaluación de discursos, editoriales y mensajes. El trabajo que se desarrolle en las siguientes sesiones tiene una aplicación eminentemente práctica, pues argumentar es un procedimiento, y como tal, se aprende ejercitando. Para ello se propondrán ejercicios en la construcción de argumentos como: el cajón del sastre (para elegir un tema), la disputación, el abogado del diablo (adopción de perspectivas diferentes), fundamentar una tesis, etc.

-En la sétima sesión trataremos de la lógica Informal y la Argumentación. Al principio -durante la exposición- la clase será del tipo enseñanza-aprendizaje para que el alumnado vaya familiarizándose y asimilando conceptos e ideas del 
dominio de la argumentación. A su vez incidiremos en la importancia de la argumentación en relación con el desarrollo de competencias básicas que se recogen en el RD 1631/2006 de 29 de diciembre, como son la competencia social y ciudadana, aprender a prender, la autonomía e iniciativa personal y la lingüística. ${ }^{11}$ En esta sesión se propondrá al alumnado un disertación entorno a los temas transversales que propongo (educación para la convivencia y la paz, una educación no sexista y una educación del consumidor), para ello el alumnado podrá emplear parte del material que está disponible en el Dropbox. ${ }^{12}$ No obstante, daré libertad de elección si el alumnado muestra inquietudes o si tiene otras fuentes de información como artículos, libros o películas para tratar el tema que propone. Ver Anexo (XI).

-En la octava sesión se explicitará de qué manera se ha de hacer una disertación. Daremos las pautas que se recogen en el apartado C) 4.1.2. (Transversalidad) para que se vea las partes que forman un texto argumentativo, las técnicas que se emplean, cómo se fundamenta y el posicionamiento del alumnado. Se propondrá tema a elegir, se dará la información, y se defenderá en clase -previa supervisión del profesor- para que sea debatida entre el alumnado. Teniendo en cuenta la limitación temporal, en la décima (la última media hora) y la onceava sesión (completa) se dedicará para este propósito. Una forma de paliar la falta de tiempo consistirá en cargar las disertaciones en el blog para que se puedan compartir las reflexiones y fundamentaciones del alumnado, y por supuesto, para que haya debate. A su vez, el empleo de las TICs nos servirá para reforzar la competencia digital en el alumnado.

-En la novena sesión trataremos sobre las falacias y los falsos argumentos. Será una clase del tipo enseñanza-aprendizaje pero participativa. La verdad es que el tema de las falacias despierta mucho interés y es relativamente sencillo ilustrar argumentaciones cotidianas donde se incurre en algún error argumentativo. Pero, no hay que olvidar que la perspectiva Taxonómica de las falacias emplean una determinada terminología que se debe memorizar, mediante nuestra práctica de enseñanza intentaremos que la memorización comprensiva se materialice. Por otra parte, mediante el dropbox daremos al alumnado un edocumento (Uso de razón) para que hagan una clasificación de casos de falacias que se engloben bajo un tipo de falacia, asimismo, pediremos que detecten e identifiquen casos de argumentaciones erróneas que puedan extraer de los medios de comunicación y discursos. Esta tarea se propondrá hacerla en grupos de cuatro o cinco personas. El trabajo que se entregará (via dropbox o en mano) se realizará a ordenador. Tendrá un titulo, aparecerán los alumnos que forman el grupo y se diferenciará la parte teórica (donde se recurre al e-documento para dar cuenta de diferentes falacias) y una parte práctica, donde se aplica los conocimientos a discursos y mensajes cotidianos. La extensión no será superior a los cuatro folios. La entrega del trabajo será antes de la última clase.

\footnotetext{
${ }^{11}$ URL $=\langle$ https://www.boe.es/aeboe/consultas/bases_datos/doc.php?id=BOE-A-2007-238>

${ }^{12}$ URL $=\langle$ https://www.dropbox.com/home/Photos/Sample\%20Album >
} 
-En la décima sesión se abordará el rol de a pregunta en el contexto argumentativo y el fenómeno de la presuposición. Esta parte es una innovación en contenido curricular. La función práctica que queremos destacar con esta sesión es advertir al alumnado sobre el uso de preguntas falaces, pues, tiene su aparición en consultas, encuestas, conversaciones y debates. Mostraremos unos casos reales y otros ejemplos clásicos para explicar de manera concisa cuál es la definición formal y la explicación funcional de cada tipo de pregunta. Como ejercicio, propondremos la lectura de un breve capítulo de Bordes Solanas y Damborenea entorno a las preguntas para dar cuenta de la confusión conceptual existente en torno a la terminología que se emplea. ${ }^{13}$ Ver anexo (IX).

-En la onceava sesión la dedicaremos a presentar las disertaciones. Con esta sesión pretendemos potenciar la competencia en argumentación. Por un lado, el alumnado tendrá que elaborar la presentación y explicarla brevemente al público. Por otro lado, habrá el turno del debate: se reconocerá el tema; se discutirá sobre los diferentes puntos de vista; se pedirá un posicionamiento; que se evalúen y se critiquen los planteamientos contrarios; que se justifique los propios planteamientos; que se adapten a la audiencia, que se contraargumente; que se negocie y sobre todo, que el debate sea una instancia real de lo que entendemos por una discusión critica y racional.

-En la última sesión haremos un examen donde se evaluarán los contenidos que se han impartido en clase, una parte versará sobre Lógica Proposicional y otra parte versará sobre lógica informal. Ver Anexo (X). ${ }^{14}$

\subsection{Recursos.}

Dos son los recursos didácticos que emplearemos: por un lado, están los recursos de carácter informático: libros, capítulos, e-documentos, páginas web, imágenes, artículos, películas, etc.; y por otra lado, están los recursos instrumentales como la disertación. En realidad, la disertación es el procedimiento por excelencia para adquirir la destreza en la competencia argumentativa, ya que, para iniciarse en la reflexión e investigación de los problemas es el procedimiento apropiado. Por ello, hay que valorarlo tanto en su utilidad práctica como en su dimensión teórica.

Por otra parte, no emplearemos libro de texto ya que disponemos de todos los materiales necesarios en soporte digital. Emplearemos el dropbox tanto para compartir la información como para recoger los trabajos, y aunque sea deseable que se haga mediante el dropbox no plantearemos problemas si el alumnado prefiere presentarlo a mano. Mediante el empleo de las TICs y con el dropbox (https://www.dropbox.com/home/Photos/Sample\%20Album) disponemos de edocumentos de lógica formal e informal, materiales para las disertaciones y también,

\footnotetext{
${ }^{13}$ URL=<https://www.dropbox.com/home/Photos/Sample\%20Al bum/Filosof\%C3\%ADa\%20L\%C3\%B3gica

${ }^{14}$ URL=<http://es.surveymonkey.com/MySurvey_EditorFull.aspx?s m=1w\%2b HhU8 AC\%2bpsS4vgs ILQYEIr KwrK3zuK\%2fxXLSL40QLw\%3d>
} 
para trabajar la transversalidad. También, disponemos de bibliografía en temática transversal sobre películas, videos del youtube, etc.

Tampoco se puede obviar que el empleo de recursos informáticos que se pueda realizar dentro del aula dependerá en gran medida de las dotaciones que disponga el centro. Una cosa es clara, estas dotaciones son inversiones costosas y no puede ser que por incompetencia docente no se usen. No solo es cuestión de desarrollar la competencia digital y el tratamiento de la información. Mediante las nuevas tecnologías podemos avanzar optimizando el tiempo, compartiendo información, colaborando en equipo sin tener que re unirse, reduciendo el consumo de papel... 
3. Texto elaborado de la Unidad Didáctica.

LÓGICA FORMAL E INFORMAL

0. Introducción

1. Lógica y Lenguaje.

1.1. Lenguaje natural y lenguaje formal.

1.2. Lenguaje objeto y metalenguaje: uso y mención.

2. Lógica proposicional.

2.1. El lenguaje de la Lógica proposicional

2.2. Proposiciones.

2.3. Conectivas lógicas.

2.4. Simbolización de proposiciones.

3. Funciones veritativas.

3.1. Tablas de verdad.

3.2. Evaluación de fórmulas mediante tablas de verdad.

3.3. Tautología, antilogía (o contradicción) y indeterminada (contingente).

4. Deducción natural.

4.1. Deducción directa e indirecta.

4.2. Esquemas de argumentos.

4.3. Reglas de inferencia.

5. Lógica Informal.

6. Falacias y falsos argumentos.

7. El rol de a pregunta en el contexto argumentativo.

7.1. El fenómeno de la presuposición.

7.2. Tipología de preguntas:

7.2.1. Pregunta compleja

7.2.2. Pregunta múltiple

7.2.3. Pregunta anfibólica. 


\section{Introducción}

El ser humano es un animal simbólico, ello quiere decir que el ser humano es capaz de comunicarse con sentido mediante signos que pertenecen a un determinado lenguaje. $Y$ mediante este mecanismo -el lenguaje- se pueden realizar diversas funciones, por ejemplo: referir (representativa), expresar (expresiva) y persuadir (apelativa). A grandes rasgos, se puede afirmar que cualquier lenguaje "natural" cumple -pero no agota- estas tres principales funciones: objetiva, subjetiva y retórica.

Asimismo, todo lenguaje tiene una triple dimensión: sintáctica, semántica y pragmática. La sintaxis estudia las relaciones entre los signos, el modo en que se forman conjuntos de signos con sentido; la semántica estudia la relación de los signos con lo que significan o designan, es decir con el mundo; y la pragmática estudia la relación de los signos con su uso y su contexto, es decir la actividad lingüística en su empleo por parte del hablante.

La relación entre lenguaje, conocimiento y argumentación es estrecha. EI lenguaje es condición indispensable para conocer, es más, sin este requisito es imposible para el ser humano adquirir conocimiento alguno, conservarlo y comunicarlo. El conocimiento entendido tanto como actividad y producto se realiza a partir del lenguaje. La argumentación es un razonamiento que se materializa en un argumento, y el argumento es un conjunto de enunciados donde unos cuentan como premisas y otro como conclusión. Por lo tanto, el conocimiento como el razonamien to son actividades lingüísticas; ello no quiere decir que toda actividad lingüística implique conocimiento o razona miento, pero sin lenguaje es imposible razonar o conocer.

\section{Lógica y lenguaje}

Etimológicamente, el término lógica viene de logos, que se traduce por palabra, verbo, discurso, lenguaje, conocimiento, ciencia. Y logos a su vez, viene de legein que significa decir, hablar, razonar, etc. Son por tanto, tres las significaciones que se pueden adscribir a la palabra logos: palabra, ciencia y razón. La conexión entre estos tres términos es estrecha, puesto que es el lenguaje el mecanismo necesario donde aparecen estos tres elementos.

Todo lenguaje es un código, es decir un sistema de signos que se ordena mediante unas reglas. De esta manera codificamos y descodificamos el sentido de los mensajes que emitimos o recibimos. La lógica también es un lenguaje, un lenguaje formal artificialmente creado para estudiar la validez y la corrección de los argumentos, esa es la razón de ser de la lógica.

\subsection{Lenguaje natural y lenguaje formal.}

La lógica como ciencia que estudia la validez y la corrección de los argumentos no está interesada en el lenguaje ordinario -el que usamos en el día a día para comunicarnos-, 
es un saber formal con pretensión universal que estudia los argumentos o razona mientos expresados lingüísticamente.

En cualquier caso, se ha de reconocer que el lenguaje natural para los objetivos de la lógica (es decir, para realizar operaciones, evaluaciones y cálculos de argumentos) es insuficiente porque carece de rigor y precisión. Los lenguajes naturales tienen unas características que no son igualables al lenguaje formal, aunque conceptualmente sean más ricos, tengan mayor capacidad expresiva y diferentes registros... La necesidad de construir un lenguaje formal responde a la necesidad de evitar ambigüedades, equivocidades, incoherencias, contradicciones y multiplicidad de interpretaciones.

Se puede objetar que no existe ningún lenguaje natural per se. Eso es cierto, ya que todo lenguaje sea natural o formal se ha construido convencionalmente, y por tanto, artificialmente (es un constructo). De todos modos, la distinción entre lenguaje natural y formal es bastante intuitiva. Por una parte, el lenguaje natural es aquel que adquirimos en nuestros contextos familiares y que está en relación a una comunidad cultural concreta; es el que heredamos desde que nacemos y empleamos en el día a día, el francés, inglés, euskera o castellano son ejemplos de lenguajes naturales. Por otra parte, a diferencia de los lenguajes antes mencionados (francés, inglés...) la matemática sería un ejemplo de lenguaje formal. Dos son las características principales de un lenguaje formal: por un lado, está compuesto mediante símbolos abstractos (léxico); y por otro lado, tiene una serie de reglas para el uso de símbolos y para la formación y trasformación de expresiones, formulas y operaciones.

Los lenguajes formales están diseñados para responder a los requisitos de exactitud, precisión y correctud que se necesita en las ciencias.

\subsection{Lenguaje objeto y metalenguaje: uso y mención.}

La distinción entre lenguaje objeto y metalenguaje responde principalmente a la necesidad de jerarquizar los diferentes niveles del lenguaje. Pongamos unos casos para ejemplificar:

a) La Al hambra está en Granada.

b) "Al hambra" es un término compuesto de 8 letras.

En el primer caso (a) empleamos el lenguaje para hacer referencia a un estado de cosas, nos referimos a una realidad extralingüística. Este empleo del lenguaje lo denominaremos lenguaje-objeto y tiene por función hablar acerca del estado de cosas (sobre la realidad). En el segundo caso (b) el empleo del lenguaje responde a una finalidad diferente, no se trata de dar cuenta de un estado de cosas, sino más bien, hablar sobre el mismo lenguaje que se está usando. Es un uso recursivo del lenguaje que está por encima del lenguaje-objeto, en este caso lo denominaremos como metalenguaje. Con el empleo del meta-lenguaje no usamos propiamente el lenguaje, sino que lo menciona mos. Para resumirlo, una cosa es el lenguaje en el que se habla, y otra 
muy diferente, el lenguaje del que se habla. La distinción entre "uso" y "mención" responde a esos dos empleos del lenguaje.

Por norma general, el empleo del lenguaje responde al lenguaje-objeto, y es raro emplearlo en el nivel meta-lingüístico. Frecuentemente, los jóvenes suelen hacer juegos de estos dos niveles del lenguaje.

c) 1- ¡Di algo por favor!

2- Algo

En este escueto dialogo se puede comprobar los diferentes empleos del lenguaje. En el caso (c.1) el uso de las palabras está en plano del lenguaje-objeto. En el caso (c.2) la mención que se hace de la palabra "Algo" esta en el nivel metalingüístico.

Para finalizar, también existe el caso en el que las palabras pueden ser usadas y menciona das de manera simultánea:

d) Decir que "la nieve es blanca" es de Perogrullo.

Cuando decimos (proferimos) la frase (d) y en concreto, la frase de "La nieve es blanca", no solo estamos usando las palabras también, las estamos mencionando. El uso de comillas es de utilidad para poder detectar cuando el empleo de la palabra responde al nivel metalingüístico.

\section{Lógica proposicional.}

Como hemos dicho anteriormente la lógica es la ciencia que estudia la validez o correctud de los argumentos ateniéndose a su forma. La lógica proposicional trata con proposiciones, estas son las unidades mínimas para formar los argumentos. Y los argumentos son conjuntos de proposiciones que constan de dos partes: por un lado, hay una proposición que cuenta como conclusión; y por otro lado, hay una serie de proposiciones que cuentan como premisas.

e)

-premisa 1. Si es una ballena, entonces es un mamífero.

-premisa 2. Si es un mamífero, entonces es un vertebrado.

-conclusión. Si es una ballena, entonces es un vertebrado.

El paso de las premisas a la conclusión es lo que estudia la lógica. En este caso (e) la conclusión se sigue de las premisas, y por ello, tenemos un argumento que es formalmente válido. Es la relación entre premisas y conclusión lo que hace que un argumento sea valido (o correcto) o no. El contenido empírico de las proposiciones poco importa a la lógica.

-premisa 1. Los elefantes son mosquitos 
-premisa 2. Los mosquitos son verdes

-conclusión. Los elefantes son verdes

El argumento (f) es un ejemplo de argumento formalmente valido. $Y$ aunque el contenido empírico de las proposiciones que forman el argumento sea falso, la estructura del argumento es válida porque la conclusión se sigue necesariamente de las premisas. Este ejemplo ilustra como la validez de un argumento no radica en el contenido material de las proposiciones, ni tampoco en la verdad de las proposiciones, sino que es una cuestión de forma. Por eso, un argumento no es verdadero o falso, será formalmente válido o no. La verdad es una propiedad de las proposiciones, la validez formal, por el contrario, es una propiedad de los argumentos.

En la primera parte de esta unidad se estudia solamente la lógica proposicional que es la más básica. Pero hay diferentes tipos de lógicas: de predicados, modal, deóntica, epistémica, difusa, erotética...

\subsection{El lenguaje de la lógica proposicional}

Ya hemos indicado varias veces que la lógica es un lenguaje formal artificialmente creado para estudiar la validez de los argumentos y que estos, se forman a partir de proposiciones.

Todo lenguaje natural y un lenguaje formal está formado a partir de tres elementos: un vocabulario, unas reglas de formación y unas reglas de transformación. En adelante explicaremos cada elemento.

a). Vocabulario: son los signos que empleamos, a diferencia del vocabulario del lenguaje natural este carece de significado. Dos tipos de signos emplearemos en lógica, que los diferenciamos entre signos lógicos y no lógicos:

Signos no lógicos:

-Términos proposicionales $(p, q, r .$.$) , representan proposiciones.$ -Paréntesis y corchetes ((), []), son muy útiles para desambiguar y precisar el significado de las formulas. En el lenguaje natural empleamos los signos de puntuación con el mismo propósito. Se llaman también, signos auxiliares.

Signos lógicos:

-Son las conectivas lógicas, su función es enlazar diferentes proposiciones para construir formulas.

-Negación $(\neg)$

-Conjunción $(\wedge)$

-Disyunción $(\vee)$

-Condicional $(\rightarrow)$

-Bicondicional. $(\leftrightarrow)$ 
b). Reglas de formación.

Establecen qué tipo de combinaciones son correctas para la construcción de formulas. Su función es la misma que las reglas gramaticales de un lenguaje natural. Por ejemplo, "Hoy he ido a la escuela" sería una frase bien formada, no así, "escuela ido a hoy he la". Una formula es una expresión bien formada que se atiene a las reglas de formación.

c). Reglas de transformación

En tanto y cuanto la lógica es la ciencia que estudia la validez de los esquemas de argumentos, es preciso tener unas reglas que establezcan que pasos son legítimos cuando se llega a la conclusión a partir de las premisas. Son estas reglas las que nos permiten hacer de ducciones y que estas deducciones sean consecuencias lógicas de las formulas que cuentan como premisas (en adelante explicitaremos tales reglas).

Con estos tres elementos (vocabulario, reglas de formación y reglas de transformación) ya tenemos un lenguaje formal listo para el análisis y la deducción de argumentos.

\subsection{Proposiciones.}

La lógica proposicional trata con proposiciones, que son las unidades mínimas para construir argumentos. A su vez, la proposición es un enunciado que tiene valor de verdad y este puede ser verdadero o falso. De ahí se sigue que otros tipos de enunciados no cuenten para la lógica como puede ser el caso de las exclamaciones, interrogaciones, promesas o mandatos.

Dos son las características principales de la lógica proposicional: por un lado, esta ciencia se centra única y exclusivamente en enunciados apofánticos (enunciados que tienen valor de verdad, a saber, verdadero o falso); y por otro lado, está lógica no contempla más que dos valores de verdad (verdadero y falso), es una lógica que se limita al principio de bivalencia (que indica que solo hay dos valores de verdad en una proposición, y estos valores no pueden darse a la vez).

Por norma general, enunciado y proposición se usa indistintamente, pero en filosofía del lenguaje se diferencia entre oraciones, enunciados y proposiciones. Las oraciones se distinguen entre declarativas (el tipo de discurso que sirve para realizar aserciones, declaraciones...) y no declarativas (el tipo de discurso que permite real izar ruegos, mandatos, interrogaciones...). Asimismo, oraciones diferentes pueden expresar un mismo enunciado:

g)

1- Está nevando.

2- It is snowing.

O 
h)

1- José es soltero

2- José no está casado.

$Y$ un mismo enunciado puede tener significado diferente, por ejemplo, si " $x$ " e " $y$ " dicen "Me voy al monte" sus enunciados serán diferentes porque los hablantes son distintos, aunque puedan estar refiriéndose al mismo monte.

Por último, merece destacar que la proposición tiene diferentes sentidos: por un lado, una proposición determina el significado convencional de la oración; por otro lado, las proposiciones son enunciados que tienen valor de verdad. En cualquier caso, se acepta que las proposiciones son entidades abstractas que denotan valores de verdad.

\subsection{Tipo de proposiciones}

Distinguiremos entre dos tipos de proposiciones: proposiciones atómicas y proposiciones moleculares. Por un lado, las proposiciones atómicas son aquellas que se pueden representar mediante un término proposicional, esto indica que la proposición atómica no puede descomponerse en otros enunciados:

i) 1- Hoy ha salido el sol.

2- El Everest está en el Himalaya.

Por otro lado, están las proposiciones moleculares, este tipo de proposiciones están formadas a partir de proposiciones atómicas, que a su vez, están relacionadas mediante conectores lógicos. Las proposiciones moleculares se pueden descomponer en proposiciones atómicas:

j) 1- Juan estudia filosofía y vive en Barcelona.

2- Si no tienes nada que hacer, entonces puedes recoger el cuarto.

En estos casos (j.1 y j.2) las proposiciones moleculares están compuestas por diferentes conectores: una conjunción (j.1) y un condicional (j.2). La conjunción (el conector " $y$ ") pone en relación estas dos proposiciones: "Juan estudia filosofía" y "Juan vive en Barcelona". De la misma manera, el condicional (el conector que tiene esta forma: Si..., entonces...) pone en relación dos proposiciones: "No tienes nada que hacer" y "Puedes recoger el cuarto". En lógica proposicional simbolizamos estas proposiciones mediante un término proposicional (si es una proposición atómica), o mediante términos proposicionales, conectivas y paréntesis (si es una proposición molecular).

\subsection{Conectivas lógicas y tablas de verdad.}

Emplearemos el término de conectiva lógica, aunque también se nombra de maneras diferentes: constante, operador, nexo, conector, juntor, partícula. Las conectivas 
lógicas permiten construir formulas o proposiciones moleculares a partir de términos proposicionales.

Como ya hemos dicho, las proposiciones tienen valores de verdad (nos abstraemos del contenido empírico), ya que la lógica proposicional se atiene al principio de bivalencia, a saber, que toda proposición es o verdadera o falsa (empleamos estos símbolos $\mathrm{F}$ y $\mathrm{V}$, o también 1 y 0 ). $\mathrm{Y}$ lo representamos con esta tabla de verdad:

k)

\begin{tabular}{|l|l|}
\hline $\mathrm{P}$ & \\
\hline $\mathrm{V}$ & 1 \\
\hline $\mathrm{F}$ & 0 \\
\hline
\end{tabular}

En función de los valores de verdad de las proposiciones podemos determinar el valor de verdad de las fórmulas. En adelante examinaremos cada una de las cinco conectivas y las representaremos gráficamente mediante tablas de verdad. Como veremos los conectores transforman el valor de verdad de la fórmula.

\subsubsection{Negación $(\neg)$}

El símbolo " $\neg$ " en el lenguaje natural lo conocemos por "no". Es la negación, y cambia el valor de verdad del término proposicional por su contrario. Si el término proposicional es verdadero, entonces la negación lo hace falso -y viceversa-. La negación, a diferencia de los demás conectores, es el único conector que se aplica a una sola proposición; aún y todo, el resultado es una proposición molecular. Estas son las condiciones de verdad:

I)

\begin{tabular}{|l|l|}
\hline $\mathrm{P}$ & $\neg \mathrm{p}$ \\
\hline $\mathrm{V}$ & $\mathrm{F}$ \\
\hline $\mathrm{F}$ & $\mathrm{V}$ \\
\hline
\end{tabular}

\subsubsection{Conjunción $(\wedge)$}

El símbolo " $\wedge$ " en el lenguaje natural se traduce por la partícula "y". Para que la fórmula sea verdadera requiere que los dos términos proposicionales que relaciona también sean verdaderos, delo contrario, la formula es falsa.

m)

\begin{tabular}{|l|l|l|}
\hline $\mathrm{p}$ & $\wedge$ & $\mathrm{q}$ \\
\hline $\mathrm{V}$ & $\mathrm{V}$ & $\mathrm{V}$ \\
\hline $\mathrm{V}$ & $\mathrm{F}$ & $\mathrm{F}$ \\
\hline $\mathrm{F}$ & $\mathrm{F}$ & $\mathrm{V}$ \\
\hline $\mathrm{F}$ & $\mathrm{F}$ & $\mathrm{F}$ \\
\hline
\end{tabular}




\subsubsection{Disyunción $(\vee)$}

El símbolo " $\vee$ " en el lenguaje natural se traduce por la partícula "o". Una formula donde el conector principal es una disyunción solo será falsa en el caso en que los términos proposicionales tengan valor de verdad falso, en las restantes combinaciones la disyunción será verdadera.

n)

\begin{tabular}{|l|l|l|}
\hline$P$ & $V$ & $q$ \\
\hline$V$ & $V$ & $V$ \\
\hline$V$ & $V$ & $F$ \\
\hline$F$ & $V$ & $V$ \\
\hline$F$ & $F$ & $F$ \\
\hline
\end{tabular}

\subsubsection{Condicional $(\rightarrow)$}

El símbolo " $\rightarrow$ " en el lenguaje natural se conoce por "Si..., entonces...". El condicional pone en relación dos términos proposicionales, al primero (p) le llamamos antecedente, y al segundo (q) le llamamos consecuente. Para que el condicional sea falso es preciso que el antecedente tenga el valor de verdad verdadero y el consecuente falso, en los demás casos el condicional será verdadero.

о)

\begin{tabular}{|l|l|l|}
\hline $\mathrm{P}$ & $\rightarrow$ & $\mathrm{Q}$ \\
\hline $\mathrm{V}$ & $\mathrm{V}$ & $\mathrm{V}$ \\
\hline $\mathrm{V}$ & $\mathrm{F}$ & $\mathrm{F}$ \\
\hline $\mathrm{F}$ & $\mathrm{V}$ & $\mathrm{V}$ \\
\hline $\mathrm{F}$ & $\mathrm{V}$ & $\mathrm{F}$ \\
\hline
\end{tabular}

\subsubsection{Bicondicional $(\leftrightarrow)$}

También llamado coimplicador. El símbolo " $\leftrightarrow$ " en el lenguaje natural lo traducimos por "Si y solo si". El bicondicional refleja una doble implicación. Para que un bicondicional sea verdadero es necesario que los dos términos proposicionales que une tengan el mismo valor de verdad, sino es falso.

p)

\begin{tabular}{|l|l|l|}
\hline$p$ & $\leftrightarrow$ & $q$ \\
\hline$V$ & $V$ & $V$ \\
\hline$V$ & $F$ & $F$ \\
\hline$F$ & $F$ & $V$ \\
\hline$F$ & $V$ & $F$ \\
\hline
\end{tabular}




\subsection{Simbolización de proposiciones.}

A la lógica no le interesa el lenguaje natural, pero trabaja con proposiciones y argumentos que están expresados lingüísticamente. Para ello es necesario toma r esas expresiones y traducirlas empleando el lenguaje del simbolismo lógico. A esa tarea la llamamos formalización.

q) 1- Me gusta ir al monte y disfrutar de la naturaleza.

2- Si ves una película de terror, tendrás pesadillas.

¿Cómo formalizamos estas expresiones complejas? Primero, tenemos que identificar las proposiciones; y segundo, tenemos que identificar el conector lógico que pone en relación ambas proposiciones. En el primer caso (q.1), tenemos dos proposiciones: "me gusta ir al monte" y "me gusta disfrutar de la naturaleza"; estas las formalizaremos mediante dos términos proposicionales: $p$ y $q$; a su vez, formalizaremos la conjunción mediante el conector lógico " $\wedge$ ". De acuerdo al lenguaje formal la formula será la siguiente:

\section{q) $1.1-p \wedge q$}

Para el siguiente caso procederemos de igual manera. Por un lado, tenemos dos proposiciones: "ves una película de terror" y "tendrás pesadillas", empleamos los términos proposicionales $r$ y s para formalizarlas. Por otro lado, está el conector lógico $" \rightarrow$ ", que se interpreta por "Si..., (entonces)...". La forma lógica será la siguiente:

q) $2.1-\mathrm{s} \rightarrow \mathrm{r}$

Una vez que obtenemos las formulas lógicas de estas expresiones podemos emplear la tabla de verdad para evaluar las formulas. En el primer caso (q-1.1), la tabla de verdad nos indicará que la formula es verdadera solo cuando ambos términos proposicionales ( $p$ y q) tienen valor de verdad verdadero. En el segundo caso (q-2.1.), la tabla de verdad nos indicará que la formula es verdadera excepto cuando el antecedente (s) es verdadero y el consecuente $(r)$ es falso.

\section{Funciones veritativas.}

Tanto en lógica como en matemática una función (F) establece una relación de correspondencia entre dos conjuntos: el argumento $(x)$ y los valores $(y)$.

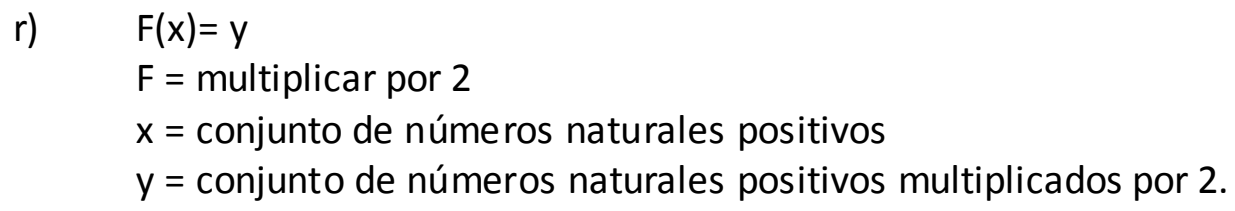

En lógica, podemos determinar el valor de verdad de una fórmula molecular porque las conectivas lógicas operan como funciones. Las conectivas lógicas son funciones 
veritativas y determinan los valores de verdad de una formula en función de los valores de verdad de sus componentes.

\subsection{Tablas de verdad.}

A las formulas atómicas asignamos valores de verdad ( $V$ y F). Para las formulas moleculares empleamos la tabla de verdad, que es una gráfica donde se especifica el valor de verdad. Estos gráficos son muy útiles porque es un procedimiento que nos sirve para evaluar las formulas. Mediante las tablas de verdad podemos averiguar qué razonamientos son válidos y cuáles no, además, podemos clasificarlos como tautológicos, contingentes y contradictorios. Todo ello, se determina en función del resultado que se obtenga con la formula seleccionada.

La construcción de una tabla de verdad es un procedimiento mecánico que requiere hacerse paso a paso. Primero, se determinan el número de términos proposicionales, que a su vez, nos indican el número de combinaciones (la regla es esta: $2^{\text {n; }}$ donde "n" es el número de términos proposicionales). Segundo, asignamos los valores de verdad a los términos proposicionales en función de las combinaciones posibles. También se ha de distinguir las diferentes subfórmulas (si las hubiera) del argumento o formula que se quiera estudiar.

\subsection{Evaluación de fórmulas mediante tablas de verdad.}

La tabla de verdad es un proce dimiento -entre otros- para el estudio y la evaluación de fórmulas y argumentos. Una vez obtenido los resultados tras haber operado con los valores de verdad y el conector lógico, se ha de interpretar el resultado final que aparece en la columna. Es entonces cuando podemos decidir qué tipo de fórmula es, a saber, si se trata de una fórmula tautológica, contingente o contra dictoria.

\subsection{Tautología, antilogía (o contradicción) y indeterminada (contingente).}

Cuando observamos el resultado que se representa en la columna final podemos, en primer lugar, decidir si la fórmula (o argumento) es válida o no; y en segundo lugar, podemos clasificar qué tipo de fórmula es. Son tres las opciones: tautología, contingencia o contradicción.

Si el resultado de la columna final está completado en su totalidad por el signo $V$, es una tautología; la fórmula es siempre verdadera. Si la columna está completada por el signo $F$, es una contradicción; y la fórmula siempre será falsa independientemente de la combinación de los valores de verdad. Por último, si encontramos en la columna final los dos tipos de signos ( $F$ y $V)$, entonces es una contingencia; y la fórmula será verdadera o falsa en función de la combinación de los valores de verdad. 


\section{Deducción natural.}

En una argumentación se establece una relación entre las premisas y la conclusión, de esta manera se pretende probar que la conclusión se sigue de las premisas. Cuando la argumentación o el razonamiento es correcto, decimos que el argumento es válido porque la conclusión se deduce necesariamente de las premisas. Si empleamos símbolos lógicos, podemos formalizar un argumento de la siguiente manera. Si p y q implica lógicamente $r$, la formula sería la siguiente: $p, q \quad F$; donde " $F$ " simboliza la relación de implicación.

En este apartado vamos a presentar las reglas de inferencia básicas para hacer cálculos deductivos. Por el momento, solo hemos hecho un trabajo de simbolización lógica para construir el lenguaje formal, y también, hemos aprendido a evaluar las fórmulas empleando tablas de verdad. Pero ahora, vamos a desarrollar el procedimiento demostrativo natural de la lógica, que consiste en probar la conclusión del argumento partiendo de sus premisas y empleando las reglas de inferencia.

\subsection{Reglas de inferencia.}

Las operaciones deductivas se realizan gracias al empleo de reglas, a las que llamamos reglas de inferencia. Estas reglas pertenecen al tercer elemento que requería cualquier lenguaje formal, a saber, las reglas de transformación. Las reglas de inferencia más importantes las hemos recogido en el cuadrado siguiente. A su vez, existen reglas básicas (1-10) y reglas derivadas (11-14). Las primeras son las más elementales y las segundas, son derivadas de las primeras.

Como ya hemos dicho, estas reglas nos permiten hacer inferencias. Mediante la barra horizontal "__ simbolizamos la relación de deducibilidad, es decir, el paso que nos permite pasar de unas proposiciones (o fórmulas) a otra proposición. La fórmula que se obtiene siempre aparece debajo de la barra. Veamos ahora las principales reglas de inferencia. Emplearemos las letras mayúsculas $X$ y $Y$ que simbolizan cualquier fórmula (están por cualquier fórmula). 


\begin{tabular}{|c|c|c|c|c|}
\hline & Regla (Nombre) & Abr. & \multicolumn{2}{|l|}{ Esquema } \\
\hline \multirow[t]{2}{*}{1} & \multirow[t]{2}{*}{ Doble negación } & \multirow[t]{2}{*}{ D.N. } & $\neg \neg \mathbf{X X}$ & $x$ \\
\hline & & & $x$ & $\neg \neg \mathbf{X X}$ \\
\hline \multirow[t]{2}{*}{2} & \multirow{2}{*}{$\begin{array}{l}\text { Introducción de la } \\
\text { disyunción }\end{array}$} & \multirow[t]{2}{*}{ I.D. } & $\bar{x}$ & $\mathrm{Y}$ \\
\hline & & & $\overline{X \vee Y}$ & $Y \vee X$ \\
\hline \multirow[t]{2}{*}{3} & \multirow[t]{2}{*}{$\begin{array}{l}\text { Eliminación de la } \\
\text { disyunción }\end{array}$} & \multirow[t]{2}{*}{ E.D. } & $\begin{array}{l}X \vee Y \\
\neg X \\
\end{array}$ & $\begin{array}{l}\mathrm{Y} \vee \mathrm{X} \\
\neg \mathrm{Y} \\
\end{array}$ \\
\hline & & & $\bar{Y}$ & $\bar{x}$ \\
\hline \multirow[t]{2}{*}{4} & \multirow[t]{2}{*}{$\begin{array}{l}\text { Introducción de la } \\
\text { conjunción }\end{array}$} & \multirow[t]{2}{*}{ I.C. } & $\begin{array}{l}X \\
Y\end{array}$ & $\begin{array}{l}Y \\
X\end{array}$ \\
\hline & & & $X \wedge Y$ & $\overline{Y \wedge X}$ \\
\hline \multirow[t]{2}{*}{5} & \multirow{2}{*}{$\begin{array}{l}\text { Eliminación de la } \\
\text { conjunción }\end{array}$} & \multirow[t]{2}{*}{ E.C. } & $X \wedge Y$ & $Y \wedge X$ \\
\hline & & & $\mathrm{X}$ & $\begin{array}{ll}Y \\
\end{array}$ \\
\hline \multirow[t]{2}{*}{6} & \multirow[t]{2}{*}{ Modus pones } & \multirow[t]{2}{*}{ M.P. } & \multicolumn{2}{|l|}{$\begin{array}{l}X \rightarrow Y \\
X\end{array}$} \\
\hline & & & \\
\hline \multirow[t]{2}{*}{7} & \multirow[t]{2}{*}{ Modus tollens } & \multirow[t]{2}{*}{ M.T. } & \multicolumn{2}{|l|}{$\begin{array}{l}\mathrm{X} \rightarrow \mathrm{Y} \\
\neg \mathrm{Y}\end{array}$} \\
\hline & & & $\neg \mathrm{X}$ & \\
\hline \multirow[t]{2}{*}{8} & \multirow[t]{2}{*}{$\begin{array}{l}\text { Introducción del } \\
\text { bicondicional }\end{array}$} & \multirow[t]{2}{*}{ I.B } & \multicolumn{2}{|l|}{$\begin{array}{l}X \rightarrow Y \\
Y \rightarrow X\end{array}$} \\
\hline & & & $\overline{X \leftrightarrow Y}$ & \\
\hline \multirow[t]{2}{*}{9} & \multirow{2}{*}{$\begin{array}{l}\text { Eliminación del } \\
\text { bicondicional }\end{array}$} & \multirow[t]{2}{*}{ E.B. } & $X \leftrightarrow Y$ & $Y \leftrightarrow X$ \\
\hline & & & $\overline{X \rightarrow Y}$ & $\mathrm{Y} \rightarrow \mathrm{X}$ \\
\hline 10 & Tertium non da tur & T.N.D. & $X \vee \neg>$ & \\
\hline 11 & $\begin{array}{l}\text { Negación de la } \\
\text { conjunción }\end{array}$ & N.C. & $\begin{array}{l}\neg(\mathrm{X} \wedge \\
\neg \mathrm{X} \vee\end{array}$ & \\
\hline 12 & Negación de la & N.D. & $\neg(X \vee Y$ & \\
\hline & disyunción & & $\neg \mathrm{X} \wedge-$ & \\
\hline 13 & Definición del & D.C.1. & $X \rightarrow Y$ & \\
\hline & condicional 1 & & $\neg X \vee Y$ & \\
\hline 14 & Definición del & D.C.2. & $X \rightarrow Y$ & \\
\hline & condicional 2 & & $\neg(X \wedge$ & \\
\hline
\end{tabular}




\subsection{Metodología para el cálculo deductivo.}

Con estas reglas ya tenemos un sistema lógico para hacer cálculo deductivo. Deducir (inferir) no es otra cosa que extraer una fórmula a partir de otra mediante la aplicación de reglas. Y por norma general, en el cálculo deductivo el propósito suele ser obtener una conclusión a partir de una serie de premisas. Si fuera el caso, diremos que la conclusión que se obtiene es lógicamente válida, y simbolizaremos la conclusión con el símbolo de implicación lógica ( $\mid$ ).

Conviene recordar que el cálculo deductivo es estratégico y metódico. A saber, hay que tener claro hacia donde se quiere ir y también, hay que ir deduciendo paso a paso. Antes de empezar, explicaremos qué son las líneas de derivación, hay tres tipos:

1) Línea interrogada: la que está precedida por un interrogante, significa que la formula hay que probarla o deducirla.

2) Línea utilizable: la formula que aparece sola o precedida por un interrogante, significa que se puede utilizar para deducir otras fórmulas.

3) Línea marcada: La formulas precedidas por una o más líneas.

La estrategia que se emplea en la deducción tiene gran importancia, puesto que es la que asegura una correcta deducción. Para ello, hay que fijarse bien en la conclusión e identificar su conector principal, en función de ese conector se empleara una u otra estrategia para derivar la conclusión. Eso sí, al menos, siempre y cuando se decida deducir la conclusión de forma directa.

\subsection{Deducción directa e indirecta.}

Por deducción directa entendemos el cálculo lógico desarrollado a partir de la línea interrogada empleando el conjunto de premisas y las reglas de inferencia para llegar a la conclusión (que es la línea interrogada). Como hemos advertido las estrategias deductivas varían en función del conector principal de la línea interrogada. Pues, la estrategia deductiva no es la misma si el conector principal es una conjunción, disyunción, condicional o bicondicional. A grandes rasgos, la deducción directa es la estrategia que nos lleva de forma directa a la conclusión a partir de las premisas.

Veamos un ejemplo de deducción directa:

Demostraremos el siguiente argumento.

$$
\begin{aligned}
& \text { s) } \mathrm{q} \rightarrow \mathrm{p}, \mathrm{s} \vee \mathrm{r}, \mathrm{r} \rightarrow \neg \mathrm{p}, \neg \mathrm{s} \vdash \neg \mathrm{q} \\
& \text { 1. } q \rightarrow p \\
& \text { 2. } s \vee r \\
& \text { 3. } r \rightarrow \neg p \\
& \text { 4. } \neg \mathrm{s} \\
& \text { 5. } r \quad \text { E.D. 2-4 } \\
& \text { 6. } \neg \mathrm{p} \quad \text { M.P. 3-5 } \\
& \text { 7. } \neg \mathrm{q} \text { M.T. 1-6 }
\end{aligned}
$$


Cuando la deducción es indirecta, la estrategia deductiva que se desarrolla es por el método del absurdo (reductio ad absurdum). La idea de este método es la siguiente: suponiendo la falsedad de la conclusión se llega a contradicción para luego, afirmar la conclusión. Si se demuestra que la negación de la conclusión que queremos probar nos conduce a una contradicción, podremos concluir que el argumento es lógicamente válido. Pues, de manera indirecta hemos concluido que lo contrario (la negación de la conclusión) es imposible de demostrar.

Veamos un ejemplo de reductio ad absurdum:

Demostraremos el siguiente argumento.

$$
\begin{array}{ll}
\text { t) } \mathrm{q} \rightarrow(\mathrm{p} \vee \mathrm{s}), \neg \mathrm{s}, \mathrm{p} \rightarrow(\mathrm{t} \vee \mathrm{r}), \neg(\mathrm{t} \vee \mathrm{r}) \vdash \neg \mathrm{q} \\
\text { 1. } \mathrm{q} \rightarrow(\mathrm{p} \vee \mathrm{s}) & \\
\text { 2. } \neg \mathrm{s} & \\
\text { 3. } \mathrm{p} \rightarrow(\mathrm{t} \vee \mathrm{r}) & \\
\text { 4. } \neg(\mathrm{t} \vee \mathrm{r}) & \\
\text { 5. } \neg \mathrm{q} & \\
\text { 6. } \dot{\mathrm{q}} \mathrm{q} & \\
\text { 7. } \neg(\neg \mathrm{q}) & \text { Supuesto } \\
\text { 8. } \mathrm{q} & \text { D.N. 7 } \\
\text { 9. } \mathrm{p} \vee \mathrm{s} & \text { M.P. 1,8 } \\
\text { 10. } \mathrm{p} & \text { E.D. 9,2 } \\
\text { 11. }(\mathrm{t} \vee \mathrm{r}) & \text { M.P. 3,10 } \\
\text { 12. } \neg(\mathrm{t} \vee \mathrm{r}) & \text { R. 4 } \\
\text { 13. } \neg[\neg(\neg \mathrm{q})] & \text { Negación del supuesto línea 7 } \\
\text { 14. } \neg \mathrm{q} & \text { D.N. 13 }
\end{array}
$$

\section{Lógica Informal}

Como hemos podido comprobar a lo largo de la primera parte, la Lógica Proposicional formaliza enunciados y argumentos para así, poder evaluarlos en función de la forma lógica. Pero la información lingüística (es decir, el contenido semántico) expresado por los enunciados y los argumentos no le interesa. La lógica Proposicional asigna a los enunciados (proposiciones) valores de verdad y los argumentos se evalúan por su validez formal; sin necesidad de dar cuenta del contenido semántico.

En el siglo XX se da un estallido de estudios en el campo de la lógica, uno de ellos es la Lógica Informal. Sobre la década de los 60 muchos estudiantes de lógica disconformes con la guerra de Vietnam exigían que sus estudios tuvieran un vínculo social y político en relación a cuestiones de interés general (política, ecologismo, pacifismo, derechos...). La Lógica informal es la rama de la lógica y la argumentación que tiene por objeto el estudio de los discursos y argumentos que se realizan en el día a día. Es decir, hace de la lógica una herramienta teórica con utilidad práctica. 
La aplicación material de la lógica informal está proyectada a la actividad pública, es ahí donde los discursos pueden ser evaluados por sus virtudes y sus defectos, teniendo en cuenta más elementos (orador, audiencia, finalidad...) que el propio argumento que se estudia. En realidad, la lógica informal es una crítica a la lógica formal como ciencia deductiva. En primer lugar, hemos comprobado que los argumentos con premisas o conclusión falsa podían ser formalmente válidos (se daba validez lógica). En segundo lugar, esta disciplina no es capaz de estudiar los argumentos ordinarios que se realizan en los debates políticos, en los medios de comunicación o en las campañas publicitarias etc. Además, la Lógica Proposicional no tiene en cuenta factores tan importantes como el contexto en que se dan esos argumentos, el modo en que se presentan o las intenciones de los interlocutores.

Principalmente, dos son los campos de interés de la lógica informal. Por una parte, trata de desarrollar un teoría de la argumentación, es decir, intenta establecer las bases de lo que se entiende por una buena argumentación; el "cómo" se debe argumentar para convencer a la audiencia al que se emite el mensaje. Por otra parte, trata de dar cuenta de argumentos que se consideran incorrectos, a saber, los argumentos que clasificamos como Falacias. Sin duda, este es el campo más fecundo para la lógica informal.

El estudio de las falacias tanto por su interés teórico así como por su utilidad práctica es algo que merece ser destacado; no debería de ser una actividad académica que se desarrolle exclusivamente dentro del aula. Su aplicabilidad se debe enfocar tanto a contextos escolares como a extraescolares, puesto que nos capacita de recursos críticos en nuestra vida de alumna/os y de ciudadana/os. ¿Por qué ponemos en valor el estudio de las falacias?

1-Por que el dialogo libre de errores argumentativos nos conduce a la resolución de conflictos de manera racional sin necesidad de recurrir a la fuerza. Es decir, la fuerza de la razón es más poderosa que la razón de la fuerza (aprender a dialogar).

2-Por que en muchas discusiones nos enfrentamos con gente que tienen habilidades retóricas para usar fraudulenta mente las palabras y las razones, y nos encontramos sin recursos teóricos para poder refutarles de manera adecuada y razonada (aprender a criticar).

3-Por que usualmente damos por bueno argumentos que no lo son; tener ciertos conocimientos teóricos es un buen comienzo para poder desarrollar un pensamiento crítico y consecuente con uno mismo (aprender a pensar).

\section{Falacias y falsos argumentos.}

La definición tradicional de falacia (siguiendo a Aristóteles) presenta la falacia como argumento que parece válido pero que en realidad no lo es. En efecto, las falacias son argumentos, más concretamente, argumentos que por un motivo u otro son 
incorrectos. La incorrección puede ser por dos motivos: formal o material. Por eso, es normal distinguir las falacias entre "formales" e "informales".

Cuándo la falacia es formal la lógica deductiva clasifica el argumento como lógicamente inválido. En estos casos, hay alguna regla lógica que se ha violado -hay un defecto de forma-, por ejemplo, es el caso de "la afirmación del consecuente" ( $p \rightarrow q$; $\mathrm{q} \vdash \mathrm{p})$; "la negación del antecedente" ( $\rightarrow \mathrm{q} ; \neg \mathrm{p} \vdash \neg \mathrm{q})$ o "la disyunción incluyente" $(p \vee q ; p \vdash \neg q)$... Cuando la falacia es informal las causas y los motivos por los que se concluye que el razonamiento es incorrecto varía, a veces, puede ser debido a la forma lingüística (equivoco, anfibolía, ambigüedad semántica o pragmática, composición, división...), o pue de ser debido al contenido expresado por el argumento (ad hominem, ad verecundiam, ad ignorantiam, ad misericordiam, ad populum, ad baculum, falsa causa, petición de principio, falso dilema etc.).

En resumen, los argumentos falaces se dan por un uso incorrecto de las palabras o porque de las premisas no se sigue la conclusión. Por eso, se dice que el argumento (razonamiento) es incorrecto, es falaz.

En cualquier caso, no podemos obviar el hecho que dentro de la teoría de la argumentación no tenemos una teoría unificada en torno a las falacias (ni tampoco, en torno al concepto de argumento). Existen diferentes puntos de vista sobre las falacias: desde una perspectiva "lógica" la falacia es el argumento que no es formalmente válido (enfoque formal); desde una perspectiva "dialéctica" la falacia es el movimiento ilegitimo en el transcurso de una discusión (enfoque funcional); y desde una perspectiva "retórica" la falacia es una mala presentación de un argumento (enfoque discursivo). Estas tres perspectivas no son excluyentes entre sí, más bien se complementan entre ellas; la primera (lógica) pone énfasis en la "consistencia" del argumento; la segunda (dialéctica) estudia los "usos" de los argumentos; y la tercera (retórica) incide en la "efectividad" del argumento en relación a la audiencia, es decir, si el argumento persuade o no.

En el siguiente apartado, cuando tratemos de analizar la pregunta en el contexto argumentativo, veremos que lo que hemos afirmado en el último párrafo es un ejemplo que prueba la necesidad de una teorización de las falacias (y del argumento), que vaya más allá de la perspectiva lógica.

\section{El rol de a pregunta en el contexto argumentativo.}

El rol de la pregunta en el contexto argumentativo es un tema largamente debatido desde Aristóteles hasta la lógica informal. Las dificultades y objeciones que presenta su tratamiento son considerables. Es innegable que la pregunta no satisface el requerimiento de argumento entendido como conjunto de proposiciones donde unas cuentan como premisas y otra como conclusión; hay críticas que ponen en entre dicho la seriedad de estas falacias porque carecen de ejemplos que sean reales; además, 
existe cierta confusión sobre los diferentes tipos de preguntas, puesto que se tratan de manera análoga y encima, se suelen generalizar bajo el término de pregunta compleja.

Generalizando, la pregunta socava las concepciones canónicas (perspectiva lógica) acerca del argumento y la argumentación. Por un lado, al tratar la pregunta como un topos/tópico (a saber, el material que forma parte de la invención retórica) permite ir más allá en la teorización del término argumento. Al menos, si entendemos por argumento el conjunto de proposiciones donde unas de ellas cuenta como premisas y la otra como conclusión. Por otro lado, la pregunta no es sólo un mecanismo dialéctico en toda regla que permite desencadenar y desarrollar el diálogo, sino que, también, es un mecanismo ilativo que propicia la ilación en la argumentación.

\subsection{El fenómeno de la presuposición.}

Uno de los elementos principales a la hora de analizar y evaluar una pregunta es la presuposición (semántica). Algunas preguntas falaces juegan con la/s presuposición/es; lo que comúnmente se conoce como el material semántico que se da por hecho "captado o aceptado". Veamos un ejemplo:

u) El rey de Francia es calvo.

v) El rey de Francia no es calvo

Ambos enunciados $[(u)$ y $(v)]$ presuponen la siguiente oración:

w) Existe un rey de Francia.

Tanto si afirmamos, negamos o preguntamos los enunciados $[(u) \circ(v)]$ presuponemos (w). El fenómeno de la presuposición ha sido abordado con relativa frecuencia en los últimos cien años, y se puede afirmar a su vez, que el fenómeno de la presuposición en relación con la pregunta ha sido estudiado en el último medio siglo. Pero no con el suficiente rigor.

En cualquier caso, el tratamiento que se da a la pregunta y al fenómeno de la presuposición en el marco de la argumentación es insuficiente; ya que no se integran estos dos elementos (pregunta y presuposición) de manera adecuada. Prueba de ello, es la confusión conceptual que hay bajo la etiqueta de "pregunta compleja"; puesto que esta etiqueta sirve para referirse a distintos tipos de pregunta que difieren entre ellas tanto en su definición formal, como en su explicación funcional.

\subsection{Tipología de preguntas: Pregunta con presuposición, pregunta múltiple y pregunta anfibólica.}

La filosofía requiere de conceptos que forman lo que llamamos la caja de herramientas conceptual; su valor y su uso se justifican porque nos permite referirnos a cosas, estados, eventos, situaciones y fenómenos con el rigor y la precisión que cualquier disciplina científica ha de tener. No obstante, ocurre que algunos conceptos pueden 
ser vacuos (oxímoron), mientras que otros conceptos pueden generar confusión por su vaguedad. Estos tipos de conceptos no nos ayudan a la hora de elucidar o desarrollar un problema. El término "pregunta compleja" tampoco nos ayuda a explicar y catalogar las diferentes preguntas falaces que pretendemos clasificar.

Por "pregunta compleja" se ha entendido diferentes tipos de preguntas que no son iguales entre ellas. Ello ha generado un tratamiento análogo por parte de los teóricos de la argumentación y de la lógica informal entre "pregunta con presuposición", "pregunta múltiple" y "pregunta anfibólica". Esto es un error que impide analizar, explicar y evaluar la pregunta tanto en el nivel formal (definición) como en el nivel funcional (procedimiento).

\subsubsection{Pregunta con presuposición.}

En este tipo de pregunta la presuposición juega un papel clave. Pues, mediante la presuposición podemos hacer que la persona que responde a la pregunta se comprometa con ella, así se atrapa a la persona y se le obliga a admitir la presuposición que quizás, rechaza. No siempre este tipo de preguntas con presuposición tienen trampa o son falaces; es el uso, el contexto y los agentes implicados los que determinan que la pregunta sea clasificada como falaz.

Ejemplo:

-¿Has dejado de estafar a hacienda?

Presuposición: Estafas a hacienda.

Tanto si se responde con un sí o con un no, el agente que responde se verá obligado a aceptar la presuposición. Un modo para evitar caer en esta trampa sería declarar la pregunta como improcedente o dividirla en partes, a saber: por un lado, preguntar si estafas a hacienda, y por otro lado (en caso de que la respuesta sea afirmativa), si lo vas a seguir haciendo.

\subsubsection{Pregunta múltiple}

Este tipo de pregunta varía con respecto a la "pregunta con presuposición" en que el mecanismo para atrapar al que responde es diferente. La estrategia consiste en presentar varias preguntas en una sola, de esta manera el que responde lo hace globalmente sin poder discriminar las preguntas que se plantean. La pregunta múltiple suele responderse con un sí o con un no, lo que indica que las respuestas ya están limitadas de antemano y no permite otro tipo de respuesta alternativa.

Ejemplo:

-Polo. - Pero ¿Qué dices? ¿No pueden (los oradores) como los tiranos, condenar a muerte a los que quieran y despojar de sus bienes y desterrar de las ciudades a quien les parezca? (Gorgias 466BD) 
-¿Vas a ir a la escuela y le vas a pedir perdón al director?

En cualquier caso, el que responde con un sí o un no se ve atrapa do con la respuesta, pues se compromete con todas las preguntas planteadas. Si no se comparte alguna de las preguntas, o si para cada pregunta hubiera una respuesta diferente, la manera de proceder en este caso sería parecida a la anterior, es decir, distinguir las preguntas que contiene la "pregunta múltiple" y responderlas por separado.

\subsubsection{Pregunta anfibólica}

Los anteriores casos que hemos estudiado son bastante frecuentes en los debates parlamentarios, en preguntas realizadas por periodistas, en interrogatorios, etc. La pregunta anfibólica es por lo general inusual, ya que es difícil hacer una buena pregunta anfibólica sin que se aprecie el engaño, pero no por ello debemos de subestimar este tipo de pregunta. De todos modos, aunque sea excepcional su ocurrencia en contextos argumentativos, a veces aparece, y su detección no suele ser nada fácil.

Ejemplo:

- ¿Has visto a José con un telescopio?

-¿Has visto al burro de Sancho Panza?

En este caso, se puede apreciar que la anfibolía no es otra cosa que la ambigüedad sintáctica, su estructura lingüística permite una doble interpretación. En el primer ejemplo podemos entender la pregunta de dos formas:

-Que José haya sido visto mediante un telescopio.

-Que José haya sido visto portando él mismo un telescopio.

Con estas estructuras ambiguas se da un juego entre interpretaciones, a veces, una de ellas es más explícita y la otra está más implícita (por ejemplo, en el segundo ejemplo "¿Has visto al burro de Sancho Panza?" la forma evidente sería Rucio; y la forma implícita, sería Sancho Panza. Porque -a menos que se le quiera ofender- Sancho Panza no es, ni puede ser un burro).

Merece tenerse en cuenta la diferencia funcional entre estos tipos de pregunta; ya que, no es lo mismo "atrapar" que "engañar" cuando se emplea la pregunta (en su uso falaz). Por un lado, en el caso de "pregunta con presuposición" y "pregunta múltiple" la persona que responde tanto a un tipo como al otro inevitablemente se compromete con la información que contiene la pregunta. A saber, en el caso de la "pregunta con presuposición" con la presuposición misma y en el caso de "pregunta múltiple", con todas las preguntas que contiene. En estos casos, el que responde admite parte de la información que posteriormente se puede emplear en su contra; por eso decimos que la pregunta atrapa al que responde. Por otro lado, con la pregunta anfibólica no ocurre lo mismo. Ya hemos explicado anteriormente que su estructura lingüística permite ser interpretada de dos formas diferentes y cuando se 
responde, es el interrogador quien puede hacerse con la interpretación que mejor le convenga. Por esa razón, decimos que la pregunta anfibólica es un engaño que juega con las diferentes interpretaciones posibles; mientras que la "pregunta con presuposición" y la "pregunta múltiple" son preguntas que te atrapan (te comprometes) con el contenido lingüístico que expresan.

La refutación para toda esta gama de preguntas falaces es la misma. En primer lugar, hay que descartar responderlas y mostrar su improcedencia (o decir que no se entiende); en segundo lugar, es preciso detectar las diferentes preguntas, interpretaciones o la misma presuposición; en tercer lugar, hay que pedir que se expliciten cada una de ellas (preguntas y presuposición) y responderlas individualmente, al menos, si se pretende dar una respuesta efectiva a la pregunta planteada. En el pasaje que citaremos a continuación Aristóteles nos da unas pautas a seguir sobre cómo proceder ante una pregunta de este tipo, en concreto, ante una pregunta anfibólica:

De manera semejante hay que salir también al paso de las cosas que se dicen oscuramente y de varias maneras. En efecto, ya que al que responde, si no entiende, le está permitido decir: No entiendo, y que, si la cosa se dice de varias maneras, no necesariamente hay que estar de acuerdo o rechazarla, es evidente que, en primer lugar, si lo dicho no está claro, no hay que privarse de decir que no se comprende: pues muchas veces se presenta una dificultad por dar audiencia a los que preguntan sin claridad. Aristóteles Topicos III (160a 15-25) 


\section{F) Documentación}

\section{Fuentes (legislación).}

Decreto 327/2010, de 13 de julio, por el que se aprueba el Reglamento Orgánico de los Institutos de Educación Secundaria.

URL=<<http://noticias.juridicas.com/base_datos/CCAA/an-d327-2010.t5.html >>

Decreto 416/2008, de 22 de julio

URL=<<http://www.adideandalucia.es/normas/decretos/Decreto\%20416-

2008\%20Bachillerato\%20Andalucia.pdf >>

Ley Orgánica de Educación

URL=<<http://www. boe.es/buscar/doc.php?id=BOE-A-2006-7899>>

LEY ORGÁNICA 2/2006, de 3 de mayo, de Educación.

URL=<<http://www.boe.es/boe/dias/2006/05/04/pdfs/A17158-17207.pdf >>

ORDEN de 5 de agosto de 2008, por la que se desarrolla el currículo correspondiente al Bachillerato en Andalucía.

URL=<<http://www.juntadeandalucia.es/educacion/portal/com/bin/Contenidos/OEE/ ordenacion/Orden_Curriculo_Bachillerato/1220265787283_orden_bachillerato.pdf >>

REAL DECRETO 1467/2007, de 2 de noviembre, por el que se establece la estructura del bachillerato y se fijan sus enseñanzas mínimas.

URL=<<http://www. boe.es/boe/dias/2007/11/06/pdfs/A45381-45477.pdf >>

\section{Bibliografía.}

Aristóteles (1982; 1988), Tratados de lógica : organon, Gredos, Madrid.

Aristóteles \& Racionero, Q. (1990), Retórica, 1 , 1 reimp edn, Gredos, Madrid.

Badesa, C., Jané, I. \& Jansana Ferrer, R. (2000), Elementos de lógica formal, Ariel, Barcelona.

Baigorri Goñi, J.A. (2008), Filosofía y ciudadanía :1o bachillerato, Laberinto, Madrid.

Beaver, D. (1997). "Presupposition". In Johan van Benthem and Alice ter Meulen, editors, The Handbook of Logic and Language, pages 939-1008. Elsevier, Amsterdam.

Beaver, David I. \& Geurts, Bart. (2011). "Presupposition", The Stanford Encyclopedia of Philosophy (Summer 2011 Edition), Edward N. Zalta (ed.), URL = $<$ http://plato.stanford.edu/archives/sum2011/entries/presupposition/>. 
Belnap, N. D. (1966). "Questions, Answers, and Presuppositions," The Journal of Philosophy, Vol. 63, No. 20, American Philosophical Association Eastern Division SixtyThird Annual Meeting (Oct. 27, 1966), pp. 609-611

Belnap, N.D. \& Steel, T.B. (1976), The logic of questions and answers, Yale University Press, NewHaven; London.

Bentham, J. \& Pendás Díaz, B. (1990), Falacias políticas, Centro de Estudios Constitucionales, Madrid.

Bordes Solanas, M. (2011), Las trampas de Circe :falacias lógicas y argumentación informal, Cátedra, Madrid.

Brockriede, W. (1975). Where is argument? Journal of the American Forensic Association, 11, 179-182.

Cattani, A. (2003). "Las reglas del diálogo y los movimientos de la polémica." Quaderns de Filosofia i Ciència, (32-33), 7-20.

Copi, I.M. \& Cohen, C. (1995), Introducción a la lógica, Limusa, México, D.F.

Deaño, A. (1996), Introducción a la lógica formal, 1a , 13a reimpr edn, Alianza Editorial, Madrid.

Domingo Moratalla, A., Domingo Moratalla, T. \& Feito Grande, L. 2008, Areté :Filosofía y ciudadanía : 1 Bachillerato, Sm, Madrid.

Dummett, M. (1993), Origins of analytical philosophy, Duckworth, London.

Estrella González, A. (2008), Filosofía y ciudadanía :1ํo bachillerato, Luis Vives, Zaragoza.

Ferrer, U. (2008), Filosofía y ciudadanía :bachillerato, Casals, Barcelona.

Frápolli Sanz, M. J. (2008). Filosofía de la lógica. Madrid: Tecnos.

García Damborenea, R. (2005). Uso de razón. URL = <http://www.usoderazon.com/>

Garrido, M. (1995), Lógica simbólica, 3a edn, Tecnos, Madrid.

González Ruiz, A. \& González Ruiz, F. (2008), Filosofía y ciudadanía :1o bachillerato, Akal, Madrid.

Güell Barceló, M. \& Muñoz Redon, J. (2008), Praxis :filosofía y ciudadanía : 1o bachillerato, Octaedro, Barcelona. 
Groarke, Leo. (2012), "Informal Logic", The Stanford Encyclopedia of Philosophy (Summer 2012 Edition), Edward N. Zalta(ed.), forthcoming URL = <http://plato.stanford.edu/archives/sum2012/entries/logic-informal/>.

Pablo D. Flores, "Falacias y Errores Lógicos", Junta de Andalucia (2002) URL = $<$ http://www.juntadeandalucia.es/averroes/emilioprados/filosof/Logica/Falacias\%20C omunes.htm>

van Eemeren, F.H. (2001), Crucial concepts in argumentation theory, Amsterdam University Press, Amsterdam.

van Eemeren, F.H. \& Grootendorst, R. (2004), A systematic theory of argumentation : the pragmadialectical approach, Cambridge University Press, Cambridge, UK ; New York.

Hamblin, C.L. (1958). "Questions", Australasian Journal of Philosophy, 36: 159-68.

Hamblin, C.L. (1970). Fallacies, London Methuen.

Harrah, D. (1998), "Questions" in Craig, E. \& Routledge (eds), Routledge encyclopedia of philosophy, Routledge, London.

Hidalgo Romero, J. L. \& Jaldo Girela, M.. Lógica de primer orden para bachiller. URL = $<$ http://www.juntadeandalucia.es/averroes/html/adjuntos/2008/02/22/0001/adjunto s/logica_1orden.pdf>

Izuzquiza, I. (2008), Filosofía y ciudadanía, :Bachillerato 1, Anaya, Madrid.

Johnson, R.H. \& Blair, J.A. (1997). "Informal logic and critical thinking". In F. van Eemeren, R. Grootendorst, \& F. Snoeck Henkemans (Eds.), Fundamentals of argumentation theory (pp. 383-86). Mahwah, NJ: Lawrence Erlbaum Associates

Lausberg, H., Orton, D.E. \& Anderson, R.D. (1998), Handbook of literary rhetoric : a foundation for literary study, Brill, Leiden.

Leff, M. (2000). "Rhetoric and Dialectic in the Twenty-first Century" in Argumentation $14: 241-254$

Mackie, J. L. (1967). "Fallacies". In The encyclopedia of philosophy, 3 vol, ed. P. Edward, 169-179.

Marina, J.A. \& Mateos,. (2008), Prosofía :Filosofía y ciudadanía 1 : Sm, Madrid.

Martínez, L., Montaner, F. \& Sanllehí, J. (2008), Filosofía y ciudadanía :Bachillerato : materia común, Almadraba, Madrid.

Morris Engel, S. (1989)."The many faces of amphiboly". Metaphilosophy 20: 347-55. 
Navarro Cordón, J.M. \& Pardo Torío, J.L. (2008), Filosofía y ciudadanía, :Bachillerato 1, Anaya, Madrid.

Perelman, C., Olbrechts Tyteca, L. \& Sevilla Muñoz, J. (2006), Tratado de la argumentación :Ia nueva retórica, Gredos, Madrid.

Plantin, C. (2001), La argumentación, 2ª edn, Ariel, Barcelona.

Platón, \& Calonge Ruiz, J. (1999), Gorgias ; Menéxeno ; Eutidemo ; Menón ; Crátilo, 13 Reimp edn, Gredos, Madrid.

Platón, Santa Cruz de Prunes,María Isabel, Vallejo Campos, A. \& Cordero, N.L. (1988), Diálogos Isabel Santa Cruz, Alvaro Vallejo Campos, Néstor Luis Cordero, Gredos, Madrid.

Reboul, O. (1989). "The figure and the argument", in M. Meyer (Ed.) From Meta physics to Rhetoric, (pp. 169-181), Dordrecht, Netherlands: Kluwer Academic.

Redal, E.J. \& Cortina, A. (2009), Filosofía y ciudadanía :1 Bachillerato, Santillana, Madrid.

Rosales Papa, D. (1994), Introducción a la lógica, 3ạ edn, Amaru, Lima.

Simons, M. (2006). "Foundational issues in presupposition". Philosophy Compass 1(4), 357-372.

Stalnaker, R. C. (2002). “Common Ground," Linguistics and Philosophy 25, 701-721.

Tindale, C.W. (1999). Acts of arguing : a rhetorical model of argument, State University of New York Press, Albany, N.Y.

Tindale, C.W. (2004). Rhetorical argumentation : principles of theory and practice, Sage Publications, Thousand Oaks, Calif. ; London.

Vega Reñón, L. (2007), Si de argumentar se trata, 2ª edn, Montesinos, Barcelona.

Vega Reñón, L. \& Olmos Gómez, P. (2011), Compendio de lógica, argumentación y retórica, Trotta, Madrid.

Walton, D.N. (1995), A pragmatic theory of fallacy, University of Alabama Press, Tuscaloosa, Ala.

Walton, D.N. (1996). Fallacies arising from ambiguity, Kluwer Academic Publishers, Dordrecht, The Netherlands; Boston. 
Walton, D.N. (1997). "Judging How Heavy a Question is Loaded: A Pragmatic Method." Inquiry: Critical Thinking Across the disciplines, Winter, Vol. XVII, No.2: 53-71.

Walton, D.N. (2008). Informal logic: a pragmatic approach, 2nd edn, Cambridge University Press, New York ; Cambridge.

Wenzel, Joseph W. (1990), "Three Perspectives on Argument: Rhetoric, Dialectic, Logic," in Perspectives on Argumentation, edited by Robert Trapp \& Janice Schuetz (Prospect Heights, IL: Waveland Press), 9-26.

Wenzel, Joseph W. (1992). "Perspectives on argument" In William L. Benoit, Dale Hample y Pamela J. Benoit (eds.), Readings in argumentation. Berlín/New York, Foris Publications, 1992.121-1141.

\section{Recursos informáticos online (propios).}

Materiales para la lógica formal e informal.

URL=<https://www.dropbox.com/home/Photos/Sample\%20Album\#!/home/Photos/Sa mple\%20Album/Filosof\%C3\%ADa\%20L\%C3\%B3gica>

Materiales para trabajar la transversalidad.

https://www.dropbox.com/home/Photos/Sa mple\%20Album\#!/home/Photos/Sample \%20Album/Filosof\%C3\%ADa

Ejercicios online.

Ambiguedad.

http://es.surveymonkey.com/MySurvey_EditorFull.aspx?sm=wqQGOS3pJkFyxWUvFF4j op7H\%2f\%2fljVwzXocFmfUE4Rh8\%3d

Conectivas.

http://es.surveymonkey.com/MySurvey_EditorFull.aspx?sm=gLNyKH1Mn8RxGCN10\% 2fVh3lb6z0d\%2fX0taf8\%2bS09sJGio\%3d

Tablas de verdad

http://es.surveymonkey.com/MySurvey_EditorFull.aspx?sm=oEnvAzWsab69KHzFPSv\% 2bp5z85gonU76xhX8Jd6zf9u4\%3d

Examen.

http://es.surveymonkey.com/MySurvey_EditorFull.aspx?sm=1w\%2bHhU8AC\%2bpsS4v gsILQYEIrKwrK3zuK\%2fxXLSL40QLw\%3d 
Anexo (I).

INTRODUCCIÓN (Real Decreto 1467/2007 de 2 de noviembre)

La materia de bachillerato Filosofía y ciudadanía se configura con un doble planteamiento: por un lado, pretende ser una introducción a la filosofía y a la reflexión filosófica; por otro, y continuando el estudio de la ciudadanía planteado en la etapa obligatoria, pretende retomar lo que es la ciudadanía y reflexionar sobre su fundamentación filosófica.

La filosofía es una actividad reflexiva y crítica que, a partir de las aportaciones de las ciencias y de otras disciplinas, pretende realizar una síntesis global acerca de lo que es el hombre, el conocimiento, la conducta adecuada y la vida social y política. Tras un primer contacto con los planteamientos éticos en la etapa anterior, es en bachillerato cuando los alumnos inician una aproximación sistemática a la filosofía; de ahí que sea necesario comenzar la materia por el estudio de lo que constituye la reflexión filosófica y su método de trabajo.

Partiendo del análisis de los distintos tipos de conocimiento y de la especificidad del conocimiento científico, se trata de que el alumno descubra el papel y lugar de la filosofía en el conjunto del saber, identificando igualmente sus peculiaridades y diferencias en relación con la ciencia. El estudio de los tipos de actividad filosófica, de la racionalidad teórica y de la racionalidad práctica, lleva a considerar las principales preguntas que, a lo largo de la historia, se ha ido planteando la filos ofía, llegando poco a poco a aquellas más próximas a la vida en común de los ciudadanos, objeto de la segunda parte de la materia.

Por ello, tras la enumeración de los procedimientos comunes que deben tratarse a lo largo de todos los temas, el primer núcleo temático analiza la caracterización del saber filosófico, distinguiéndolo de otros tipos de saber y analizando las relaciones y diferencias que mantiene con la ciencia.

El estudio de las dos grandes dimensiones de la racionalidad, su vertiente teórica y su vertiente práctica, deja paso a la consideración de los problemas y preguntas fundamentales que se ha planteado la filosofía a lo largo de su historia. Se busca con ello proporcionar a los alumnos y alumnas una visión global de lo que representan los distintos saberes y creencias, así como una visión integrada del quehacer filosófico, abordando de manera global todos los problemas filosóficos de forma que sea posible asimilar lo que ha supuesto la filosofía como saber acerca de la totalidad de la experiencia humana.

Tras esta breve aproximación a lo que es el saber filosófico, se plantea el estudio de las distintas dimensiones del ser humano, la biológica, la sociocultural y la simbólica, abriendo paso a la consideración de las distintas antropologías, las diferentes concepciones filosóficas del ser humano llevadas a cabo a lo largo de la historia del pensamiento.

Una vez tratado lo que es el saber filosófico y las distintas concepciones del ser humano, se abre paso a la fundamentación de la ciudadanía, la segunda parte de la materia. Así, culmina la propuesta de Educación para la ciudadanía que los alumnos han venido desarrollando a lo largo de la educación obligatoria. Durante tres cursos los alumnos han podido estudiar, analizar y reflexionar sobre alguna de las características más importantes de la vida en común y de las sociedades democráticas, sobre los principios y derechos establecidos en la Constitución española y en las Decla raciones 
de los Derechos Humanos, así como sobre los valores comunes que constituyen el sustrato de la ciudadanía democrática en un contexto global.

Continuando con la reflexión iniciada en el último curso de educación secundaria obligatoria, se trata ahora de que los alumnos puedan razonar y profundizar conceptualmente en las bases que constituyen la sociedad democrática, analizando sus orígenes a lo largo de la historia, su evolución en las sociedades modernas y la fundamentación racional y filosófica de los derechos humanos.

Esta reflexión filosófica sobre la ciudadanía debe, por tanto, tener una orientación interdisciplinar para poder describir y fundamentar adecuadamente los roles del oficio de ciudadano y las dimensiones fundamentales de la ciudadanía; por ello, partiendo de las aportaciones de la antropología filosófica y cultural, vistas en la primera parte, incorpora rá también las teorías éticas, las aportaciones de la sociología, de las ciencias económicas y de las teorías políticas que tienen su origen en el individualismo, el liberalismo, el socialismo, el colectivismo y el personalismo.

Así, las bases psicológicas, sociológicas, legales y morales sobre las que se constituye la vida en común dan paso al estudio de los distintos tipos de vida en sociedad y, a partir de ahí, de la aparición del Estado, de sus formas y de las características que definen el Estado democrático y de derecho. El origen y legitimación del poder y la autoridad, las distintas teorías acerca de la justicia, los problemas derivados de la globalización y mundialización cierran los temas objeto de estudio en la materia.

La extensión de los valores y planteamientos de lo que es la ciudadanía a todos los ámbitos y actividades del centro escolar sigue siendo uno de los aspectos característicos de la materia; por ello, lejos de tratarse una materia puramente teórica, debe plantearse desde una dimensión globalizadora y práctica, tratando de extender a la vida diaria de los centros el concepto de ciudadanía y el ejercicio práctico de la democracia, estimulando la participación y el compromiso para que los alumnos se ejerciten como ciudadanos responsables tanto en el centro como en el entorno social.

Culminación de las enseñanzas de Educación para la ciudadanía, Filosofía y ciudadanía prepara al alumnado para el estudio en profundidad de la problemática filosófica que se plantea en Historia de la filosofía. La materia tiene, por tanto, un doble carácter, terminal y propedéutico, que es necesario equilibrar y no decantar exclusivamente hacia uno de los lados.

\section{INTRODUCCIÓN:}

\section{Orden 5 de agosto de 2008.}

El currículo de Filosofía y Ciudadanía incluye los objetivos, contenidos y criterios de evaluación establecidos para esta materia en el Real Decreto 1467/2007, de 2 de noviembre, junto con las aportaciones específicas para la Comunidad Autónoma de Andalucía que se desarrollan a continuación.

\section{Relevancia y sentido educativo.}

La filosofía, en general, desempeña un importante papel en la educación del alumnado de bachillerato, que se prepara para estudios superiores y para instalarse en la vida adulta como seres humanos libres, responsables y comprometidos con su entorno vital. La propia naturaleza del saber filosófico contribuye a desarrollar la capacidad de análisis racional y favorece la adquisición de un hábito de reflexión que ayuda a los humanos a orientarse en la vida. La materia "Filosofía y ciudadanía» puede contribuir de manera eficaz a conseguir ciudadanos racionales, críticos y creativos, dispuestos a 
participar mediante el diálogo en la construcción permanente de la sociedad democrática en la que deben vivir.

La vinculación temática de los conceptos «filosofía» y «ciudadanía» no es nueva. Desde sus orígenes en la antigua Grecia, la filosofía, entendida como actividad racional que se construye mediante la reflexión y el diálogo, tuvo como marco el desarrollo de la polis. En el "logos» democrático confluían intereses contrapuestos entre clases sociales diferentes $y$, mediante el recurso racional al necesario consenso, se producía el reconocimiento de los derechos conquistados y el cumplimiento de los deberes asociados a estos derechos. A partir de este momento, los saberes filosóficos y ciudadano, el aprendizaje filosófico y el aprendizaje ciudadano, han estado unidos. En la actualidad, fruto de las conquistas el pensamiento moderno, tan fuerte es esta unión entre la filosofía y la ciudadanía que la segunda es parte de la primera y necesita de aquélla para su justificación.

Si hasta este momento de su proceso educativo los alumnos y alumnas sólo han tenido experiencias concretas acerca de lo que significa ser ciudadano, a partir de ahora, desde el momento en que empiezan el bachillerato, parece conveniente que conozcan la evolución histórica de la noción de ciudadanía, que comprendan su justificación filosófica y sepan analizar de manera reflexiva, crítica y creativa el reto que representa ser ciudadano o ciudadana en los albores del siglo XXI, así como los requerimientos del mundo globalizado.

En el primer curso de bachillerato la filosofía deberá servir para plantear problemas relativos al universo como totalidad, al significado de la vida, al ser humano y a su condición de ciudadano, a los contenidos simbólicos de la cultura (ciencia, arte, filosofía), a la conciencia, materia, espíritu, persona, naturaleza, cultura, verdad, libertad, democracia, estado de derecho, persona, justicia, dialéctica, relativismo cultural, multiculturalismo, etc., por citar una muestra de ideas relevantes procedentes de la «filos ofía académica " y convertidas en problemas de la «filosofía mundana», con arreglo a la conocida distinción establecida por Kant.

Reflexionar sobre las vertientes ética, política y estética de determinados problemas que plantean en el mundo actual la ciencia y la tecnología (tecnociencia); problemas relativos a la conservación de la biosfera (calentamiento del planeta, contaminación ambiental, etc.); la diversidad de las culturas, civilizaciones, razas y géneros del mundo actual, así como los problemas concretos que generan (violencia de estado, terrorismo, integrismos de toda índole, etnocentrismos políticos y religiosos, sexismo, homofobia, etc.); el ejercicio del poder y las formas de organización social y política, la legitimidad de los mecanismos de poder, el valor de las doctrinas políticas, el análisis de la historia y de sus retos, el alcance de las utopías sociales, la dificultad del cambio social, etc.; todos estos aspectos son sólo una muestra de los problemas que deben aparecer en la clase de Filosofía y sobre los que la juventud de be reflexionar y adquirir su propio criterio. Todo ello con un objetivo claro y consustancial con esta asignatura: la búsqueda de la verdad; pero no de una verdad dogmática, sino provisional, crítica y creativa, obtenida desde el convencimiento de que la búsqueda de la verdad es más preciosa que su posesión.

\section{Núcleos temáticos:}

1. Características generales del saber filosófico y de la argumentación válida. 2. Antropología filosófica. 


\section{Filosofía moral y política.}

\section{Democracia y ciudadanía.}

Estos núcleos temáticos se podrán organizar de diferentes maneras: bien en bloques de temas distintos, bien en temas concretos conectados entre sí por un hilo conductor. En cualquiera de los dos casos, y por razones pedagógicas, las unidades didácticas deben ser cortas y concisas. Los temas excesivamente largos y complejos afectan negativamente al interés del alumnado y le restan motivación.

Con arreglo al criterio kantiano de que no basta con aprender filosofía, sino que también hay que aprender a filosofar, se debe reconocer que en una materia como ésta no es suficiente aprender ideas. Tan importantes como éstas son los procedimientos. Hay, pues, que enseñar y aprender en la escuela una serie de destrezas que no son innatas al individuo y que resultan necesarias para conseguir que los alumnos y alumnas se conviertan en ciudadanos y ciudadanas conscientes y protagonistas de su destino: tener criterios propios, saber argumentar, tener ideas adecuadas y coherentes, tener capacidad crítica, saber instalarse en la complejidad y en la incertidumbre de lo real y del conocimiento, aprender a posicionarse frente al dogmatismo, la intransigencia y la superstición, adquirir la habilidad de llegar a acuerdos sociales mediante el diálogo racional, etc.

\section{NÚCLEO TEMÁTICO}

1. Características generales del saber filosófico y de la argumentación válida.

\section{Relevancia y sentido educativo.}

Puesto que la filosofía es una disciplina de la que el alumnado tiene escasos conocimientos previos, parece conveniente que la materia comience situándolo en ella de una manera general y breve: el origen de la filosofía, su falta de especialización hasta el siglo XVIII, la naturaleza propia de este saber, sus ramas, métodos y diferencias con otros saberes (mito, ciencia, religión, arte).

Por otro lado, después de una breve introducción sobre la naturaleza propia de la filosofía, como saber racional, es conveniente que el alumnado conozca la importancia de la argumentación válida en la construcción de los saberes racionales (ciencia y filosofía) y en la vida cotidiana. Aunque razonar bien y argumentar correctamente espontánea, es obvio que para hacer estas operaciones con mayor eficacia se requiere atención y estudio sistemático de la lógica formal e informal, que se convierte en instrumento (órgano) al servicio de los saberes racionales en el sentido genuinamente aristotélico, así como en un hábito racional necesario en la vida cotidiana.

\section{Contenidos y problemáticas relevantes.}

Los aspectos de la filos ofía señalados constituyen el hilo conductor en el desarrollo de este núcleo temático que remite a otras cuestiones relevantes, como son la relación entre verdad y realidad.

Organizados en forma de preguntas o problemas, los contenidos se pueden presentar de este modo. 
-¿Cómo surge el conocimiento en el transcurso de la evolución de la especie humana?, ¿dónde y cuándo se origina la filosofía occidental?, ¿sobre qué conocimientos previos se construye?, ¿qué condiciones económicas, sociales y culturales fueron necesarias para que surgiese?, ¿se constituyó al margen de otros saberes (mito, magia, religión, técnica, arte, etc.) o, por el contrario, se formó en estrecha relación con ellos?, ¿son los mitos meras supersticiones ignorantes?, ¿qué características ventajosas presenta la narración filosófica frente al mito?

-¿Por qué se dice que la filosofía es un saber racional?, ¿existen otros saberes racionales con los que la filosofía haya mantenido o mantenga una estrecha relación?, ¿cuáles son las preguntas o problemas funda mentales de la filosofía?, ¿cuáles de estas preguntas o problemas pertenecen a la racionalidad teórica y cuáles a la racionalidad práctica?, ¿en qué se diferencian estos dos tipos de racionalidad?

-¿Es necesario argumentar correctamente para poder mantener un diálogo racional?, ¿y para hacer ciencia?, ¿qué requisitos son necesarios para que un argumento sea válido?, ¿es posible que en un argumento el contenido concreto de las premisas y conclusión sean verdaderos $y$, sin embargo, el argumento no sea válido?, ¿existe relación entre la estructura lógica del pensamiento y la realidad física?, ¿qué relación existe entre las tablas de verdad y los circuitos eléctricos?

-¿La lógica nos permite saber si un enunciado o argumento es siempre verdadero, siempre falso o unas veces verdadero y otras falso?, ¿de qué depende?, ¿se puede saber si un argumento concreto, por muy complejo que éste sea, está bien construido?, ¿qué es un argumento deductivo?, ¿y un argumento inductivo?, ¿en qué consiste un argumento por analogía?, ¿en qué se diferencia un sofisma de una falacia?, ¿cuáles son las falacias más frecuentes y cómo se reconocen?, ¿es irracional o humillante dejarse convencer por los argumentos racionales?

-¿Qué es la verdad?, ¿y la realidad?, ¿qué relación existe entre verdad y realidad?, ¿y entre la razón y la verdad?, ¿en qué consiste el relativismo?

\section{Sugerencias sobre metodología y utilización de recursos.}

Si en el proceso de enseñanza y aprendizaje de la Filosofía y ciudadanía en el bachillerato el objetivo principal es aprender a plantear problemas, a hacer preguntas e intentar responderlas con la ayuda de la filosofía, la metodología activa será la más apropiada. Esto supone que el alumnado no puede ser en el aula un simple espectador, sino un protagonista en la construcción de su propio aprendizaje, que, necesariamente, deberá ser significativo.

Desde este primer núcleo temático y en los sucesivos, de manera continua y prog resiva en lo que se refiere al grado de complejidad, se deberá iniciar al alumnado en una serie de procedimientos imprescindibles en esta materia: la interpretación de textos filosóficos breves que tengan relación con el origen y la naturaleza de la filosofía, que deberán ir acompañados de unas pautas sencillas de reflexión personal, tanto orales como escritas, o los ejercicios sobre un texto explicativo acompañado siempre de una serie de cuestiones sobre dicho texto, para facilitar una mejor comprensión del mismo, sobre los que se deberán realizar esquemas, mapas conceptuales y resúmenes, y en suma al ejercicio de dos de las operaciones básicas de la mente: el análisis y la síntesis. Documentos audiovisuales o escritos sobre algún filósofo relevante-a ser posible actual-, la información oral o escrita a cargo del 
profesorado, los artículos de prensa, etc., pueden ser recursos apropiados para que el alumnado comience a plantearse preguntas y a esbozar respuestas.

La metodología a seguir en el estudio de la lógica formal e informal, centrada en el estudio de los argumentos, deberá ser eminentemente práctica. Los recursos que se pueden utilizar en este apartado son variados: proposiciones filosóficas, fragmentos de textos científicos, recortes de prensa, etc.

\section{Criterios de valoración de los aprendizajes.}

Se valorará la comprensión de un vocabulario básico sobre la naturaleza del saber filosófico, así como la capacidad para identificar y diferenciar entre sí los saberes racionales y no racionales, o las semejanzas y diferencias entre filosofía y ciencia, filosofía y religión, filos ofía y arte.

Se valorará también la capacidad para trabajar con textos filosóficos de corta extensión e identificar en ellos el tema y sus principales ideas, operación preliminar para hacer esquemas o mapas conceptuales, resúmenes, etc.

Se valorará también la capacidad del alumnado para escribir en lenguaje simbólico enunciados atómicos y moleculares, en forma de proposiciones y de argumentos; mediante tablas de verdad, saber diferenciar en distintas fórmulas si son tautologías, contradicciones o indeterminaciones; reconocer y construir argumentos válidos, e identificar falacias de diferentes tipos.

\section{Anexo (II).}

\section{OBJETIVOS (Real Decreto 1467/2007 de 2 de noviembre):}

La enseñanza de la Filosofía y ciudada nía en el bachillerato tendrá como finalidad el desarrollo de las siguientes capacidades:

1. Identificar y apreciar el sentido de los problemas filosóficos y emplear con propiedad y rigor los nuevos conceptos y términos asimilados para el análisis y discusión.

2. Adoptar una actitud crítica y reflexiva ante las cuestiones teóricas y prácticas, funda mentando adecuada mente las ideas.

3. Argumentar de modo coherente el propio pensamiento de forma oral y escrita, contrastándolo con otras posiciones y argumentaciones.

4. Practicar y valorar el diálogo filosófico como proceso de encuentro racional y búsqueda colectiva de la verdad.

5. Analizar y comentar textos filosóficos, tanto en su coherencia interna como en su contexto histórico, identificando los problemas que plantean, así como los argumentos y soluciones propuestas.

6. Utilizar procedimientos básicos para el trabajo intelectual y el trabajo autónomo: búsqueda y selección de información, contraste, análisis, síntesis y evaluación crítica de la misma, promoviendo el rigor intelectual en el planteamiento de los problemas.

7. Adoptar una actitud de respeto de las diferencias y crítica ante todo intento de justificación de las desigualdades sociales y ante toda discriminación, ya sea por sexo, etnia, cultura, creencias u otras características individuales y sociales.

8. Valorar la capacidad normativa y transformadora de la razón para construir una sociedad más justa, en la que exista una verdadera igualdad de oportunidades. 
9. Valorar los intentos por construir una sociedad mundial basada en el cumplimiento de los derechos humanos, en la convivencia pacífica y en la defensa de la naturaleza.

10. Consolidar la competencia social y ciudadana fundamentando teóricamente su sentido, valor y necesidad para ejercer una ciudadanía democrática.

11. Desarrollar una conciencia cívica, crítica y autónoma, inspirada en los Derechos Humanos y comprometida con la construcción de una sociedad democrática, justa y equitativa y con la defensa de la naturaleza, desarrollando actitudes de solidaridad y participación en la vida comunitaria.

\section{Anexo (III).}

\section{CRITERIOS DE EVALUACIÓN DE LA MATERIA}

Tal como se recoge en el Real Decreto 1467/2007, los criterios de evaluación de esta materia son los siguientes.

1. Reconocer y explicar con precisión y rigor la especificidad de la filosofía distinguiéndola de otros saberes o modos de explicación de la realidad, diferenciando su vertiente teórica y práctica, centrándose en preguntas y problemas fundamentales.

2. Razonar con argumentaciones bien construidas realizando un análisis crítico y elaborando una reflexión adecuada en torno a los conocimientos adquiridos.

3. Exponer argumentaciones y componer textos propios en los que se logre una integración de las diversas perspectivas y se avance en la formación de un pensamiento autónomo.

4. Utilizar y valorar el diálogo como forma de aproximación colectiva a la verdad y como proceso interno de construcción de aprendizajes significativos, reconociendo y practicando los valores intrínsecos del diálogo como el respeto mutuo, la sinceridad, la tolerancia, en definitiva, los valores democráticos.

5. Obtener información relevante a través de diversas fuentes, elaborarla, contrastarla y utilizarla críticamente en el análisis de problemas filosóficos, sociológicos y políticos.

6. Conocer y analizar las características específicas de lo humano como una realidad compleja y abierta de múltiples expresiones y posibilidades, profundizando en la dialéctica naturaleza y cultura, e individuo y ser social, que constituyen la persona.

7. Conocer y valorar la naturaleza de las acciones humanas en tanto que libres, responsables, normativas y transformadoras.

8. Comprender y valorar las ideas filosóficas que han contribuido, en distintos momentos históricos, a definir la categoría de ciudadano y ciudadanía, des de la Grecia clásica hasta la ciudadanía global del mundo contemporáneo, haciendo especial énfasis en la llustración y en la fundamentación de los Derechos Humanos.

9. Reconocer y analizar los conflictos latentes y emergentes de las complejas sociedades actuales, sus logros y dificultades, sus cambios y retos más importantes que contextualizan la actividad socio-política del ciudadano, manifestando una actitud crítica ante todo intento de justificación de las desigualdades sociales o situaciones de discriminación.

10. Señalar las diferentes teorías acerca del origen del poder político y su legitimación, identificando las que fundamentan el Estado democrático y de derecho y analizar los modelos de participación y de integración en la compleja estructura social de un mundo en proceso de globalización. 


\title{
Anexo (IV).
}

Una manera de fomentar el uso de Internet consiste en proponer al alumnado, por ejemplo, un caza tesoros o Webquest que les ayude a dar respuesta a diversas cuestiones relativas a la unidad didáctica. Asimismo se puede ejercitar el alumnado en ejercicios de deducción natural. Una dirección electrónica especializada en lógica "Aprende Lógica" es la siguiente:

URL=<ntic.educacion.es/w3//eos/MaterialesEducativos/mem2003/logica/logica/menu temas/menutemas.html>

Muy buena Web, ofrece recursos para entrenarse en la lógica de enunciados (proposiciones) con diversos ejercicios de formalización:

URL $=\langle$ http://cibernous.com/logica/index.html $>$

Hay otras webs muy interesantes, contienen diverso material sobre lógica: conceptos, tablas de verdad, reglas de deducción, etc. Glosario de lógica. Actividades relacionadas con el tema que se estudia. Y además, contiene ejercicios de autoevaluación: verdad, validez y solidez; fórmulas bien formadas; formalización; conectivas dominantes; definiciones básicas y Tablas de verdade interpretaciones semánticas:

URL $=<$ http://www.educared.org/wikiEducared/index.php?title=L\%C3\%B3gica_proposicional > URL=<http://www.juntadeandalucia.es/averroes/emilioprados/filosof/Logica/Logica\%20y\%20 Discurso\%20-\%20index.htm>

En la Web del ministerio de educación encontramos material de lógica para ampliar conocimiento así como para realizar ejercicios.

URL $=\langle$ http://recursos.cnice.mec.es/filosofia/actividades.html\# $>$

Por parte de la lógica informal tenemos estas fuentes (revistas) que son de interés. Además, no solo vamos a fomentar el uso de Internet, hay muchas webs que sus contenidos están en inglés y por lo tanto, ta mbién reforza remos su aprendizaje:

\author{
Argumentation \\ Informal Logic \\ Philosophy and rhetoric
}

Y también tenemos en la red E-documentos:

Muy buena página sobre falacias, aunque mantiene la definición tradicional de falacia. Buenas, definiciones, ejemplos y además, contiene ejercicios:

URL $=<$ http://courses.csusm.edu/fallacies $/>$

Mission: Critical. Buena página de pensamiento crítico, contiene lista y ejercicios. 
URL $=<$ http://www.sjsu.edu/depts/itl/ $>$

URL $=<$ http://www.logicalfallacies.info/ >

Este E-libro también es recomendable, su interés radica en la selección de ejemplos de argumentos incorrectos seleccionados, en su gran mayoría, de la vida política y medios de comunicación. Además está en castellano. En cuanto a su concepción de falacia es psicologista.

URL $=<$ http://www.usoderazon.com/ $>$

Páginas con taxonomía de falacias:

The Nizkor Project:

URL $=<$ http ://www. nizkor.org/features/fallacies $/>$

Es muy recomendable esta página ya que proporciona ejemplos de falacias en la vida real y medios de comunicación. Además, contiene un apartado en relación a las encuestas y preguntas.

$U R L=<h t t p: / / w w w . f a l l a c y f i l e s . o r g />$

Stephen's Guide to the Logical Fallacies

$\mathrm{URL}=<\mathrm{http}: / /$ onegoodmove. $\mathrm{org} /$ fallacy/ $>$

Falacias en castellano

URL $=<$ http://galeon.his pavista.com/elortiba/falacias.html.

\section{Anexo (V).}

1. ¿De los siguientes casos cuáles pertenecen a un lenguaje formal?

a) $3+4=7$

b) ¿Cómo lo has hecho?

c) $E=\mathrm{mc} 2$

d) La distancia más corta entre dos puntos es la recta.

2. Elabora una lista de casos de malentendidos tomados del lenguaje natural en los que se da ambigüedad sintáctica, semántica y pragmática.

3. Distingue entre lenguaje objeto y metalenguaje:

a) El Pisuerga pasa por Valladolid.

b) "Valladolid" tiene diez letras.

\section{Anexo (VI).}

1. De las siguientes frases ¿cuáles son proposiciones?

a) Los niños tienen mucha curiosidad y los animales también.

b) ¿Cuál es la capital de Italia? 
c) Yo no lo sé.

d) Algún vecino mío es universitario.

e) ¡Dios mío, ayúdame!

f) Si tuvieses tanta curiosidad como afirmas, estudiarías.

2. De las siguientes frase señala cual es una proposición atómica y cual no.

a) El Támesis es un río.

b) Hoy es martes y hace frío

c) El Everest es una montaña

d) Si estudias, aprobarás.

e) Hoy iré al cine o me iré al monte

3. Escribe 5 proposiciones moleculares y señala el conector lógico empleado.

4. Suponiendo que:

$p=$ María es deportista.

$q$ = María es buena estudiante.

$r=$ La profesora de gimnasia está contenta.

Tradúcelas siguientes expresiones:

p y q y

Si $p$ y no $q$, entonces no $r$ :

rsi ysolosi p y q:

Si no $p$, entonces no $q$ :

5. Relaciona los términos (disyunción, conjunción, condicional, bicondicional, negación) con los correspondientes símbolos lógicos $(\vee, \rightarrow,, \neg, \leftrightarrow)$.

6. Añada paréntesis a la expresión

$\neg \mathrm{p} \wedge \mathrm{q} \rightarrow \mathrm{r} \vee \neg \mathrm{q}$

de modo que resulte una fórmula cuya forma sea la que se indica a continuación:

a) negación de un condicional,

b) negación de una disyunción,

c) negación de una conjunción,

d) negación de una negación,

e) conjunción,

f) condicional cuyo antecedente es una conjunción,

g) condicional cuyo antecedente es una negación

h) disyunción de negaciones,

i) disyunción de una conjunción y una negación

j) disyunción de un condicional y una negación

7. Obtenga subfórmulas de las siguientes fórmulas:
a) $[(p \rightarrow q) \wedge \neg q)] \rightarrow(\neg p \vee r)$
b) $(p \wedge q) \rightarrow \neg(p \vee q)$
c) $[(p \rightarrow q)] \wedge(\neg p \rightarrow q)] \rightarrow q$ 


\section{Anexo (VII).}

Realizar las correspondientes tablas de verdad para las siguientes fórmulas (diciendo qué clase de fórmula tenemos después de ver su tabla de verdad).

$$
\begin{aligned}
& \text { 1. }(p \rightarrow q) \leftrightarrow(p \wedge \neg q) \\
& \text { 2. }(p \leftrightarrow q) \leftrightarrow(p \leftrightarrow \neg q) \\
& \text { 3. }(p \leftrightarrow r) \rightarrow(r \rightarrow \neg p) \\
& \text { 4. } p \wedge(q \vee r) \leftrightarrow((p \wedge q) \vee(p \wedge r)) \\
& \text { 5. }(p \rightarrow q) \wedge(p \wedge \neg q) \\
& \text { 6. }(p \leftrightarrow q) \leftrightarrow[(p \wedge \neg q) \wedge(\neg p \wedge q)] \\
& \text { 7. }(p \wedge q) \vee(\neg t \rightarrow p) \\
& \text { 8. } \neg(p \wedge t) \rightarrow(\neg r \wedge p) \\
& \text { 9. }(p \vee r) \rightarrow(r \vee \neg q) \\
& \text { 10. } \neg(p \vee q) \leftrightarrow(\neg p \wedge \neg q)
\end{aligned}
$$

Anexo (VIII). Deducción.
a) $p \rightarrow q, r \rightarrow q, p \vee r \vdash q$
b) $p \rightarrow(\neg q \wedge r), q \wedge r, \vdash \neg p$
c) $p \rightarrow q, r \rightarrow s, p \vee r \vdash q \vee s$
d) $[(\neg p \wedge \neg q) \wedge[(r \rightarrow p)] \wedge(s \rightarrow q)]] \rightarrow(\neg s \wedge \neg r)$

\section{Anexo (IX).}
a) ¿Has dejado de golpear a tu esposa?
b) ¿Vas a ir al médico y al dentista?
c) ¿Es calvo el rey de Francia?
d ¿Has visto al burro de Sancho Panza?

\section{Anexo (X).}

Examen- $1^{\circ}$ Bachiller.

1. ¿Qué tipo de ambigüedad es la siguiente oración? "He visto a María con gafas".
a) semántica
b) sintáctica
c) pragmática

2. ¿Qué tipo de ambigüedad es la siguiente oración? "José ha ido al banco con su amiga Julia"
a) sintáctica
b) semántica
c) pragmática

3. La expresión "Si llueve, la calles se mojan", la expresión "Si llueve" se llama... 

a) consecuente
b) condicional
c) antecedente

4. La verdad es una propiedad de...
a) las expresiones
b) los argumentos
c) de las expresiones y los argumentos

5. $\neg[(\mathrm{p} \vee \mathrm{q}) \wedge(\mathrm{r} \rightarrow \mathrm{t})]$ Esta expresión es un/a...
a) negación
b) conjunción
c) disyunción
d) condicional

6. $\neg(\neg \mathrm{p} \rightarrow \neg \mathrm{q}) \wedge(\mathrm{p} \vee \mathrm{r})$ Esta expresión es un/a...
a) negación
b) conjunción
c) disyunción
d) condicional

7. $(\mathrm{p} \vee \neg \neg \mathrm{q}) \vee[(\mathrm{p} \wedge \mathrm{r}) \wedge(\mathrm{r} \rightarrow \mathrm{s})]$ Esta expresión es un/a...
a) negación
b) conjunción
c) disyunción
d) condicional

8. Si ninguna interpretación de una expresión es verdadera, la expresión es una...
a) tautología
b) contradicción
c) contingencia

9. 'No prestaré atención a tus consejos, en tu familia hay personas implicadas en casos de corrupción”. ¿Qué tipo de falacia comete esta afirmación?
a) Ad hominem
b) Ad baculum
c) Ad verecundiam

10. Si no te portas bien, te pondré un negativo y afectará negativamente a tu evaluación. ¿Qué tipo de falacia comete esta afirmación?
a) Ad hominem
b) Ad baculum
c) Ad verecundiam 
Anexo (XI).

\section{$\underline{\text { Recursos Films y documentales }}$}

\section{Tema (2) Educación para la paz y convivencia}

Cien películas en la educación para la paz

URL $=<$ http://www.educarueca.org/spip.php?article827>

\section{Convivencia}

1- La Haine (el odio). (Mathieu Kassovitz)

2- 14 kilómetros. (Gerardo Olivares)

3- The Immigrant (A Modern Columbus). (Charles Chaplin)

4- Gran Torino. (Clint Eastwood)

5- American History X. (Tony Kaye)

6- Una historia del Bronx (A Bronx Tale). (Robert De Niro)

7- This is England. (Shane Meadows)

\section{Sobre el poder y el control}

8- Zeitgeist: Moving Forward 2011 spread. (Peter Joseph)

9- 1984. (George Orwell)

10- Fahrenheit 9/11. (Michael Moore)

\section{Tema (3) Consumo y consumismo. Educación del consumidor}

1- Comprar, tirar, comprar. (Cosima Dannoritzer)

¿Qué es la obsolescencia programada? Se denomina obsolescencia programada u obsolescencia planificada a la determinación, planificación o programación del fin de la vida útil de un producto o servicio de modo que este se torne obsoleto, no funcional, inútil o inservible tras un período de tiempo calculado de antemano, por el fabricante o empresa de servicios, durante la fase de diseño de dicho producto o servicio. La obsolescencia programada tiene un potencial considerable y cuantificable para beneficiar al fabricante dado que el producto va a fallar en algún momento, obligando al consumidor a que adquiera otro producto nuevamente.

URL = <http://www. youtube.com/watch?v=0DzMCBRChaU\&feature=youtu.be $>$

Parte 1: URL = <http://www.youtube.com/watch?v=0DzMCBRChaU> 
Parte 2: URL $=<$ http://www.youtube.com/watch?v=qsWSGcvB1TA $>$

Parte 3: URL $=<$ http://www.youtube.com/watch?v=V-HVE_xfF2w>

Parte 4: URL $=<h t t p: / / w w w . y o u t u b e . c o m / w a t c h ? v=01 V-p f X P 7 i U>$

2- Simiocracia, crónica de la gran resaca económica. (Aleix Saló)

Mientras que las familias y las empresas están "fatal de lo suyo", por falta de crédito, Simiocracia cuenta su teoría de por qué nuestra burbuja inmobiliaria no dio paso a una bajada de precios tan acusada como la de Irlanda o Estados Unidos. No faltan sátiras de la orgía de administraciones públicas, cajas de ahorros e inmobiliarias y de las alegrías futboleras de 2008 y 2010.

3- Españistán, de la Burbuja Inmobiliaria a la Crisis (Aleix Saló)

Exitoso cortometraje que alcanzó enorme repercusión (tres millones de visionados en Youtube en menos de un mes, aparición en varias televisiones nacionales e internacionales, etc.) y que se basa en el cómic homónimo "Españistán, de la Burbuja Inmobiliaria a la Crisis", de Aleix Saló, donde se analizan y dan las claves sobre la crisis económica en España desde un punto de vista irónico.

4- Inside Job (Charles Ferguson)

5- Debtocracy (Aris Hatzistefanou, Katerina Kitidi)

Analiza las causas de la crisis económica que azota Grecia y propone soluciones.

6- Capitalismo: Una historia de amor (Capitalism: A Love Story). Michael Moore.

7-La gran superficie: consume hasta morir. María González, Pedro Ramiro e Isidro Jiménez.

\section{Tema (5) Igualdad Educación para la igualdad de oportunidades entre sexos}

1- Te doy mis ojos (Icíar Bollaín)

2- Libertarias. (Vicente Aranda)

3- Memorias de una geisha (Rob Marshall)

4- "Vides Transsexuals" (María Popova)

\section{Páginas de interés en Internet.}

\section{Tema (2) Educación para la paz y convivencia}

Declaración Universal de Derechos Humanos

URL = <http://www.un.org/es/documents/udhr/pedagogy.shtml> 
Sanidad Derecho Universal (Ana Mato, ministra de sanidad, 18-4-2012)

URL=<http://www.elpais.com/audios/espana/explicaciones/Ana/Mato/elpaudnac/201 20418csrcsrnac_11/Aes/>

\section{Crisis}

En la página Finyanes tenemos unos buenos recursos que dan cuenta sobre el origen y las causas de la crisis económica desarrollado por Daniel Pink, a su vez, también se abordan aspectos claves a valorar fuera de un óptica capitalista pero, acorde con los principios y valores que queremos desarrollar desde los temas transversales.

URL $=<$ http://finyanes.blogspot.com.es $/>$

URL $=\langle$ http://www. youtube.com/watch $? v=s V 2 D o-h i u C c \&$ feature=player_e mbedded $>$

URL=<http://www.youtube.com/watch?v=mMZmcDILeSY\&feature=player_embedded $>$

- Periódicos

\section{Huelga General 29 de marzo}

Editoriales de periódicos de España ante el anuncio de Huelga General convocada por los Sindicatos mayoritarios.

URL $=<$ http://kiosko.net/es/2012-03-10/>

\section{Editoriales de periódicos}

URL $=\langle$ http://kiosko.net/es/2012-03-10/>

\section{Campaña electoral (Colombia)}

URL $=<$ http://www.youtube.com/watch?feature=player_detailpage\&v=UyKG91nnJM4>

\section{Tema (3) Educación del consumidor}

La Educación del consumidor y el usuario

URL=<http://www.eumed.net/rev/cccss/06/jcfe.htm>

Sexismo publicitario

URL=<http://youtu.be/XpRZWL24sxQ>

http://youtu.be/gdcAHIDhUSM

Publicidad de Axe (desodorante masculino) 
URL=<http://youtu.be/BimbOYKqGWw>

Estereotipos Femeninos

URL=<http://youtu.be/crHnd1RFZjA >

Los padres como modelo para sus hijos - EDUCACION - editado por Albertini

URL=<http://youtu.be/FrtD7ZLQa0Q>

Universidad de Granada entorno al sexismo publicitario

URL=<http://www.ugr.es/ educasi/3-3-3.htm>

\section{$\underline{\text { Tema (5) Educación para la igualdad de oportunidades entre sexos }}$}

Guia de la buena esposa (youtube)

URL $=<$ http://www. youtube.com/watch?v=200z4bfL3-w>

Spot "2a Jornadas por la Igualdad de Género"

URL=<http://www.youtube.com/watch?v=wkkvDzJkJVk\&feature=youtu.be >

La igualdad de género en la Universidad de Granada

URL $=<$ http://youtu.be/dr2WBVRnA68>

La discriminación genera violencia. Spot derechos género.

URL $=\langle$ http://youtu.be/nRXJ7TA5E9c>

Cinco cortos creados por adolescentes conciencian sobre la violencia de género / La 2 Noticias

URL $=<$ http://youtu.be/g M13 mUSKTNw>

Síntomas, Signos e Indicadores de Abuso Emocional

URL $=\langle$ http://youtu $\cdot$ be/2hoXONXnus $>$

Discurso de un Abusador

URL $=\langle$ http://youtu.be/wHcSzlS9OXo>

Página con una gran oferta de películas y documentales sobre la mujer.

URL=<http://Irmgenerandoconocimientodegenero2. blogspot.com.es/\#!/2011/12/dere cho-de-voto-para-las-mujeres.html>

$\mathrm{URL}=<\mathrm{http}: / /$ www.agrupacionpuntog.blogspot.com.es/> 